\title{
Real lives on paper plans
}

\author{
Citation for published version (APA):
}

Herps, M. (2017). Real lives on paper plans: individual support planning for people with intellectual disabilities. [Doctoral Thesis, Maastricht University]. Maastricht University. https://doi.org/10.26481/dis.20171026mh

Document status and date:

Published: 01/01/2017

DOI:

10.26481/dis.20171026mh

Document Version:

Publisher's PDF, also known as Version of record

\section{Please check the document version of this publication:}

- A submitted manuscript is the version of the article upon submission and before peer-review. There can be important differences between the submitted version and the official published version of record.

People interested in the research are advised to contact the author for the final version of the publication, or visit the DOI to the publisher's website.

- The final author version and the galley proof are versions of the publication after peer review.

- The final published version features the final layout of the paper including the volume, issue and page numbers.

Link to publication

\footnotetext{
General rights rights.

- You may freely distribute the URL identifying the publication in the public portal. please follow below link for the End User Agreement:

www.umlib.nl/taverne-license

Take down policy

If you believe that this document breaches copyright please contact us at:

repository@maastrichtuniversity.nl

providing details and we will investigate your claim.
}

Copyright and moral rights for the publications made accessible in the public portal are retained by the authors and/or other copyright owners and it is a condition of accessing publications that users recognise and abide by the legal requirements associated with these

- Users may download and print one copy of any publication from the public portal for the purpose of private study or research.

- You may not further distribute the material or use it for any profit-making activity or commercial gain

If the publication is distributed under the terms of Article $25 \mathrm{fa}$ of the Dutch Copyright Act, indicated by the "Taverne" license above, 


\section{REAL LIVES ON PAPER PLANS}

Individual Support Planning for People with Intellectual Disabilities

Marjolein Herps 


\section{REAL LIVES ON PAPER PLANS}

Individual Support Planning for People with Intellectual Disabilities

The research presented in this thesis was conducted at the Governor Kremers Centre (GKC) Maastricht University Medical Centre (MUMC+) and Vilans.
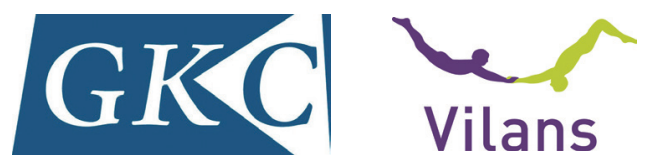

The studies presented in this dissertation were funded by Vilans, GKC, Fonds VG and ZonMw.

Cover design and layout: evelienjagtman.com

Printed by: Gildeprint, Enschede

ISBN: 978-94-6233-727-5

(C) Copyright Marjolein Herps, Maastricht 2017 


\section{REAL LIVES ON PAPER PLANS}

Individual Support Planning for People with Intellectual Disabilities

\section{PROEFSCHRIFT}

ter verkrijging van de graad van doctor

aan de Universiteit Maastricht,

op gezag van de Rector Magnificus,

Prof.dr. Rianne M. Letschert

volgens het besluit van

het College van Decanen,

in het openbaar te verdedigen

op donderdag 26 oktober 2017 om 12.00 uur

door

Marjolein Herps 


\section{Promotor:}

Prof. dr. L.M.G. Curfs

\section{Copromotor:}

Dr. W.H.E. Buntinx

\section{Beoordelingscommissie:}

Prof. dr. G. G. van Merode (voorzitter)

Prof. dr. P. J. C. M. Embregts (Tilburg University)

Prof. dr. H. L. G. R. Nies (Vrije Universiteit Amsterdam)

Prof. dr. R. A. C. Ruiter

Prof. dr. D. M. R. Townend 


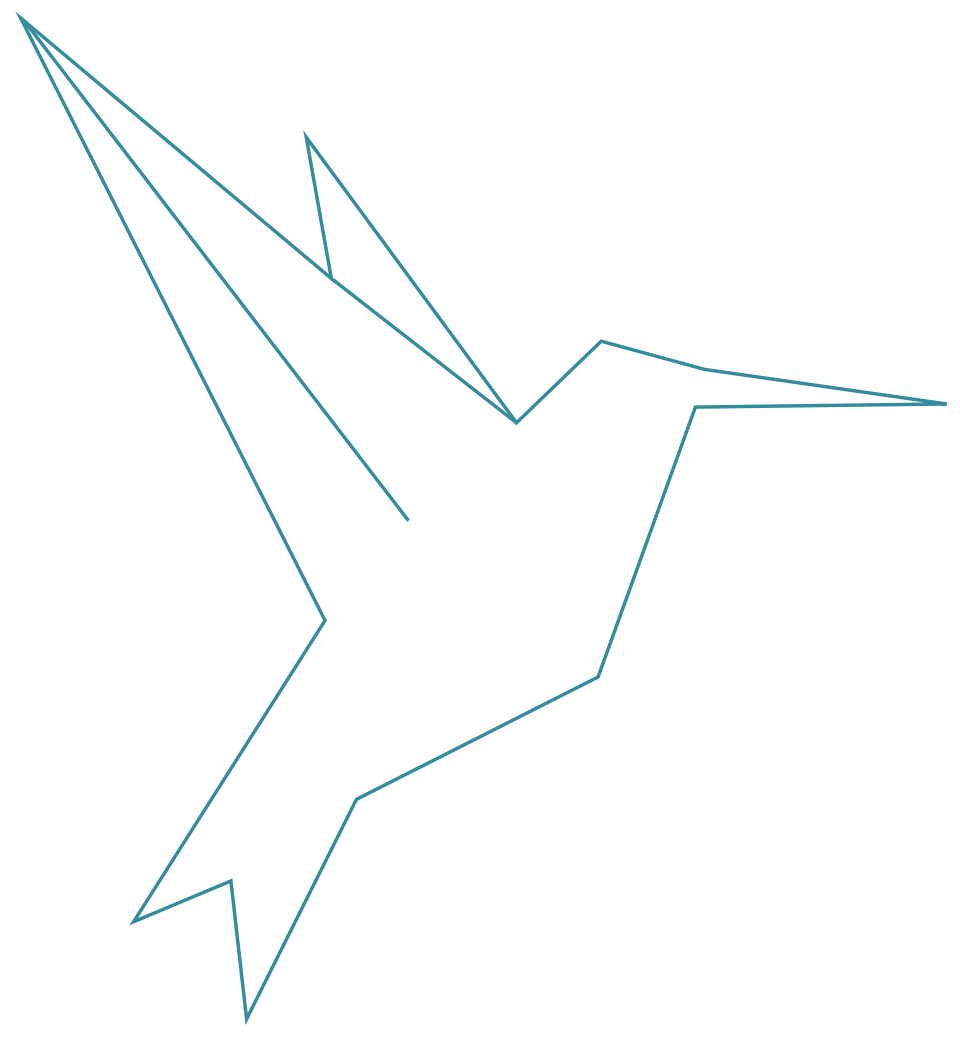




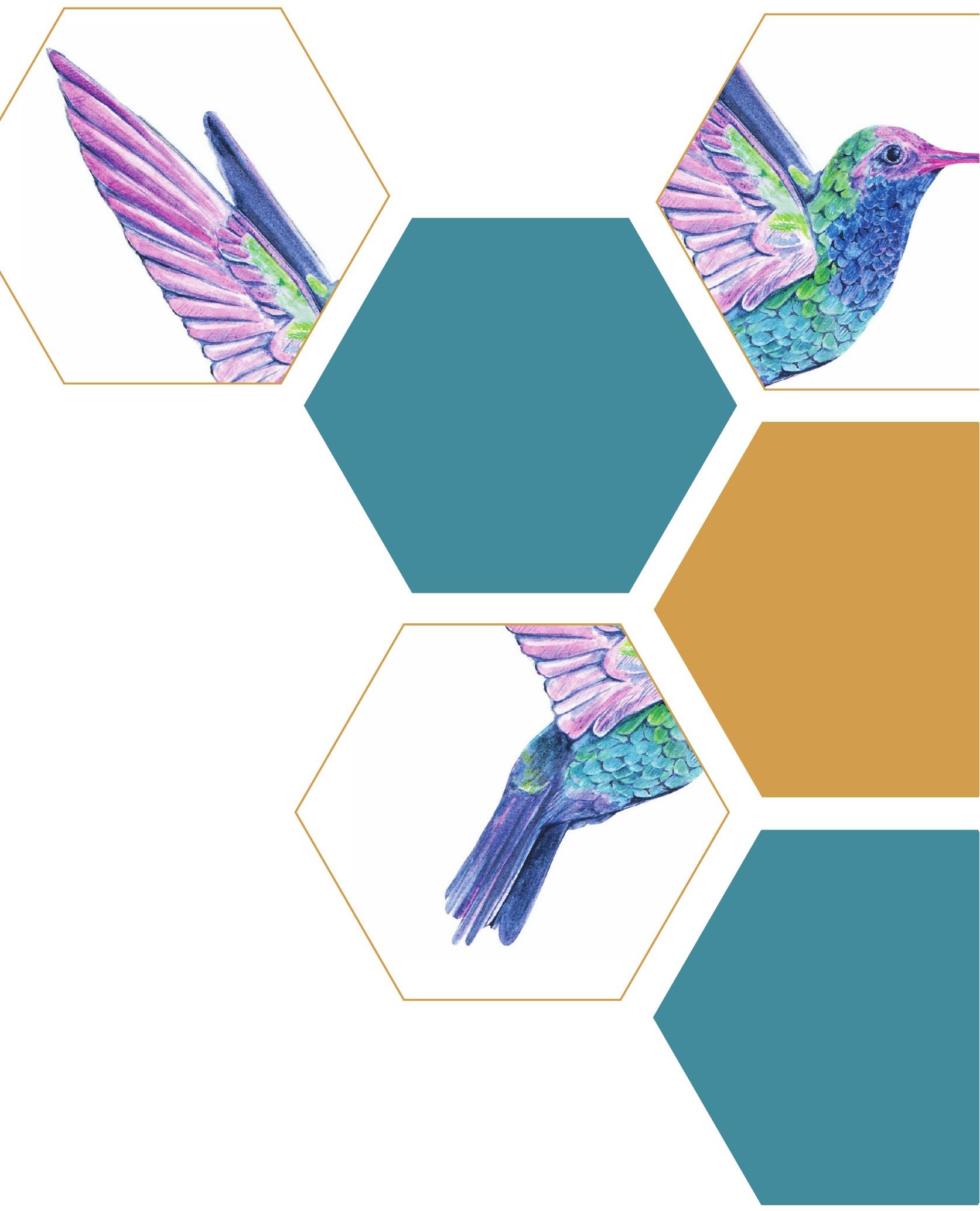




\section{CONTENTS}

Chapter I Introduction

\section{Section I Individual support planning policy}

Chapter 2 Official requirements and stakeholders' expectations

\section{Section 2 Individual support planning in daily practice}

Chapter 3 Perceptions and expectations of people

with intellectual disabilities in the Netherlands

Chapter 4 Barriers and facilitators in attaining individual support plan goals.

\section{Section 3 Content of individual support plans}

Chapter 5 Content analysis of individual support plan documents.

Chapter 6 Sexual health and sexual rights in individual support plans.

Chapter 7 Discussion

Summary

Samenvatting

Valorisation

Dankwoord

List of publications

Curriculum Vitae 



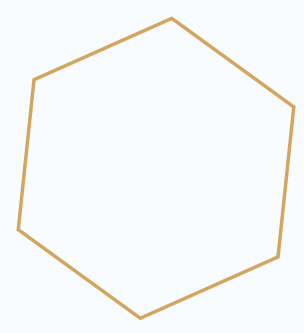

\section{Chapter I}

Introduction 


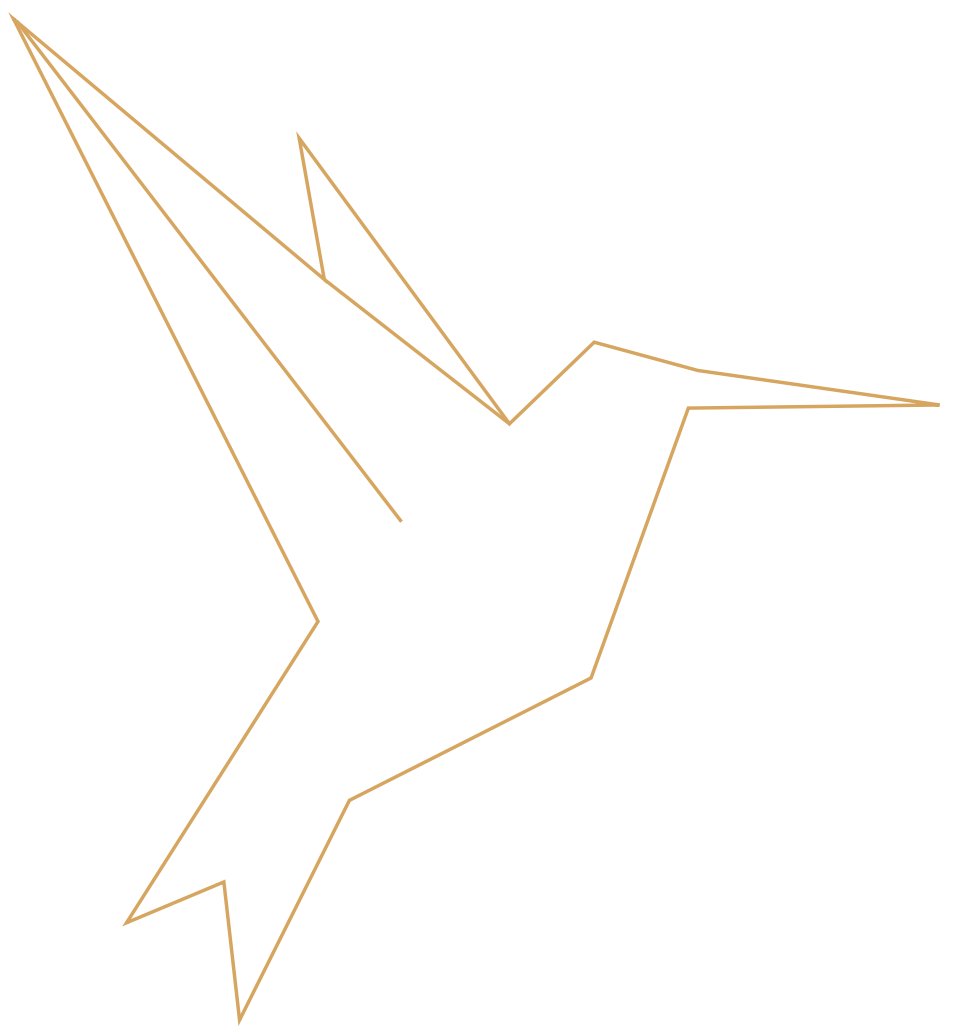




\section{INTRODUCTION}

This thesis focuses on individual support planning (ISP) for people with intellectual disabilities (ID) in the Netherlands. An ISP document is a written or digital document reflecting selected individual goals set for (and by) the person with ID, and the agreement with the service provider to help realise these goals. Individualised support planning is a legal requirement in the Dutch Chronic Care Act (Stb. 20 14, 52 I).

A number of different terms are, around the world, used to refer to ISP, for example individualised service planning, individualised programme planning (IPP), individualised education planning (IEP), individualised transition planning (ITP), individualised written rehabilitation planning (IVRP), individualised habilitation planning (IHP), person-directed planning (PDP), and individual family service planning (IFSP) (Thompson et al., 2009). In the Netherlands, the Chronic Care Act uses the term 'care plan', while the Dutch Association of Service Providers (VGN) uses the term 'support', which they believe acknowledges the self-determination of the person with ID and the facilitator role of the professional. This thesis uses the terms 'individual support plan' and 'individual support planning'.

This thesis reflects on policy and practice of ISP for people with ID in the Netherlands to develop a better understanding of how ISP functions in practice, how it is used and impacts support processes. We now go on to consider the context ID care and the organisation of ID support in the Netherlands, before setting out the research questions that underlie this thesis.

\section{INTELLECTUAL DISABILITY IN THE NETHERLANDS}

\section{Key facts and numbers}

There are an estimated 170.000-231.000 people with ID living in the Netherlands (Woittiez, Ras, \& Oudijk, 20 I2). Not all of them make use of professional support. In early 2016 , 96,432 people with ID had access to long-term care as defined by the Chronic Care Act $(\mathrm{ClZ}, 20 \mathrm{I}$ 6a). This comprises approximately one-third of all people in the Netherlands that have access to this type of care. These also include older people and people with psychiatric disorders (CIZ, 20 I6b). Around 82.825 people work for organisations providing this support for people with ID (based on 20 I I figures) and approximately $€ 4.7$ billion is spent on residential long-term care for people with ID (Kwartel, 20 I3). 


\section{How ID support is organised}

\section{Long-term care in transformation: the legal context}

This section describes how the care for people with ID in the Netherlands is organised. Long-term care in The Netherlands has undergone major transitions since 2015 in terms of access, funding and scope. As the studies in this thesis took place during these transitions, we examine the situations both before 2015 and since 2015 .

Before 2015, everyone who needed long-term care could access it under the Exceptional Medical Expenses Act (AWBZ)'. In 2009, ISP became a legal requirement under the ISPamendment ('Besluit Zorgplanbespreking AWBZ-zorg') to the Exceptional Medical Expenses Act ${ }^{2}$.The scope for setting this standard was as follows:

'To make long-term care person-centred and with that to improve the quality of care, it is necessary that service providers develop the ISP in co-operation with the focus person. This amendment focuses specifically on the role of the focus person at the development of the ISP, not on the presence of an ISP.' (MvT, art.4).

The 2009 amendment required that when a service provider starts to deliver support to a new person, it should organise a meeting with him/her as soon as possible to discuss at least:

- the support goals, set for a certain period, based on the individual's wishes, strengths and disabilities

- the actions needed, both by the service provider and by the person for the goals to be achieved

- who is responsible for (parts of the) support, how different providers are coordinated and who the individual should contact with regard to this coordination

- how often, and under what circumstances, the provider will review and update the support that it provides.

The results of this meeting should be described in the ISP document, which the amendment also stresses should be edited to make it clear and understandable to the person (MvT,art.7).

In 20 I 5, the AWBZ was replaced by a number of different Acts setting out access to care. For our purposes with this thesis, the most important of these is the Chronic Care Act $(2014)^{3}$. Care provided under this act is available only to people in need of permanent surveillance or 24-hour care, due to psychogeriatric conditions, intellectual disabilities, physical or sensory

| Stb. 1967,617.

2 KB, Stb. 2009, 131.

3 Stb. 20|4, 521 . 
disabilities. The Act aims to create a shift in thinking about care, from a 'people fitting the system' approach to a more person-centred approach and a system that is congruent with people's needs. Creating this shift requires continuous dialogue with service users (Kamerstukken II, 2015/16, 34 104, nr. I05) 4 .

\section{ISP requirements in the Chronic Care Act}

The 2009 ISP-amendment was included in the Chronic Care Act, along with additional requirements. These are:

- The person with ID has the right to develop a personal plan on his or her own initiative, describing his or her wants and preferences, and should be taken into account when developing the ISP document ( $\$ 3$, art. 8.1.I WIz)

- The person with ID should receive a copy of the ISP document ( $\$ 1$, art. 8.I.3 WIz)

- The ISP document is evaluated at least twice a year (\$7, art.8. I.I WIz).

- A total of nine topics should be discussed during the ISP meetings. Examples include the person with ID having control over his or her own life and the need to involve natural support resources ( $\$ 2$, art. 8.I.I WIz).

The person can choose whether they want to receive the support at home or in a residential facility. Either way, each organisation providing support is required to develop an ISP for the individual. This means that one person can have several ISP documents (Kamerstukken II, $2013 / 14,33891, \mathrm{nr} .75)^{5}$.

\section{The role of key stakeholders}

In addition to the national legislator, various stakeholders develop their own policies regarding ISP practices in ID. These stakeholders regard ISP as an important tool for enhancing and controlling quality of care and person-centredness. The stakeholders considered here are: budget allocation agencies, the Healthcare Inspectorate and the service providers themselves (represented by the Dutch Association of Service Providers).

\section{Budget allocation agencies}

In the Netherlands, budget allocation is managed through insurance companies. Until 20I5, they set general criteria for service providers that had to be met in order to receive budgets. Besides these general criteria, each insurance company develops its own additional criteria and uses additional incentives with respect to quality items in their negotiations with individual service providers. These items may also relate to ISP. Meeting these 'local' criteria would result in allocation or withdrawal of a partial additional budget for the service provider.The nationwide, general criteria and the additional criteria do influence ISP procedures or content.

4 Brief van de Staatssecretaris van Volksgezondheid van 26 februari 2016, 34 I04, nr. 105.

5 Kamerstukken II, 20। 3//4, 33 89I, nr.75. 
As person-centredness is a key concept in the Chronic Care Act (Kamerstukken II, 20 I 5/ I6, 34 104, nr. I05), insurance companies are developing more tailored approaches to budget allocation strategies. In 2016 , they experimented with a 'dialogue model', in which service providers can have additional funding after they have written a development plan and discussed this with the budget allocation agency (Zorgverzekeraars Nederland, 20 16; Kamerstukken II, 2015/16, 34 104, nr. 105). This gives service providers the opportunity to tailor funding to their needs, rather than getting funding by ticking standardised boxes, some of which items may not be relevant for that particular organisation.

\section{The Healthcare Inspectorate}

The role of the Healthcare Inspectorate is to inspect healthcare practices to ensure efficient and effective enforcement of the legislation. They visit sites and assess them against a set of criteria that have to be met, and ISP is one of the domains they assess. Not meeting such criteria could result in the Inspectorate taking measures to enforce compliance to improve the facility's performance.

Currently, the Inspectorate is expanding its instruments for assessing care practices with instruments that address the dialogue between the service provider and the person with ID and the quality of life of individuals (Inspectie voor de Gezondheidszorg [IGZ], 20 I 6a, 20 I 6b). One of these instruments is the Short Observational Framework for Inspection (SOFI), a person-centred observation instrument that allows inspectors to assess the quality of care and support from the perspective of individuals receiving care (IGZ, 20 I6b; Verkaik, Friele, \& Francke, 2015). Although the Inspectorate is also changing its working methods to more person-centred procedures, it still has a role in reducing and preventing provider quality risks in healthcare (IGZ, 20 I6a).

\section{Quality Framework as set by the Dutch Association of Service Providers}

Service providers, as represented by the Dutch Association of Service Providers, have developed a quality framework for themselves. Every member organisation is required to report on a set of criteria through standardised annual surveys (Vereniging Gehandicaptenzorg Nederland [VGN], 20 I3). In 20 I6, the association was in a process of renewing this quality framework. Under the new system, service providers will have to self-assess several aspects of their work (one of which is ISP) and write a report of their findings (VGN, 20 I5). 


\section{DEVELOPMENTS AND CURRENT USE OF ISP}

Individualised support planning is not restricted to the Dutch context of ID. ISP has become a key aspect of service delivery in ID in a range of countries, and in several has become a legal requirement (Robertson et al., 2007). This section describes some important developments relating to ID and how these have influenced ISP, resulting in a shift from programme planning to person-centred planning.

In the 1960 and 1970s, custodial care, depersonalisation and rigidity of routine were common features of long-term care for people with ID (Goffman, I96I; King, Raynes, \& Tizard, 197I). There was little expectation of change and therefore no need to plan anything. As the principle of normalisation -which means the utilisation- of normative means by people with ID (Wolfensberger, Nirje, Olshansky, Perske, \& Roos, 1972)- emerged, this led the way to individualising care practices in services for people with ID (Greasley, 1995; Humphreys, \& Blunden, 1987; Mansell \& Beadle-Brown, 2004). Individual programme planning was carried out by a planning team (consisting of professionals) and to individuals with ID being assigned to specific facilities or to institutionalised educational programmes. However, programme planning was criticised for being more system centred than person centred and not achieving the expected results.

This resulted in an increase in person-centred approaches to planning (O'Brien \& O'Brien, 2002), as we see in the following section. This shift in planning approaches is documented in literature from in and outside Europe as a means for reforming systems (Greasley, 1995; Holburn, Jacobson, Schwartz, Flory, \& Vietze, 2004; O'Brien, O’Brien, \& Mount, 1997).

\section{Person-centred planning}

Person-centred planning (PCP) is a generic term used to address a family of methods that share common values and characteristics: seeing individuals as people first rather than as bearers of diagnostic labels; using common language and images rather than professional jargon; actively searching for a person's gifts and capacities in the context of community life; strengthening the voices of the person and of those who know the person best in learning about his or her history, evaluating his or her present conditions in terms of valued experiences, and defining desirable changes in his or her life (O'Brien \& O'Brien, 2002).

Well known PCP-methods include Personal Futures Planning (PFP), Essential Lifestyle Planning (ELP), Planning Alternative Tomorrows with Hope (PATH) and McGill Action Planning System (MAPS) (O'Brien \& O'Brien, 2002). Person-centred planning is strongly driven by social role valorisation and the inclusion movement. These approaches aim to reduce social isolation and segregation, promote friendships, increase opportunities to engage in preferred activities, develop competence, and promote respect (Wolfensberger, 20 I I; Claes, Van 
Hove, Vandevelde, van Loon, \& Schalock, 20 I0; Holburn, 2002).

The process of PCP is characterised by the person with ID having a strong influence, a positive vision of the person, involvement of natural sources of support, and not being restricted to the services of an organisation (Butterworth, Steere, \& Whitney-Thomas, 1997; Mansell \& Beadle-Brown, 2004).

\section{THE ROLE OF ISP IN DUTCH ID SUPPORT}

Individualised support planning for people with ID in the Netherlands has evolved from a tool merely for professional accountability to a tool used to promote person-centredness and enhance quality of life and quality of services (Herps, Buntinx, \& Curfs, 20 I 0). These coexisting functions are explained here.

Individualised support planning in the Netherlands became widespread in the late 1980s to early 1990s. It was considered an important tool for professionals. The cyclical support process (individualised support planning, multidisciplinary collaboration within support organisations and collaboration in the team of support staff working with the individual) requires a platform for communication and planning (Kievit, Tak, \& Bosch, 1998). Therefore, ISP is a tool for professional support delivery. The ISP document provides the support team with an overview of the goals and objectives of the support of the person with ID, to help facilitate continuous orientation on strategies and reflection on the process and outcomes (Barnhard \& Meerveld, 1992; Van Gemert \& Dekkers-Van der Veen, 201 I).

Individualised support planning is also regarded as an important tool for promoting personcentred support (KB, Stb. 2009, I 3 I). This is because it focuses on personal preferences and goals and facilitating personal outcomes (Schalock, Verdugo, Bonham, Fantova, \& Van Loon, 2008). Individualised support is characterised by being based on the person's interests, preferences and needs; actively involve the person with ID and his or her natural network in planning and implementing support; flexible across the life span, with meaningul choices to be made; create chances for effective social inclusion, improving relations and empowering the focus person; based on an assessment of the pattern and intensity of support needs and outcomes (Schalock et al., 2008; Wehmeyer, 2002).

Individualised support planning presupposes that a service provider will carry out an assessment of the person's functioning and support needs in order to identify the type, intensity, resources and strategies of support that will enhance personal outcomes in terms of quality of life (Buntinx \& Schalock, 20 I0; Schalock et al., 2008; Schalock et al., 20 I0). 
ISP is also important in the context of quality and accountability. Professional service providers are publically funded and are required to demonstrate whether they effectively produce personal outcomes and how they ensure efficient use of resources (Lawlor \& York, 2007; Mansell \& Beadle-Brown, 2004; Osgood, 2005; Schalock \& Verdugo, 20 I 2). Important quality and safety issues can be addressed in ISP documents, so they also play a role in quality assurance.There are formal requirements, both at the national and regional level, with respect to ISP process. Content service providers also develop their own requirements to ISP.

Kinsella (2000) argues that ISP is used for too great a variety of purposes. Service providers and other stakeholders place too much emphasis on control and uniformity. Because organisations are pressured to standardise support delivery, tensions can arise when individual preferences and needs require flexibility from service providers in form, processes and content of the ISP (Claes et al., 20 I0). This creates the risk of ISP becoming a paper exercise that is unrelated to the real lives of individuals (Claes et al., 20 I0; Dowling, Manthorpe, \& Cowley, 2007; Greasley, 1995; Holburn \& Vietze, 1999; Kinsella, 2000; Mansell \& Beadle-Brown, 2004; Osgood, 2005; Williams \& Robinson, 2000). Dowling et al. (2007) state that inter-agency collaboration can help ensure that goals are attained, but that this collaboration is often lacking.

\section{THE COMPONENTS OF INDIVIDUAL SUPPORT PLANNING}

Individual support planning is a process consisting of several components, approaches, use and potential outcomes (Holburn, 2002; Thompson et al., 2009; Towell \& Sanderson, 2004). Here we consider the elements usually found in Dutch ISP procedures, and some related difficulties that are sometimes encountered.

First, there needs to be an understanding of the individual's support needs. People with ID often need specialist support that people without ID do not need. Moreover, the support needs of people with ID are often long term. It is important to assess the individual's support needs to determine the types and intensity of support that they will receive. Different sources of information are important in assessing individual support needs, including the person with ID and their close relatives, as well as professional support staff and other professionals. During an ISP meeting, all these perspectives come together to help prioritise support needs and determine goals for the next period. Often, this meeting involves two elements: first, evaluating the previous timeframe and how far goals have been achieved to date, and then prioritising support needs and determining goals for the next period. It is essential that these discussions are not constrained by available services or by perceived barriers such as financial restrictions or limitations in a person's skills (Kamerstukken II, 20 I 5/ I6, 34 I04, nr. I 05). 
Involving the person with ID is a crucial aspect of individualised support planning, but it can present a challenge. People with ID may have difficulty understanding the concept and procedures of ISP, may need support with communication that goes beyond verbal communication. Some may find social interaction difficult, or may sometimes have challenging behavior which hinders interaction (Carnaby, 1997; Dowling et al., 2007; Kinsella, 2000; Mansell \& Beadle-Brown, 2004; Robertson et al., 2007a; Williams \& Robinson, 2000). In addition, people with ID often have limited social networks, making it difficult to involve others who could possibly help (Mansell \& Beadle-Brown, 2004). In determining priorities and goals for the next period, tensions can arise when the person with ID expresses wants and needs that do not tally with professional views on what is needed (Claes et al., 20l0).

After the meeting, the ISP document is written, usually by the person's direct support provider.The ISP document describes the individual goals, and sets out the actions that have been agreed on to meet these goals. If all parties agree with the content of the ISP document, implementation starts. Everyone involved in the support provision is informed about the new goals and what is expected from them. The providers then need to monitor the interventions and provide continuous feedback on progress towards the goals, to assess whether commitments are being met and the desired outcomes achieved (Latham \& Locke, 2006; Schalock et al., 20 I0). However, for this to work well, staff needs sufficient time and skills to develop and implement the ISP. High turnover can pose a threat to the implementation of the ISP (Dowling et al., 2007; Kinsella, 2000; Mansell \& Beadle-Brown, 2004; Robertson et al., 2007).

After a set period of time (in 2015, the ISP policy requirement for an annual ISP meeting increased to twice a year), an ISP meeting is planned to assess progress towards goals. This marks the beginning of the next cycle of developing a new or revised ISP document.

\section{THE EVIDENCE BASE}

There have been a number of studies on the effectiveness of ISP. Most literature on ISP effectiveness comes from the UK and USA and focuses mainly on the effectiveness of implementing PCP. First we take an overview of the important lessons from these studies, before looking at the literature on Dutch ISP and finally the potential barriers that may hinder ISP-effectiveness.

Several large-scale and longitudinal studies have been carried out on the implementation of a PCP approach (for example, Coyle, Moloney, \& Services, 1999; Holburn, Jacobson, Schwartz, Flory, \&Vietze, 2004; Robertson et al., 2005). These studies use different outcome measures. 
For example, Holburn et al. (2004) used quality of life indicators, moving into the community and changes in PCP processes. Robertson et al. (2007) measured growth of the social network, community involvement, scheduled day activities, choice, community-based service, hospital-based service, physical activity, current medication, health problems, strengths and difficulties, and risk. A systematic review of Claes et al. (2010) that includes these studies, among others, highlighted the benefits of PCP on social networks, community participation and choice making. However, most studies focus on comparing outcomes before and after implementation of PCP.A problem with determining the effectiveness of ISP is the lack of a clear and universally adopted definition of individualised planning and its expected outcomes, along with a lack of research on ISP as daily practice (Holburn, Jacobson, Vietze, Schwartz, \& Sersen, 2000). It may be expected that different approaches lead to different outcomes.

Another problem with determining ISP effectiveness is that today, individualised planning is no longer new and in many situations it has become a mandatory element of support delivery. This raises questions about how to examine the effects of ISP so many years after it has been introduced, as well as examining the effects of ISP use versus non-use. Only Adams et al. (2006) studied PCP effectiveness by comparing personal outcomes in people with high quality plans of good quality with those of people with plans of lesser quality. They found no differences in personal outcomes.

In the Netherlands, little research has been done on the effectiveness of ISP. In 20 I 3, an evaluation of the Exceptional Medical Expenses Act (2009) by Ploegman, Gijzel, \& Otte showed that the implementation of the Act led to an increase in people having an ISP document and being involved in the process of developing an ISP.The results also showed that these individuals would like to have more influence on their ISP meeting.

There has been extensive research on the effectiveness of a support programme for people with profound intellectual and multiple disabilities (PIMD) (see, for example, the work of Vlaskamp \& van der Putten, 2009; Zijlstra ,2003). This programme is described as 'an individual educational plan (IEP) that includes an implementation strategy and evaluation instruments for persons with PIMD in order to make the changes in their lives that they preferred, and to organise the services and support needed for this' (Vlaskamp \& van der Putten, 2009, p. 874). Effects on people with PIMD included improvements in communication, mood, contact, interaction and alertness, as well as improved interdisciplinary and multidisciplinary collaboration. These outcomes are achieved in organisations that follow the exact programme and implementation strategy. Effectiveness of this programme with this population does not automatically mean effectiveness of general ISP with other people with ID. 


\section{RESEARCH QUESTIONS AND THESIS OUTLINE}

The aim of this thesis is to reflect on the practice of individualised support planning for people with ID in the Netherlands. It addresses five research questions, to contribute to a better understanding within three areas:

I. ISP policy

2. ISP in daily practice

3. the content of ISP documents.

Each of these three points are addressed in turn below.

\section{ISP policy}

The first section addresses ISP policy. As this introduction has shown, different stakeholders play an important role in ISP content and procedures. This first section focuses on the following research question, which is addressed in Chapter 2.

I. What are the formal requirements impacting on ISP content and procedures formulated in Care Acts and national policy documents, and what are the expectations of stakeholders such as self-advocate organisations, the Dutch Association of Service Providers, quality management officers working for ID service providers and legal advisers specialised in Care Acts regarding ISP in the Netherlands?

Because different ID policy and practice stakeholders develop their own understanding and expectations of what constitutes a high quality ISP, we carried out a study to examine not only the formal requirements, but also the expectations of stakeholders and experts in the field of ID in the Netherlands. We used desk research to identify the official legal and regulatory requirements, and then consulted with experts and professionals working in the field of ID.

\section{ISP in daily practice}

The second section in this thesis focuses on ISP in daily practice. The following research questions are addressed in chapters three and four:

2. What are experiences and expectations of persons with ID with respect to their ISP?

3. What are barriers and facilitators to ISP goal attainment?

The first study, a participative, qualitative study (described in Chapter 3), examined experiences and expectations of people with ID with respect to their ISP. The study involved conducting semi-structured interviews with 6 I people with ID, who received support from 23 provider organisations, to gather qualitative information about their experiences and perceptions of the different components of ISP.The research team also included two people with ID who themselves had experience of ISP practices. 
The second study in this section (Chapter 4) focused on the goals that are selected and formulated in ISP documents, in order to gain insight in the barriers and facilitators to people with ID attaining their goals. Goals are essential elements of ISP documents, based on the idea that setting goals leads to improved functioning (Locke \& Latham, 20।3). We studied IOI individual support goals, set out in 34 ISP documents, by interviewing support staff who were responsible for the ISP documents in question.

\section{Content of the ISP document}

The final section of the thesis consists of two studies that explored the content of ISP documents. We collected a sample of 209 ISP documents from eight different service providers in order to answer the following research questions:

4. What are ISP features with respect to the number and content of goals and the nature of support resources in relation with client characteristics?

5. How is sexuality addressed in ISP documents?

To tackle these two research questions, we analysed a set of ISP documents from different service providers. In our first study, we looked at general characteristics of the ISP documents such as the number of pages and number of goals. Next, we analysed goal content against the backdrop of a quality of life framework (Schalock et al., 2008). We then conducted mixed linear regression analyses to examine the relationship between client characteristics (age, gender and intellectual disability) and the content of goals and support resources. This study is presented in Chapter 5 .

In our second study in this section (Chapter 6), we looked at the extent to which important but sensitive topics are present in ISP documents. These might include substance misuse or the use of restrictive interventions, force or coercion, or (the topic that we chose) sexuality and sexual rights. Sexuality is important for the quality of life of individuals with ID and part of the UN Convention on the Rights of People with Disabilities (Article 25; United Nations, 2006). Sexuality can be a difficult subject to address as it is associated with various taboos, concerns and ethical questions and some people find it difficult to talk about because it can be a private subject.

Finally, Chapter 7 offers a general discussion. It reviews and discusses the results of the studies in this thesis. It then draws conclusions and recommendations for further research, and highlights implications for ISP policy and practices in the Netherlands. 


\section{REFERENCES}

Adams, L., Beadle-Brown, J., \& Mansell, J. (2006). Individual planning: an exploration of the link between quality of plan and quality of life. British Journal of Learning Disabilities, 34(2), 68-76.

Barnhard, M.C., \& Meerveld, J.H.C.M. (1992). Handleiding Zorgplannen. Methodisch werken in de zorg voor verstandelijk gehandicapten. Utrecht: Nationaal Ziekenhuis Instituut.

Buntinx,W. H. E., \& Schalock, R. L. (20 I 0). Models of Disability, Quality of Life, and Individualized Supports: Implications for Professional Practice in Intellectual Disability. Journal of Policy and Practice in Intellectual Disabilities, 7, 283-294.

Butterworth, J., Steere, D. E., \& Whitney-Thomas, J. (1997). Using Person-Centered Planning to address personal Quality of Life. In R. L. Schalock (Ed.), Quality of Life. Volume II. Application to persons with disabilities (pp. 5-25). Washington, D.C.: American Association on Mental Retardation.

Carnaby, S. (1997). "What do you think?": a qualitative approach to evaluating individual planning services. Journal of Intellectual Disability Research, 4 I (3), 225-31.

CIZ (2016a). Kwartaalrapportage CIZ 2015 QI t / m Q4 Indicatiestelling WIz. Utrecht.

$\mathrm{ClZ}$ (2016b). I jaarWlz. Een overzicht. Utrecht.

Claes, C., Van Hove, G., Vandevelde, S., van Loon, J., \& Schalock, R. L. (20I0). Person-centered planning: analysis of research and effectiveness. Intellectual and Developmental Disabilities, 48(6), 432-53.

Coyle, K., Moloney, K., \& Services, K. S. (1999). The Introduction of person-centred planning in an Irish agency for people with intellectual disabilities : An introductory study. Journal of Vocational Rehabilitation, 12, 175-180.

Dowling, S., Manthorpe, J., \& Cowley, S. (2007). Working on person-centred planning: from amber to green light? Journal of Intellectual Disabilities, 1 / (I), 65-82.

Goffman, E. (1961). Asylums. Essays on the Social Situation of Mental Patients and Other Inmates. New York: Anchor Books.

Greasley, P. (1995). Individual Planning with Adults who Have Learning Difficulties : Key issues - key Sources. Disability \& Society, 10(3), 353-364.

Herps, M. A., Buntinx, W. H. E., \& Curfs, L. M. G. (20 I0). Ontwikkelingen in het ondersteuningsplan in Nederland. Nederlands Tijdschrift voor de Zorg aan mensen met Verstandelijke Beperkingen, 36(2), I I I-136.

Holburn, S. (2002). How Science Can Evaluate and Enhance Person-Centered Planning. Research and Practice for Persons with Severe Disabilities, 27(4), 250-260.

Holburn, S., Jacobson, J.W., Schwartz, A. A., Flory, M. J., \& Vietze, P. M. (2004). The Willowbrook futures project: a longitudinal analysis of person-centered planning. American Journal of Mental Retardation, 109( I), 63-76.

Holburn, S., Jacobson, J.W., Vietze, P. M., Schwartz, A. A. \& Sersen, E. (2000). Quantifying the Process and Outcomes of PersonCentered Planning. American Journal on Mental Retardation, 105(5), 402-4I6.

Holburn, S., \& Vietze, P. (1999). Acknowledging Barriers in Adopting Person-Centered Planning. Mental Retardation, 37(2), $117-124$.

Humphreys, S., \& Blunden, R. (1987). A collaborative evaluation of an individual plan system. British Journal of Mental Subnormality, $33(1), 19-30$.

Inspectie voor de Gezondheidszorg (2016a). Meerjarenbeleidsplan 2016-2019. Gezond vertrouwen. Utrecht: Inspectie voor de Gezondheidszorg.

Inspectie voor de Gezondheidszorg (2016b). Werkplan 2016. Utrecht: Inspectie voor de Gezondheidszorg. 
Kievit,T.,Tak, A., \& Bosch, J. D. (Eds.). (1998). Handboek psychodiagnostiek voor de hulpverlening aan kinderen. Maarssen: Elsevier/De Tijdstroom.

King, R. D., Raynes, N.V., \& Tizard, J. ( 197I). Patterns of residential care. Sociological studies in institutions for handicapped children.

London: Routledge \& Kegan Paul.

Kinsella, P. (2000). What are the barriers in relation to Person Centred Planning? York: Joseph Rowntree Foundation.

Kwartel, A. J. J. (2013). Brancherapport Gehandicaptenzorg 2012. Utrecht.

Latham, G. P., \& Locke, E. A. (2006). Enhancing the Benefits and Overcoming the Pitfalls of Goal Setting. Organizational Dynamics, 35(4), 332-340.

Lawlor, D., \& York, M. (2007). Assessing goal attainment for quality improvement. Journal of Intellectual Disabilities, I I (3), 24 I-55.

Mansell, J., \& Beadle-Brown, J. (2004). Person-Centred Planning or Person-Centred Action? Policy and Practice in Intellectual Disability Services. Journal of Applied Research in Intellectual Disabilities, 17, I-9.

O'Brien, C. L., \& O'Brien, J. (2002). The origins of person-centered planning: a community of practice perspective. In S. Holburn \& P. M.Vietze (Eds.), Person-Centered Planning. Research, Practice, and Future Directions (pp. 3-28). Baltimore: Paul H. Brookes.

O'Brien, C. L., O'Brien, J., \& Mount, B. (1997). Person-Centered Planning has arrived... or has it? Mental Retardation, 35(6), 480-484. Osgood, T. (2005). Managing the tensions between the interests of organisations and service users. In P. Cambridge \& S. Carnaby (Eds.), Person centred planning and care management with people with learning disabilities (pp. 5I-64). London: Jessica Kingsley Publishers.

Ploegman, M., Gijzel, H., \& Otte,W. (20।3). Evaluatie Besluit zorgplanbespreking. Eindrapportage. Den Haag: Deloitte.

Robertson, J., Emerson, E., Hatton, C., Elliott, J., Mclntosh, B., Swift, P., ... Joyce, T. (2007). Person-centred planning: factors associated with successful outcomes for people with intellectual disabilities. Journal of Intellectual Disability Research, 5I (3), 232-243.

Robertson, J., Hatton, C., Emerson, E., Elliott, J., Mcintosh, B., Swift, P., ... Joyce, T. (2007a). Reported Barriers to the Implementation of Person-Centred Planning for People with Intellectual Disabilities in the UK. Journal of Applied Research in Intellectual Disabilities, 20, 297-307.

Robertson, J. M., Emerson, E., Hatton, C., Elliott, J., Mclntosh, B., Swift, P., ... Joyce,T. (2005). The impact of person centred planning. Lancaster University. Retrieved from http://eprints.lancs.ac.uk/33076/

Schalock, R. L., Borthwick-Duffy, S. A., Bradley,V. J., Buntinx, W. H. E., Coulter, D. L., Craig, E. M., ... Yeager, M. H. (20 I 0). Intellectual disability: definition, classification, and systems of supports. Washington, D.C.:American Association on Intellectual and Developmental Disabilities.

Schalock, R. L., \& Verdugo, M. A. (20।2). A leadership guide for today's disabilities organizations: Overcoming challenges and making change happen. Baltimore: Paul H. Brookes Pub.

Schalock, R. L.,Verdugo, M. A., Bonham, G. S., Fantova, F., \& Van Loon, J. (2008). Enhancing Personal Outcomes: Organizational Strategies, Guidelines, and Examples. Journal of Policy and Practice in Intellectual Disabilities, 5(4), 276-285.

Thompson, J. R., Bradley,V. J., Buntinx, W. H. E., Schalock, R. L., Shogren, K. A., Snell, M. E., ... Yeager, M. H. (2009). Conceptualizing supports and the support needs of people with intellectual disability. Intellectual and Developmental Disabilities, 47(2), $135-46$.

Towell, D., \& Sanderson, H. (2004). Person-Centred Planning in its Strategic Context: Reframing the Mansell/Beadle-Brown Critique. Journal of Applied Research in Intellectual Disabilities, 17(1), 17-21.

Van Gemert, G., \& Dekkers-Van derVeen, M. (201 I). Persoonlijke ondersteuningsplanning in de praktijk. Assen: Koninklijke Van Gorcum. 
Verkaik, R., Friele, R., \& Francke, A. L. (20I5). Evaluatie van een nieuwe vorm van cliëntgericht toezicht: het Short Observational Framework for Inspection (SOFI). Utrecht: NIVEL.

VGN (2013). Kwaliteitskader Gehandicaptenzorg. Utrecht:VGN.

VGN (20I5). Nieuwsbrief Kwaliteit inzicht, (december 20I5). Utrecht:VGN.

Vlaskamp, C., \& van der Putten, A. (2009). Focus on interaction: the use of an Individualized Support Program for persons with profound intellectual and multiple disabilities. Research in Developmental Disabilities, 30(5), 873-83.

Wehmeyer, M. L. (2002). The confluence of Person-Centered Planning and Self-Determination. In S. Holburn \& P. M. Vietze (Eds.), Person-Centered Planning. Research, Practice, and Future Directions (pp. 5 I-69). Baltimore: Paul H Brookes.

Williams, V., \& Robinson, C. (2000). "Tick this, Tick that": The views of people with learning disabilities on their assessments. Journal of Intellectual Disabilities, 4(4), 293-305.

Woittiez, I., Ras, M., \& Oudijk, D. (2012). IQ met beperkingen. De mate van verstandelijke handicap van zorgvragers in kaart gebracht. Den Haag: Sociaal en Cultureel Planbureau.

Wolfensberger,W. (20I I). Social role valorization: A proposed new term for the principle of normalization. Intellectual and Developmental Disabilities, 49, 435-440.

Wolfensberger,W. P., Nirje, B., Olshansky, S., Perske, R. \& Roos, P. (1972). The Principle of Normalization In Human Services. Toronto: National Institute on Mental Retardation.

Zijlstra, H. P. R. (2003). Dansen met olifanten, een onderzoek naar de implementatie van het opvoedingsprogramma in de zorg voor mensen met ernstig meervoudige beperkingen. Groningen: Stichting Kinderstudies.

Zorgverzekeraars Nederland (2016). Inkoopkader Langdurige Zorg 2016. Retreived from Zorgverzekeraars Nederland website: https://www.zn.nl/336986 | 25/Publicaties?folderid=3392 | 4376\&title=Inkoopkader+langdurige+zorg\&parentid= 342097937\&parenttitle=ZN-brieven

\section{Legal documents}

Brief van de Staatssecretaris van Volksgezondheid van 26 februari 2016, 34 I04, nr. I05. 'Waardig leven met zorg'.

Algemene Wet Bijzondere Ziektekosten: Stb. 1967, 617.

Algemene Maatregel van Bestuur: KB, Stb. 2009, 131. Besluit zorgplanbespreking AWBZ-zorg.

Wet langdurige zorg: Stb. 2014, 521 .

Amendement over het mogelijk maken van een zorgplanbespreking bij een modulair pakket thuis:

Kamerstukken II, 2013/14, 33 891, nr.75. 




\section{Section I
Individual support planning policy \\ Section I
val support planning policy \\ Individual support planning policy \\ Section I
al support planning policy}

$-$ 


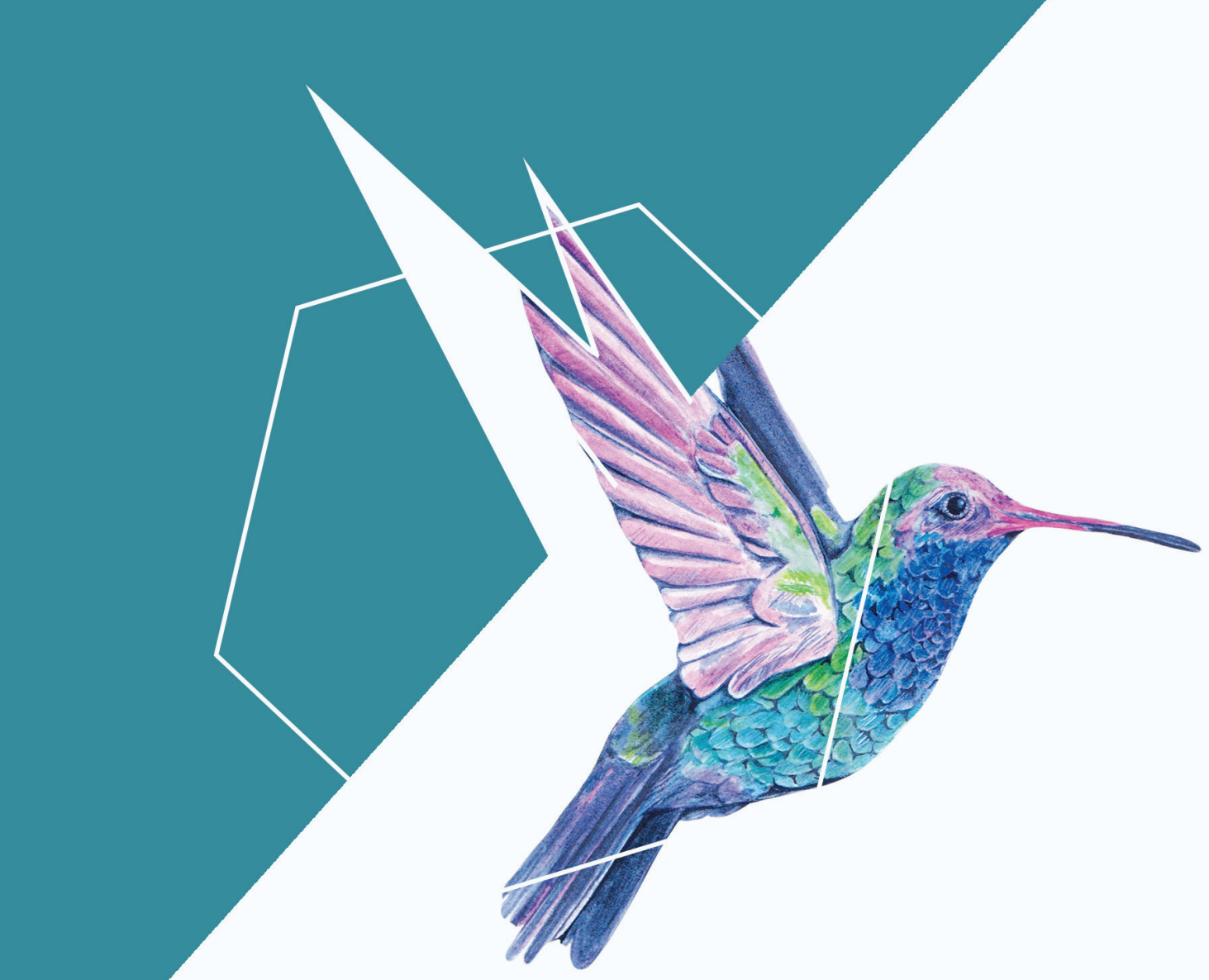



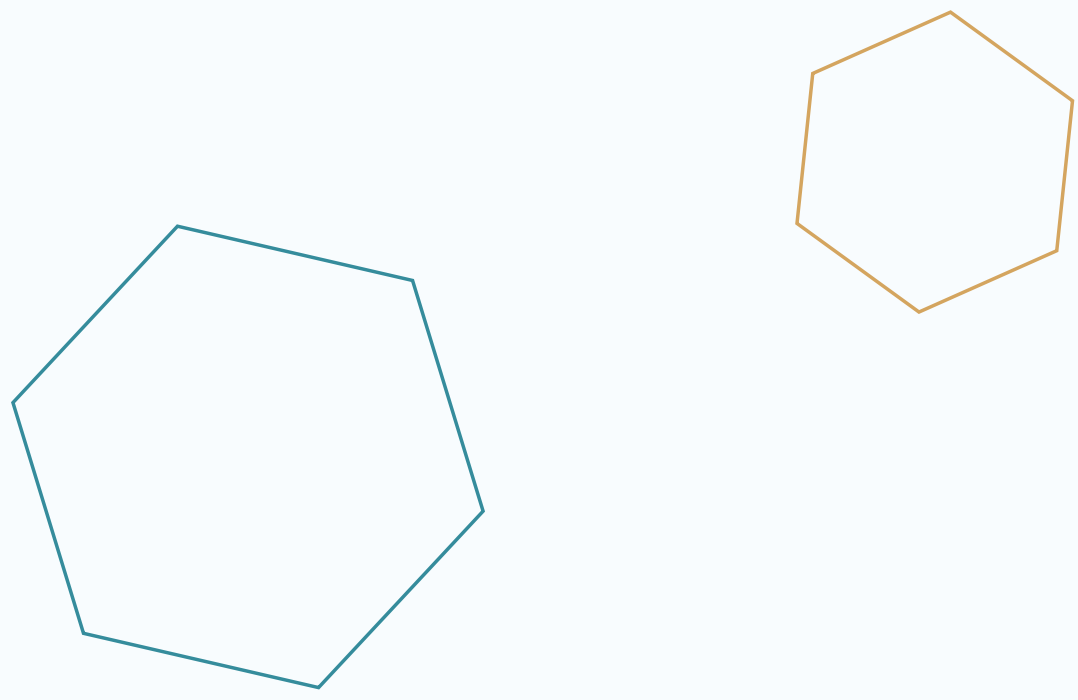

\section{Chapter 2}

\section{Official requirements and stakeholders' expectations}

\section{Published as:}

Herps, M.A., Buntinx,W.H.E., \& Curfs, L.M.G. (20 I 6). Individual support planning with people with ID in The Netherlands: Official requirements and stakeholders' expectation. Alter, European Journal of Disability Research, 10, 281-288. 


\section{ABSTRACT}

\section{Introduction}

Individualized support planning (ISP) has become a key aspect of supports for people with ID and is mandated in several countries. Different stakeholders develop policies and expectations regarding ISP. In this study, we report on requirements as found in Dutch official ID policy and on the results of consultations of panels of stakeholders and experts working in the field of ID. It was intended to describe, summarize and discuss these requirements for the purpose of enhancing ISP practices.

\section{Method}

A combination of desk research of policy documents and consultation of two expert panels was performed.

\section{Results}

A variety of criteria on content, procedures, quality and person-centeredness of ISP is being used by different stakeholders. These criteria were described and summarized.

\section{Discussion}

The broad range of inconsistent requirements and sometimes conflicting expectations from different stakeholders hamper a clear conceptualization of ISP and affect the use of ISP in practice. 


\section{INTRODUCTION}

Individualized support plans (ISP) are mandatory in several countries, such as England, the Netherlands, Belgium, Canada and several states of the United States of America (Felce, 2004; Herps, Buntinx, \& Curfs, 20 I3; Robertson et al., 2007). Individualized planning has become an important instrument in providing professional supports for people with intellectual disabilities (ID).The term 'individualized support planning' is used to address a multi-faceted, long-term intervention aimed at supporting persons with intellectual disabilities (Holburn, 2002). It consists of a continuous cycle of identifying desired life experiences, assessing support needs, defining personal objectives and goals, developing required strategies and resources in order to achieving these objectives and goals, monitoring the progress and, finally, evaluating the extent to which personal outcomes have been realized (Buntinx \& Schalock, 2010 ; Schalock et al., 20 I0; Thompson et al., 2009). Therefore, ISP is regarded as a tool for person-centered support (e.g. Adams, Beadle-Brown, \& Mansell, 2006; Mansell \& BeadleBrown, 2004; Robertson et al., 2005; Schwartz, Holburn, \& Jacobson, 2000). Person-centered support is based on the individual's interests, preferences and strengths; require active involvement of the focus person and people who are important to him/her; supposes that the focus person has meaningful choices; uses, when possible, natural resources; is focused on relationships, inclusion, dignity and respect; offers a range of experiences and opportunities; is collaborative and recurring; and aims at the person's satisfaction with his/her activities and support (Schwartz et al., 2000).

Different stakeholders in ID policy and practice, such as self-advocacy and parents' associations, Healthcare inspectorates or budget allocation agencies, develop their own understanding and interpretation of what constitutes a 'good quality ISP' (Charmaz, 2006). Each of these stakeholders cherishes their own beliefs about a good quality ISP and accordingly set and relays their criteria to the field. It has been argued that increasing formal requirements regarding ISP documents enhances the risk that in practice, formally meeting criteria ('ticking boxes') may become more important than using ISP in daily support practices to the benefit of persons with ID (Smull \& Lakin, 2002). The aim of the present study is to explore rules and expectations regarding ISP in the Netherlands. So far, in the Netherlands, no overview of different ISP requirements and consequences for not meeting such expectations is yet available. The present authors therefore undertook a desk research to make an inventory of official requirements as found in Dutch ID policy documents and applicable laws (referred to as 'formal requirements') and subsequently consulted panels of professionals working in the field of ID to add their expectations and to discuss the implications that requirements have on ISP in ID practice. 
The study was part of a larger, nation-wide improvement program on ISP practices in the field of ID. This program was initiated by the Dutch Association of Service Providers in the field of ID (VGN) and funded by the Netherlands Organization for Health Research and Development (ZonMw). One of the aims of the program was to develop a set of recommendations for service providers in ID that would be compatible with official requirements, congruent with relevant stakeholders' visions, and could be used as guidelines in practice. In this article, we report on requirements as found in Dutch ID policy and on the results of consultations of panels of stakeholders and experts working in the field of ID. The research questions are: (I) what formal requirements on ISP process and/or content exist; and (2) what are expectations regarding ISP according to stakeholders and experts in the field of ID. 


\section{METHOD}

\section{Desk research identifying formal requirements}

The study started with a desk research of relevant Dutch Acts and official policy documents to identify requirements that affect the process and/or content of ISP. Official documents in this project were considered Health Care Acts and complementary regulations that have a mandatory impact on ISP and may lead to consequences for service provider organizations in case such requirements would not be met. Included in this study were:

- Care Acts: Exceptional Medical Expenses Act (AWBZ), Individual Healthcare Professions Act (Wgbo), Psychiatric Hospitals Compulsory Admission Act (BOPZ);

- current requirements from the Dutch Healthcare Inspectorate with respect to ISP in the field of ID;

- the quality framework for service provision as formulated by the Dutch Association of Service Providers (VGN, 20 I 3);

- regulations stemming from budget allocation agencies (insurance agencies).

For retrieving the requirements in these documents, we read each document and searched with the Dutch equivalents of the terms 'care plan(ning)' and/or 'support plan(ning)' and '(intellectual) disability' and/or 'mental retardation'.

\section{Consulting stakeholders and experts}

Consultations with stakeholders took place in the course of one year.Two panels were set up. Panel A was asked to reflect on the formal requirements, their organization in domains and later, to evaluate the outcomes of Panel B and to decide on the final list of requirements. Panel A consisted of relevant stakeholders at the national policy level. Purposive sampling was used to decide which organizations should participate in this panel and invitations were sent by the researchers to these organizations to participate and to form their delegation in the panel. All invited organizations accepted the invitation. Panel A comprised eleven representatives from: four different self-advocate organizations $(n=4)$, the Dutch Association of Service Providers $(n=1)$, quality management officers from four service provider organizations $(n=4)$, and legal advisors specialized in Health Law: one legal advisor worked in a service provider organization and the other worked at the Dutch Association of Service Providers $(n=2)$. Panel A was consulted twice: first after the initial desk research to formulate the input document for Panel $B$ and later after consulting Panel B.

Panel B comprised three groups of professionals working in the field of ID. The first group consisted of an existing advisory expert network of legal advisors $(n=7)$ facilitated by the VGN.The second group was an expert network of quality officers working in Dutch service provider organizations $(n=10)$ facilitated by the VGN. The people that participated in this network work at different service provider organizations and differ from the people and 
organizations that participated in panel A. The first author visited a regular meeting of each of these networks and initiated an open group discussion on what, from their professional point of view, was considered important for ISP. The researcher led the discussion and detailed minutes of the discussion were taken and afterwards checked by the participants. The third group consisted of project leaders $(n=28)$ that were participating in the nationwide improvement program on working with ISPs in The Netherlands. Project leaders were professionals with a bachelor or masters degree in psychology, special education or health care sciences. These groups were offered a document with the provisional outcome of the desk research and comments of Panel A. They were subsequently asked to answer the question:'what do you find important to appropriately work with ISP in professional support of people with ID?'The groups of Panel B were invited to eventually add requirements they considered important in practice. The results of these consultations were finally presented to Panel A in order to produce a list of ISP requirements based on formal requirements, and views of stakeholders and experts in the Dutch field of ID.

The requirements that were found during the desk research and the statements that were made by the people during the consultation phase were categorized by the researchers according to the domains of: content, process, quality and person-centeredness of ISP. 


\section{RESULTS}

The requirements as found in the desk research and in the consultations are summarized in Table I. Identification numbers are used to tag the source of the criterion: 'I ' when that the requirement was found in Health Care Acts; '2' for Healthcare Inspectorate requirement; ' 3 ' for a requirement from the Dutch Quality Framework of service providers 2013 (VGN); ' 4 ' for a requirement from Dutch Insurance companies; and ' 5 ' to tag the outcomes of the consultation of the panels.

\section{Formal requirements}

\section{Care Acts}

The rights of people with ID who are clients of professional service providers are protected through several acts. A central aspect in these acts is the focus on the right to self-determination (Herps, Buntinx, \& Curfs, 20 I 0; Frederiks \& Dörenberg, 20 I2). This right is reflected in various acts that refer to ISP.The 'Besluit Zorgplanbespreking AWBZ-zorg' (2009) mandates the use of ISP with the aim of enhancing person-centeredness. It states that there should be an ongoing dialogue between professional support workers and people with ID regarding their support and that the results of that dialogue should be incorporated in the ISP document as mutual agreements regarding the provision of support. If the person with ID is not thought to be 'mentally competent' to decide on (parts of) the ISP, this dialogue is between the paid support worker and the legal representative of the person with ID. The Individual Healthcare Professions Act (Wgbo) states that a personal file should be kept for each individual. The ISP is regarded to be part of this file. The Psychiatric Hospitals Compulsory Admission Act (BOPZ) is applicable whenever a person is admitted to a residential service for persons with ID against his or her will, if they do not agree with the provided care and/ or if the person is unable to give or withhold consent for admission. In these cases, a professional 'treatment plan' is to be put in place, describing the treatment and how the 'danger' the person poses to himself or to others is being reduced or eliminated (Herps et al., 20 I 0). 
Table I Overview of ISP requirements as formulated in official policy sources and stakeholders and experts in the field of ID.

Domain Requirements

\section{Content:}

What should be addressed in an ISP document?

\section{Process:}

What are procedural requirements?

\section{Quality:}

Requirements regarding organizational ISP-policy person-centeredness

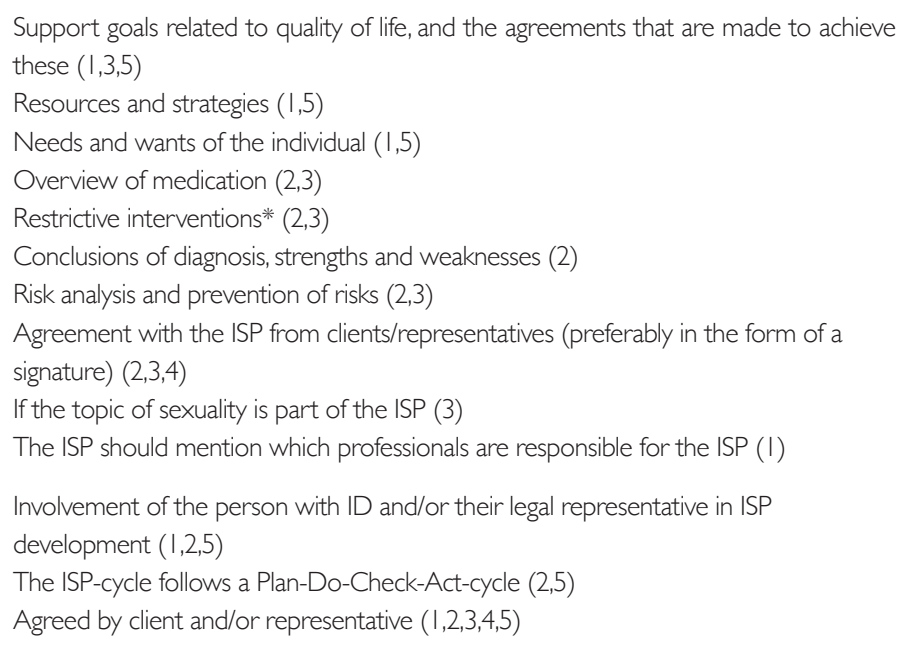

Support goals related to quality of life, and the agreements that are made to achieve these $(1,3,5)$

Resources and strategies $(1,5)$

Needs and wants of the individual $(1,5)$

Overview of medication $(2,3)$

Restrictive interventions* $(2,3)$

Conclusions of diagnosis, strengths and weaknesses (2)

Risk analysis and prevention of risks (2,3)

Agreement with the ISP from clients/representatives (preferably in the form of a signature) $(2,3,4)$

If the topic of sexuality is part of the ISP (3)

The ISP should mention which professionals are responsible for the ISP (I)

Involvement of the person with ID and/or their legal representative in ISP

development $(1,2,5)$

The ISP-cycle follows a Plan-Do-Check-Act-cycle $(2,5)$

Agreed by client and/or representative $(1,2,3,4,5)$

A first ISP document should be written within the first six weeks of support delivery

$(1,3)$

Yearly review of the ISP $(1,2,3,4)$

Involvement of a multidisciplinary teams (2)

Each organization should have a policy document regarding ISP $(3,4)$

This policy document should be reviewed on a regular basis (3)

Organizations need to protect the privacy of clients (5)

Every organization describes who is responsible for the procedures (5)

ISP is part of the client's file and makes references to other (personal) information and professional (treatment) plans $(1,5)$

Having a vision on ISP and develop the ISP procedures and format accordingly (5)

ISP related documents should be understandable/in clear language $(1,5)$

Active involvement of the person with ID*** in all ISP components $(1,2,3,5)$

The annual review meeting should be based on equality between the individual, their representatives and professionals (5)

Client and representatives are informed about the development and evaluation of ISP policy (5)

The individual with ID is in control (choices in content and process, resources) $(1,3,5)$

Clients and/or their representatives have access to their personal file and to their ISP document (I)

The individual has a copy of their ISP (5)

The individual is seen in the context of his/her social network (5)

*what interventions are used, the reasons for using these interventions, perspectives of clients, representatives and involved professionals regarding the use of these interventions. **and/or their legal representatives. 


\section{Requirements by the Healthcare Inspectorate}

The Healthcare Inspectorate pays announced and unannounced visits to locations of service providers. A quick-scan is used to assess risks with respect to safety, restrictive interventions, ISP and quality of staff and organization. During these site visits, the inspectorate talks with clients, staff and managers and inspects samples of ISP documents and files. The items with respect to ISP are summarized in Table I (tagged 2). Based on the results of the quick scan, the Healthcare Inspectorate decides if the location meets their criteria and if not, what measures need to be taken. Measures vary from improving specific items to getting placed under guardianship of the Healthcare Inspectorate.

\section{The official quality framework as set by the Association of service providers.}

In 2013 , the Dutch Association of service providers implemented a quality framework (VGN, 20I3). This framework is based on a vision document (VGN, 2007, 20I3) in which 'selfdetermination' and 'quality of life' are the leading concepts. ISP is regarded to be one of four preconditions for delivering quality support. The other three preconditions are safety; quality of staff and organization; and consistency in care and support. Every member organization of the Dutch Association of Service Providers is required to report on these preconditions through standardized surveys on a yearly basis. Table I (tag 3) mentions indicators in this surveys regarding ISP that were part of the mandatory data set in 2013.

\section{Nation-wide regulations stemming from budget allocation agencies.}

Service provider organizations receive their budgets through insurance companies. Budgets are approved provided that the organization meets specific criteria. Regarding ISP, insurance companies require that the service provider organization documents the ISP process and that every person with ID or his/her representative signs their ISP. As part of their quality policy, regional offices of these insurance companies can set extra criteria as incentives for extra budget. These criteria differ per region and per year. Organizations that work in more regions have to deal with requirements from different insurance companies. ISP related criteria of insurance companies are shown in Table I (tag 4). Not meeting criteria set by budget allocation services, can lead to missing funding.

\section{Consultation of stakeholders and experts}

The discussions in the panels finally led to a confirmation of the importance of some of the formal requirements (see Table I, tag 5). For example, the AWBZ states that the ISP should describe the goals and agreements between a person with ID and a service provider organization. This requirement was found important by all stakeholders that were involved in this study. 
The consultation also added extra requirements regarding ISP. For example, stakeholders discussed that the increasing use of digitalized files and ISP documents raised issues of client privacy (who has access to the individuals' files) and that it presents an important quality aspect. 


\section{DISCUSSION}

The study identified nation-wide requirements regarding the content of ISP documents, the procedures regarding ISP, the policy that service provider organizations need to install for ISP within their organization, the requirements related to person-centeredness and the function that ISP has according to different stakeholders. The results seem to confirm the statement of Charmaz (2006) that different stakeholders develop their own understanding of what constitutes 'good ISP'. The variety of requirements and different perspectives with respect to ISP quality can have several implications in ID practice.

First, the amount of and variety within the criteria can lead to confusion about the principles, methods and desired outcomes of ISP (Schwartz et al., 2000, p. 236). Workers in the field of ID face the challenge of balancing the criteria in workable ISP procedures. This results in a tendency to include a vast amount of information in the ISP, resulting in ISP documents ranging up to fifty pages and more (Herps, Buntinx, Schalock, Van Breukelen, \& Curfs, 20I 6). This increases the staff's workload, bureaucracy and reduces the likelihood of using the ISP in practice (Stancliffe, Hayden, \& Lakin, 1999).

Second, even though the legal justification for mandating ISP is based on 'enhancing personcenteredness', few formal requirements address this aspect. These requirements leave little room for tailoring the content of ISP documents and procedures in developing and implementing ISP. Standardized forms and processes are implemented leaving little room for flexibility and person- centered approaches to planning (Mansell \& Beadle-Brown, 2004; Kinsella, 2000; Schalock et al., 2008; Cambridge \& Carnaby, 2005; Adams et al., 2006; Stancliffe et al., 1999).

Third, setting criteria and consequences for not meeting the criteria, is no guarantee that the intention or goal behind those criteria is met (Cook \& Odom, 2013; Smull \& Lakin, 2002). For example, one criterion is that the person with ID and/or his representative are involved in the process of developing and reviewing their ISP. A study of Herps et al. (20 I3) demonstrated that even though people with ID are often present at ISP review meetings, they do not feel involved because they do not fully grasp the meaning of the meeting or a non-person-centered approach is used during these meetings. It is important that a written ISP document that ticks all the boxes is not the outcome, but rather that the implementation of the goals and agreements that are set in the ISP document have effectively led to the enhancement of the person's quality of life. 
As the present study was part of a larger, nation-wide program, concessions had to be made regarding the selection of participating organizations and people, and regarding the analyses of the outcomes. The present study had a pragmatic approach and although it resulted in a description of the current formal criteria and expectations of stakeholders, an interesting next step would be to develop solutions for the issues raised here, involving both policy and practice. Therefore, the results of the present study highlight some key issues in ISP in policy and practice and can be regarded as a first step in improving ISP policy and practice in The Netherlands.

\section{Disclosure of interest}

The authors declare that they have no competing interest. 


\section{REFERENCES}

Adams, L., Beadle-Brown, J., \& Mansell, J. (2006). Individual planning: An exploration of the link between quality of plan and quality of life. British Journal of Learning Disabilities, 34(2), 68-76.

Buntinx,W. H. E., \& Schalock, R. L. (20।0). Models of disability, quality of life, and individualized supports: Implications for professional practice in intellectual disability. Journal of Policy and Practice in Intellectual Disabilities, 7, 283-294.

Cambridge, P., \& Carnaby, S. (2005). Considerations for making PCP and care management work: Summary observations and concluding remarks. In P. Cambridge \& S. Carnaby (Eds). Person Centred Planning and Care Management with People with Learning Disabilities (pp. 2| 8-231). London: Jessica Kingsley Publishers.

Charmaz, K. (2006). Constructing grounded theory. A practical guide through qualitative analysis. Thousand Oaks, CA: Sage Publications. Cook, B. G., \& Odom, S. L. (20।3). Evidence-based practices and implementation science in special education. Exceptional Children, $79(2), 135-144$.

Felce, D. (2004). Can person-centred planning fulfil a strategic planning role? Comments on Mansell \& Beadle-Brown. Journal of Applied Research in Intellectual Disabilities, 17, 27-31.

Frederiks, B., \& Dörenberg,V. (20 12). The legal position of vulnerable people in the future: Improving or going backwards? European Journal of Health Law, 19(5), 485-502.

Herps, M. A., Buntinx,W. H. E., \& Curfs, L. M. G. (2010). Ontwikkelingen in het ondersteuningsplan in Nederland. Nederlands Tijdschrift voor de Zorg aan mensen met Verstandelijke Beperkingen, 36(2), I। 1-136.

Herps, M. A., Buntinx, W. H. E., \& Curfs, L. M. G. (2013). Individual support planning: Perceptions and expectations of people with intellectual disabilities in The Netherlands. Journal of Intellectual Disability Research, 57( I I), I027-1036.

Herps, M. A., Buntinx, W. H. E., Schalock, R. L., Breukelen, G. J. P.Van, \& Curfs, L. M. G. (20 I 6). Individual support plans of people with intellectual disabilities in residential services: content analysis of goals and resources in relation to client characteristics. Journal of Intellectual Disability Research, 60(3), 254-262.

Holburn, S. (2002). How science can evaluate and enhance person-centered planning. Research and Practice for Persons with Severe Disabilities, 27(4), 250-260.

Kinsella, P. (2000). What are the barriers in relation to person centred planning? York: Joseph Rowntree Foundation.

Mansell, J., \& Beadle-Brown, J. (2004). Person-centred planning or person-centred action? Policy and practice in intellectual disability services. Journal of Applied Research in Intellectual Disabilities, 17, I-9.

Robertson, J., Hatton, C., Emerson, E., Elliott, J., Mcintosh, B., Swift, P., ... Joyce, T. (2007). Reported Barriers to the Implementation of Person-Centred Planning for People with Intellectual Disabilities in the UK. Journal of Applied Research in Intellectual Disabilities, 20, 297-307.

Robertson, J. M., Emerson, E., Hatton, C., Elliott, J., Mclntosh, B., Swift, P., ... Joyce, T. (2005). The impact of person-centred planning. Lancaster University. Retrieved from http://eprints.lancs.ac.uk/33076/

Schalock, R. L., Borthwick-Duffy, S. A., Bradley, V. J., Buntinx, W. H. E., Coulter, D. L., Craig, E. M., ... Yeager, M. H. (20 I 0). Intellectual disability: definition, classification, and systems of supports. Washington, D.C.: American Association on Intellectual and Developmental Disabilities.

Schalock, R. L.,Verdugo, M. A., Bonham, G. S., Fantova, F., \& Van Loon, J. (2008). Enhancing personal outcomes: Organizational strategies, guidelines, and examples. Journal of Policy and Practice in Intellectual Disabilities, 5(4), 276-285.

Schwartz, A. A., Holburn, S. C., \& Jacobson, J.W. (2000). Defining person centeredness: Results of two consensus methods. Educa- 
tion and Training in Mental Retardation and Developmental Disabilities, 35(3), 235-249.

Smull, M., \& Lakin, K. C. (2002). Public policy and person-centered planning. In S. Holburn, \& P. M.Vietze (Eds.), Person-Centered Planning. Research, Practice, and Future Directions (pp. 379-397). Baltimore: Paul H Brookes.

Stancliffe, R. J., Hayden, M. F., \& Lakin, K. C. (1999). Effectiveness and quality of individual planning in residential settings: An analysis of outcomes. Mental Retardation, 37(2), 104-116.

Thompson, J. R., Bradley, V. J., Buntinx, W. H. E., Schalock, R. L., Shogren, K. A., Snell, M. E., ... Yeager, M. H. (2009). Conceptualizing supports and the support needs of people with intellectual disability. Intellectual and Developmental Disabilities, 47(2), $135-46$.

VGN (2007). Kwaliteitskader Gehandicaptenzorg Visiedocument. Utrecht:VGN.

VGN (2013). Kwaliteitskader Gehandicaptenzorg. Utrecht:VGN. 




\section{Section 2 \\ in daily practice

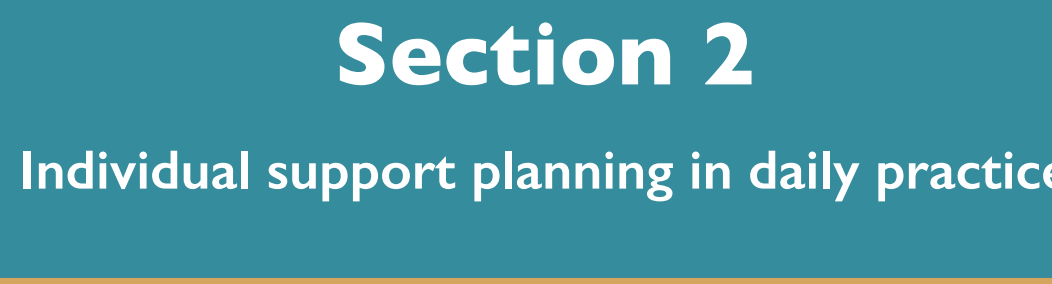 \\ $-$}

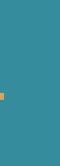

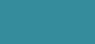

S

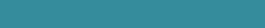
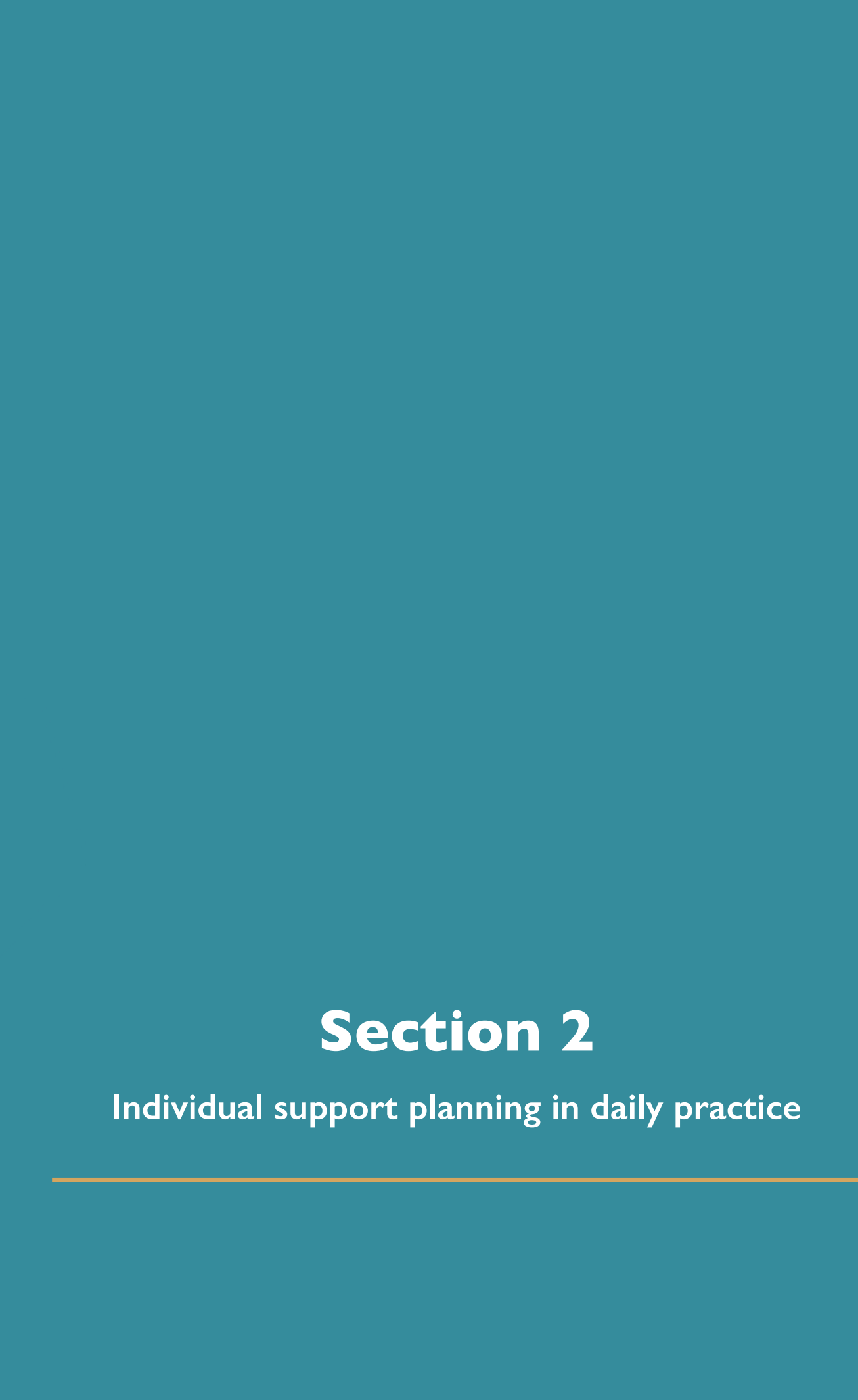


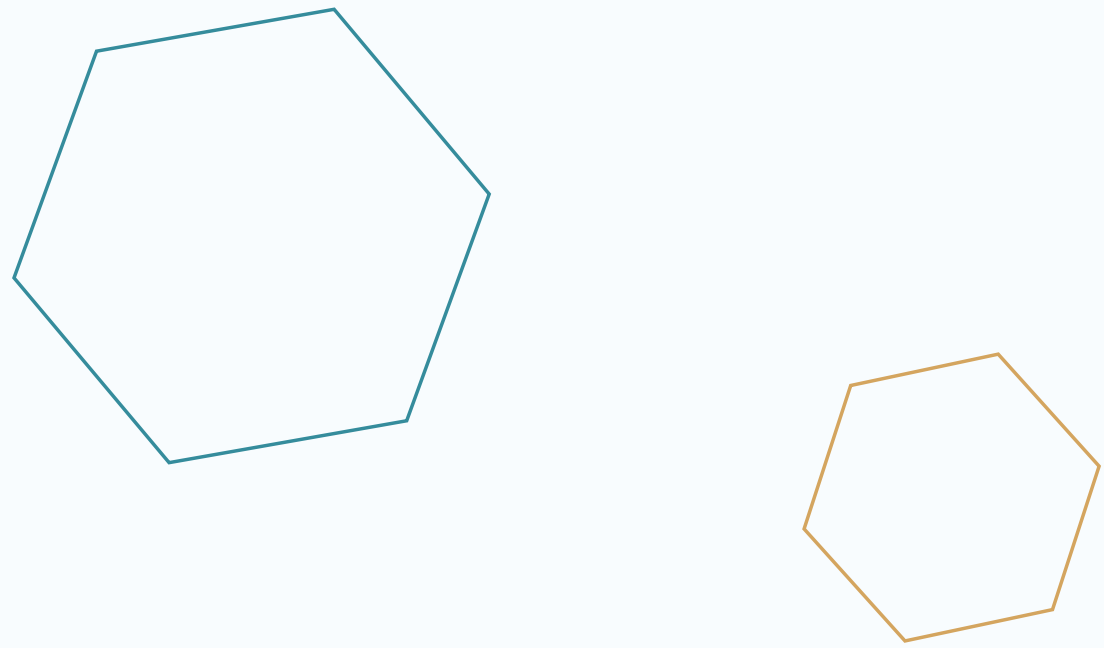

\section{Chapter 3}

\section{Perceptions and expectations of people with ID}

\section{Published as:}

Herps, M.A., Buntinx,W.H.E. \& Curfs, L.M.G. (20 I3). Individual support planning: perceptions an expectations of people with intellectual disabilities in the Netherlands. Journal of Intellectual Disability Research, 57, 1027-1036. 


\section{ABSTRACT}

\section{Introduction}

According to Dutch jurisdiction, individual support plans (ISP) should register the mutual agreements between a person with intellectual disabilities (ID) and a professional service organization with respect to the support that will be provided. In planning for support, active involvement of both parties is necessary. The current study focuses on the perceptions and experiences of Dutch persons with ID with respect to their involvement in their ISP.

\section{Method}

Data were gathered through semi-structured interviews with 61 people with mild to moderate ID. Participants were recruited in 23 Dutch service provider organizations. A systematic qualitative analysis was performed on the interview transcripts.

\section{Results}

Although persons with ID are present at their ISP meeting, active client involvement in developing, executing and evaluating the ISP is not common practice. Issues of accessibility and lack of control over the process and content of ISP hamper effective involvement of people with ID.

\section{Discussion}

The study raises questions concerning ISP practices in the Netherlands. The question needs to be addressed as to how to facilitate active involvement of people with ID in planning for support. The results further suggest that support organizations perceive an ISP rather as a formal document to comply with bureaucratic rules than as an instrument of empowerment to enhance control of persons with ID over their own lives. 


\section{INTRODUCTION}

In providing support for people with intellectual disabilities (ID), the use of individual plans has become a central aspect of services (Adams et al, 2006). Individual planning aims to provide person-centred care for people with ID, to coordinate services and to describe resources used to achieve goals (Herps et al, 20 I 0). The current article describes the planning of support in the Netherlands. As the term 'support planning' varies between countries, we first explain how this term is defined in the Netherlands. After that, we briefly discuss the differences and similarities in definition and process of support planning in other countries.

In the Netherlands, individual care planning became widespread use in the 1990s. Its main function was to promote professionalism by systematically assessing needs, setting goals and evaluating them within the context of a service provider. In a development towards more person-centeredness (Herps et al, 20 I0), it became legally required in 2009 that every person should have an Individual Support Plan (ISP). The Dutch General Exceptional Medical Expenses Act (see 'Besluit Zorgplanbespreking AWBZ' 2009) defines an ISP as the description of the support agreements between a person with ID and a professional support organisation. Professional support organisations are required to document their agreements with their clients on each of their client's support needs as well as responses to these needs. This can be seen as a process of dialogue about wants, support needs, resources and strategies in which both the professional perspective and the perspective of the person with ID are important. Goals and agreements that stem from this discussion are written down in the ISP and are focused at enhancing the quality of life of the client (Thompson et al., 2009; Schalock et al., 20 I 0).

In the literature, a variety of terms are being used to describe individual planning, each reflecting a different emphasis. Individual Programme Plans (IPPs) (Alexander \& Hegarty, 200 I) aim to improve the quality of life using individualised support. The process consists of assessment, planning, delivery and evaluation of services for an individual by an interdisciplinary team, chaired by a professional. The IPP document contains goals for each individual, and lists the specific objectives and teaching strategies with which to attain these goals (Rudkin \& Rowe, 1999).

Person-centred planning (PCP) approaches [e.g. Planning Alternative Tomorrows with Hope (PATH), Making Action Plans (MAPs), Essential Lifestyle Planning, Individual Service Design] are a reaction to the more traditional or systems-led approaches of IPPs (Holburn et al., 2004) and have a strong foundation in concepts such as normalisation and social role valorisation (O'Brien \& O'Brien, 2002). The focus person and his or her chosen main carers and friends are actively involved and focus on strengths and capabilities rather than on disabilities 
and labels (Rudkin \& Rowe, 1999; O'Brien \& O'Brien, 2002). Furthermore, PCP should not be limited to what an organisation can manage, but should encompass the support required to achieve goals, including support delivered by mainstream and informal care (Mansell \& Beadle-Brown, 2004). As Robertson et al., (2007) showed, PCP has a positive effect on choice and relationships.

With the development of personal budgets, the term 'support planning' is used to describe the process in which a plan is developed that describes the way the personal budget will be spent. This plan is developed in collaboration between an independent person or organisation and the person with ID and his or her network (Chenoweth \& Clements, 2009; Williams \& Porter, 201 I). This differs greatly from individualised support planning in the Netherlands, where the support plan is developed within the service organisation and with professionals from that organisation, after resource allocation took place.

In 2002, Thompson et al., proposed a four- component approach to support needs assessment and planning. This approach combines the strengths of both IPP and PCP.The term 'Individual Support Plan (ISP)' is used to describe a document that 'enables an individual to have life experiences and goals that mirror his or her desired life experiences and goals as closely as possible' (p. 396). In the development of an ISP, PCP approaches are used to define the subjective support needs. The objective support needs are also determined using professional instruments such as the Supports Intensity Scale (SIS). The planning team (including the person) develop a plan in which the what, when, where, who and by whom of support are documented (Thompson et al., 2002).

In the present study, the term individual support planning (ISP) is used to describe the process of determining support needs with and of a person with ID, specifying agreements and goals on what, where, when, support is being delivered and by whom. It encompasses monitoring implementation and evaluation of the agreements and goals. A Dutch ISP as defined in the General Exceptional Medical Expenses Act (AWBZ) of 2009 is limited to the services of one professional organisation, operating under this act, and contains the goals, agreements and strategies that aim to enhance the quality of life.

In developing an ISP, active involvement of both parties (the person with ID and the professional) is implied. A dialogue is needed as professional support is an interactive and mutual endeavour of both the provider and the recipient of the support services. As Wehmeyer (2002) states: 'this [involvement of the perspectives of both parties] does not mitigate the need to do everything possible to ensure that it is the person, to the greatest extent feasible, who is the plan maker' (p. 59). Making decisions in partnership can be seen as an expression of autonomy and real participation in the ISP process (Lotan \& Ells, 20 I0). A key concept in 
planning individualised support is therefore 'person-centeredness'. The characteristics of this concept are that (I) the activities of a person with ID are based on his or her wants, needs and interests; (2) the focus person is actively involved in making informed decisions; (3) there are meaningful choices to be made; (4) support is as much as possible to be found in the natural network of the person with ID; (5) activities are aimed at improving relationships, inclusion and respect; (6) the person has many opportunities and experiences; (7) ongoing commitment of the focus person when planning; and (8) the person is satisfied with his or her life (Wehmeyer, 2002).

Even though active involvement of the person with ID in planning and developing support seems self-evident, previous research shows that it comes with challenges (Crocker, 1990; Carnaby, 1997; Williams \& Robinson, 2000; Parley, 200 I; Mansell \& Beadle-Brown, 2004; Dowling et al., 2007). Challenges are found at different levels. At the individual level, for example level of cognitive functioning, problems in communication, challenging behaviour (Mansell \& Beadle-Brown, 2004), a lack of skills and courage to speak up for oneself or to speak up at a meeting can be found (Carnaby, 1997; Williams \& Robinson, 2000; Dowling et al., 2007). As Mansell \& Beadle-Brown (2004) describe, in the interaction between a professional and a person with ID, staff members can misjudge the needs of (adjusted) communication as people may have problems in understanding or have low expectations of the receptive communication levels. At the third level, people with ID have little control over the format and process of ISP (Crocker, 1990; Greasley, 1995; Carnaby, 1997; Williams \& Robinson, 2000; Dowling et al., 2007). They can be unsure as to the aims of the meeting (Carnaby, 1997) or can feel that the ISP is meant to monitor their progress, rather than to plan for their future (Williams \& Robinson, 2000).

Furthermore, the ISP is often a written document, full of jargon and not accessible to people with ID. Many people with ID depend on staff to read and 'translate' the plan for them (Williams \& Robinson, 2000). The lack of control over the process and formats of ISP highlights the asymmetrical balance in power between the person with ID and the professional (Greasley, 1995). Lotan \& Ells (2010) describe a relationship of asymmetrical power as follows: 'Two persons, $A$ and $B$, are in a relationship of asymmetrical power when the following two conditions occur simultaneously: (I) A possesses, or is believed by $B$ to possess, something that is of significance to $B$; and (2) B has no inde- pendent access to this something other than obtaining it from A.' (Lotan \& Ells 20 10, p. I 16). Both Carnaby (1997) and Greasley (1995) point out that the ISP is mostly a tool for the service provider organisation as opposed to a tool for people with ID. 
The present study aims to collect information about the situation in the Netherlands regarding the experiences and expectations of Dutch persons with ID, with respect to their involvement in their ISP.The following research questions will be addressed:

I. How do people with ID in the Netherlands perceive their involvement in making agreements about the provision of professional support?

2. What are expectations of people with ID concerning their ISP?

3. How do people with ID in the Netherlands perceive the functions of their ISP?

4. What are experienced outcomes of the ISP?

5. What do people with ID in the Netherlands suggest to improve their ISP?

These questions will be addressed in a qualitative research design. The sample consists of persons with ID who use support from professional service provider organisations under the Dutch 'AWBZ reach'. Persons involved in this study are people with ID who volunteered to participate and gave their consent for participating in the interviews. 


\section{METHOD}

This study aims at exploring the experiences and expectations of people with ID in the Netherlands. The semi-structured interview questions were developed and discussed with two people with ID who were actively involved in the research, a method the researchers were familiar with (Tuffrey-Wijne \& Curfs, 20I2). They advised the project and actively participated in discussing the findings. The method used to do this is described by Tuffrey-Wijne \& Butler (20 I0). The project group recruited them from a self-advocacy organisation in the Netherlands.

\section{Informants: recruitment procedure}

In recruiting informants, we aimed at inviting persons with ID personally and with as few as possible other people involved who eventually would decide for them. An invitation flyer was distributed across the country, for example at meetings for people with ID, in client newsletters from professional organisations, and at the Dutch Self- Advocacy Federation (LFB). Social media such as Facebook and Twitter were also used to announce the research and to broadcast the call to participate. People interested in participating in the study were invited to contact the research group (first author). Twenty-one informants responded to the invitation. Informants who were recruited this way were people living quite independently, with little support from a professional organisation. To include people receiving more extensive support, we also recruited informants through service organisations. We distributed the flyer to service organisations so that staff could talk with clients about the project. It was the person with ID who decided to participate in the study. This procedure resulted in 47 informants.

\section{The interview}

The interview took place wherever and whenever the informant felt most comfortable. In most cases this was at the informant's house; in one case the informant preferred to meet in a local cafe. The interview lasted between 25 and 75 min. The interviewees were offered the opportunity to have a supporter or family carer in the interview. A staff member was present during nine (15\%) interviews to assist with communication if necessary, or if the informant wished so. At the start of the interview, the interviewer explained the nature of the conversation, the guarantee for anonymity of data collection, how the data would be processed and published, and the right to revoke consent at any time without any questions from the researchers. There were no communication aids used during the interviews. We recruited people who were able to have a verbal interview. The interview was recorded, except when informants objected to this. This was the case in four (7\%) interviews. In these cases, the interviewer took handwritten notes. As little paperwork as possible was used during the interview, in order to make the conversation in the interview as natural as possible. 
The interview started with questions to get to know the informant: what were his or her hobbies, where did he or she come from, etc. These questions were building the interview to the point where the interviewer would ask if the agreements about the support they received were discussed and written down. This would most often lead to the ISP. In some cases, however, people were confused; they did not know if there was an ISP. Explanation of what was usually in an ISP and how this was developed helped the informant to understand what the interview was actually about.

\section{The interview: materials}

Informants were asked about their experiences with ISP in a semi-structured interview following a topic list to guide the conversation (see Table I). The topic list was presented in a flexible way to adapt the interview to the communication skills of the informants. The interview also allowed informants to exercise control over the progress of the interview and the depth of the discussion (Seidman, 2006). During the interviews, the topic list was kept out of view to prevent a test-atmosphere making informants nervous. Nevertheless, it was made sure that all topics were discussed in each interview.

\section{Table I. Topic list}

\section{Topic}

Introduction to the interview and consent

Agreements on receiving support from the organization

Facts (with whom, when, where, about)

Experiences (do you feel listened to, is it about what is important to you)

Control (who determines?)

The ISP

Facts (accessibility, content, who uses it)

Experiences (accessibility, content)

Control (accessibility, content)

Perceived functions of the ISP

Does it concern the issues important to you?

What does it mean to you to have an ISP?

Experienced outcomes

Implementing ISP

Improvements (in life and received support)

Suggestions for improvement 


\section{Informants}

Inclusion criteria for this research were that the informant (I) uses professional services and therefore has an ISP; and (2) is able and consenting participating in an interview. From the original sample of 68 people, data from 61 people with ID were included in this study. The dropout of seven informants is due to not having an ISP (I), not having an ID (I) and lack of understanding of the questions (5). Thirty informants (49\%) were male and 31 (5I\%) were female. Ages ranged from 20 to 78 years $(M=43, S D=13.6)$. All informants received support from a professional organisation operating under the AWBZ law, with a total of 23 different organisations nationwide. The support they received varied from several hours a week to 24/7 care. The level of ID varied between mild (38) and moderate ID (I2). The level of intellectual functioning of I I interviewees was unknown (Table 2).

\section{Table 2. Informant characteristics}

\begin{tabular}{|c|c|}
\hline Characteristic & $N(\%)$ \\
\hline \multicolumn{2}{|l|}{ Gender } \\
\hline Male & $30(49 \%)$ \\
\hline Female & $31(51 \%)$ \\
\hline \multicolumn{2}{|l|}{ Age } \\
\hline M & 43 \\
\hline$S D$ & 13.6 \\
\hline \multicolumn{2}{|l|}{ Level of intellectual disability } \\
\hline Mild & $38(62 \%)$ \\
\hline Moderate & $12(20 \%)$ \\
\hline Unknown & II (| $8 \%)$ \\
\hline Staff present at the interview & $9(15 \%)$ \\
\hline Had copy of their own ISP & $21(34 \%)$ \\
\hline
\end{tabular}

\section{Data analysis}

All interviews were written out immediately after the interview. The 57 recorded interviews were typed out verbatim, using pseudonyms to guarantee anonymity; the notes of four unrecorded interviews were written out. The interviewer also wrote out observations made during the time with the informants. All this text material was imported in MaxQDA, and analysed using content analysis techniques proposed by Rubin \& Rubin (2005). Phrases and short parts of texts were coded to get an overview of the topics discussed. Three researchers coded independently to enhance reliability (Burnard, 1991; Gilbert, 2004). 


\section{RESULTS}

In this section, we present the results along the thematic headings of the interview guide.

\section{Agreement on receiving support from the organization}

Although most informants (82\%) were involved in the development of their ISP, there is a great variety in what is meant by this 'involvement'. Overall, staff determines who, when, where and what will be discussed. A majority of the informants (57\%) were present at the multidisciplinary meeting where their ISP is discussed. Besides the person with ID, other people are involved such as family, direct caregiver, psychologists, staff from day care and management of the service provider organisation. Only in rare cases, the person with ID is asked who he or she would like to invite to the meeting. One informant noted that because of her hearing difficulties, she finds it difficult to be in a meeting with many people.

'There are a lot of people, have to listen, it's hard. Due to my hearing problems, I have trouble hearing. If I look at you, it's okay, but if there are ten or twelve people, I cannot follow.' (Marjanne).

These informants felt that the meeting was about 'how things are', 'what I do well and what I can do better', 'the past and the future'. However, no adjusted communication was used or people talked in jargon which makes it hard to really follow and participate in the meeting.

Informants who mentioned 'the past' as a topic often had traumatic experiences and did not like nor understand why this was discussed on a yearly basis.

'Yeah, it is a lot of work, it [the ISP] contains a lot of history, past, and you have to look at everything and talk, it takes you three hours at least to talk every- thing through.' (Chiel).

Sixteen per cent of the informants have a conversation with their direct (paid) care worker about the ISP: what went on past year and what should be in your ISP next year? A few informants (5\%) mentioned that the questions that were being asked derived from a standard questionnaire developed by the organisation. It is unclear to the informants how professional input for the ISP is being organised and who and how the final decisions in the actual ISP are made. The ISP meeting regularly takes place, varying from once every 6 months to once every 2 years. Two people (3\%) state they are 'on and off' involved and seven informants (12\%) reported that they are not involved at all in the ISP process. With four people (6\%), it was unclear as to whether they were involved.

Twenty-six per cent of the informants have the feeling they are listened to by staff.'Oh yes, they listen really well. Often it's like: do you have anything you want to talk about?' (Tom). Eight inform- 
ants (13\%) feel staff does not listen to them well, or feel they are not being taken seriously:

'So for example my wish to have a child. I don't think they [staff] appreciate that (.. .). It is being written down, but in the end, nothing is being done with it' (Petra).

\section{The Individual Support Plan}

Of the 61 informants, 34\% had direct access to their own ISP. In these cases, the ISP is kept in their room or home and they can read it whenever they want to. The other 66\% has no direct access to their own plan. In these cases, the ISP is kept at 'the staff's office'. These informants have to ask permission from staff to access their own plan. The reason why these informants have no copy of their own plan is unknown to them, or they state it has to do with privacy. Most people have trouble reading or under- standing the complex language (professional or organisational jargon) that is being used in the ISP.

Informants state that the ISP concerns the current situation and a description of themselves. The information in the ISP is, for example, a description of 'what I can and cannot do' and other (basic) information: for example, name and address, personal budget category, where they work. Furthermore, the ISP contains agreements on the delivery of support and of things the informant has to learn (for example, doing household chores) and wishes or dreams the informant has.

The informants who do have direct access to their plan and can understand the content of their ISP talk with a sense of pride about their ISP.They feel the plan is truly of them and shows who they are. In these cases, the ISP often contains many pictures, which the informant looks up. They feel the ISP is of use for them. Corry, for example, always carries her plan with her. She is proud of it and it contains memories such as photos from her vacation to Africa. She even asks the interviewer to take pictures of her with her ISP. The informants who have no direct access to their plan and cannot read it themselves perceive the ISP to be a document for professional caregivers. The person is not using it and he or she has no desire to read it.

Professional service provider organisations use a standard format for their ISP.The formats differ between organisations, as is the possibility of adaption to individual needs or wishes.

\section{Perceived functions of the Individual Support Plan}

The issues in the ISP are found important by the majority of the informants. With 69\% of the informants it was possible to talk about the function of their ISP. From these informants, $74 \%$ of the informants found it important to have an ISP.They find it important to write down the agreements, to keep everything together; as a tool to remember what to work on; or as a tool to have clarity about goals, expectations and agreements. Nine informants (21\%) state 
the ISP is not useful for them. These people perceive the ISP as an instrument for the staff, or do not see an added value at the ISP with respect to the quality of their lives. One informant remarks: 'But they mean it well' (Sanne). Two informants (5\%) find it important that staff knows what to do, but they do not understand the need for specific information in the ISP.

\section{Experienced outcomes}

The informants regularly meet with their direct caregiver (member of staff). They then talk mostly about 'how things are'. During these conversations, the ISP is not present. This leads to some informants only seeing the ISP once a year.The agreements that are being made in the ISP are realistic and are being delivered in daily life. In exceptions when agreements are not being met, this is discussed with the person with ID.

This is a difficult subject to discuss. With $34 \%$ of the respondents it was possible to address the subject. Only two people state that the received support has been improved, as they can talk about everything and solutions are being found. Four people experience improvements in their life: one person has a new job; the other three persons have become more independent. Two people answer they do not really know if anything has changed, as they do not recall how it used to be.

\section{Suggestions for improvement}

During the interviews, asking about the interviewee's suggestions for improvements did not result in any direct response. The interviewer then provided examples of possible improvements, most times linked to what the informant already had brought up during the interview. This resulted often in responses showing enthusiasm, seeing the potential of the ISP and wondering why this was not already in place.

Thirty people (49\%) presented ideas for improving their ISP. Twelve people (20\%) suggested improvements concerning the accessibility of the ISP. As most people recognise the importance of the ISP as it is about agreements with the organisation, they would like to be more involved equally with the professional. This was expressed in wishes for improvement in clarifying and accessibility of their ISP. Seven informants (I $2 \%$ ) suggested that it would be better if aspects of the process of ISP were more flexible. Informants who were asked to fill in a standard questionnaire stated this and the questions were not relevant to them. For example, one informant did not understand the need to answer a question about 'fainting in the street', as this did never happen to him. Other aspects of flexibility concern the need to choose who is involved in planning for support.

'And, ehm, if I can be truly honest here, I sometimes wonder, could we, as residents, who it's essentially about, be more involved' ( Jeroen). 


\section{DISCUSSION}

As an ISP consists of the agreements on support between a person with ID and a professional service provider organisation, active involvement of the person with ID should be self-evident. The Dutch AWBZ mandates active involvement of people with ID in the development of their own ISP. With regard to the first research question about the client's involvement in the ISP process, there is a variety in the way in which people with ID are involved in this development. This is remarkable as the informants are people with good verbal capacity who can express their needs and wants. To participate in the process, adjustments have to be made to meet the competences of persons with ID, especially when there are difficulties reading or speaking up at a meeting. There are, however, few of these adjustments being made. This raises the question whether the participation is actual functional rather than symbolic. Informants are, for example, present at the evaluation of their ISP, but they have difficulties understanding what is being said and there is no supported communication during these meetings. Also, people with ID have hardly a say in who are present at the ISP meeting or in the location where the meeting is held. It happens that persons with ID attend these meeting without knowing the function of the other participants and their role in the meeting. The results indicate that the process of planning for support for people with ID in the Netherlands is (still) more service-centred than client-centred (Greasley, 1995).

The second research question concerns the expectations of people with ID regarding their actual ISP. It is striking that only one-third of the informants had direct access to their own plan. As it contains the agreements between two parties, it raises the question why only one of the parties would have direct access to these agreements. In doing so, the client of the organisation cannot follow up the implementation or the service organisation's compliance with the agreements.

Furthermore, little effort is made to clarify the aims, process, roles and content to people with ID. People with ID therefore show a lack of understanding of the 'what and how' of ISP and perceive it to be a tool for professionals. Williams \& Porter $(20 \mathrm{I} \mathrm{I})$ concluded in their study that (accessible) information about the organisation is necessary to actively participate in planning support. This could be an improvement service provider organisations in the Netherlands can easily make. These findings suggest there is an asymmetrical power balance; the professional service organisation possesses the agreements that are of significance to the person with ID and the person with ID has no independent access to these agreements other than obtaining them from staff (Lotan \& Ells, 20।0). 
The fourth research question concerns the experienced outcomes of the ISP to people with ID in the Netherlands. The results show that most informants in the present study cannot present any examples of outcome with respect to their quality of life or the quality of the support received. In the view of the informants, their ISP has not a convincing impact on their lives.

The results further suggest that the ISP is not used in the daily routines or in the regular conversations informants have with their direct caregiver. This results in informants only seeing the actual ISP once a year, during the evaluation. As stated earlier, the informants in the present study perceive the ISP to be an instrument for staff. Whenever the ISP is not used in daily support practice, this feeling can be strengthened.

The final research question of this study concerns suggestions for improvement by people with ID. As most people value the ISP as a document in which agreements are being made, it makes sense that the suggestions for improvement concern themes like accessibility and using clear language. It was striking to see the enthusiasm in some interviews, when informants realised the possibility of an understandable document.

The findings of the present study show a number of tensions and difficulties in the ISP as a tool for the professional planning and delivery of support. It seems that informants of the present study are merely passive recipients who are subject to standard and highly bureaucratic formats rather than being in control of their lives and discussing on an equal footing with the professionals (Greasley, 1995; Wehmeyer, 2002).

Professional service provider organisations have to manage conflicting priorities. The priorities of organisations 'often concern compliance with regulatory standards rather than attainment of individually desired outcomes or inclusion' (Magito-McLaughlin et al., 2002, p. 128). This may also be true for the Netherlands, where external parties such as the national Healthcare Inspectorate, health insurance agencies, the resource allocation agency, the Dutch Association of Service Providers and expertise centres impose 'standards' and expectations with respect to ISP content and process (Herps et al., 20I0). The ISP is therefore used to hold the service organisations to account, what can have an impact on what goes into them. Moreover, these parties proclaim their criteria independently from each other. This adds to the risk that meeting a number of bureaucratic output criteria may be considered more important than obtaining good client outcomes (Smull \& Lakin, 2002; Osgood, 2005; Pilnick, Clegg, Murphy, \& Almack, 20I I). Furthermore, it restricts the freedom of organisations to develop individualised programmes. 
Having an ISP for every client means that the professional organisation complies with the law. It does not mean that they implement person-centred approaches. Whereas large facilities focus on standardisation of ISP formats, uniformity and controlability, individualised support planning requires dynamic and flexible processes and formats. This also means that ISP entails uncertainties (Osgood, 2005).

The ISP in the Netherlands is restricted to the services provided by that organisation. This creates several difficulties. First of all, it does not stimulate organisations to look over their own boundaries. In fact, it promotes that the person with ID is using as many as possible services from that organisation, rather than promoting the involvement of the personal network and inclusion and participation in society. People with ID are more often using services from different organisations. It then is unclear as to who is 'in control', and it happens that the person with ID has to develop multiple ISPs, from multiple organisations (Herps, Buntinx \& Curfs, 20I I). The process, form and content of the ISP in the Netherlands can be seen as rather organisation-driven, with little flexibility that is needed to promote personcenteredness. PCP approaches embrace the use of informal and mainstream care (Mansell \& Beadle-Brown, 2004); however, this can only be achieved if the entire system would be changed. Perhaps, the support planning for personal budgets (Williams \& Porter, 20 I I) could model for the new system.

There are several limitations to the present study. First, the interviewees are not representative for the entire Dutch population of 'people with ID'. The informants in the present study are people who can be expected to be actively involved, as they are able to verbalise their experiences and suggestions. It therefore might be hypothesised that people with less verbal abilities or who have a severe disability are even less involved in planning their support. As the interview process bringing up the various topics was flexible, not all questions were posed exactly in the same wording and in the same order.This could have affected the results. Further, as much as possible, questions were asked openended, but for some informants, it was found that closed-ended questions were better understood. This was especially the case in asking for improvements.

In interviewing people with ID it is recommended to plan the interview over a longer period and several meetings (see for example: Atkinson, 1988; Carnaby, 1997; Stalker, 1998). Because of limitations in time and finances, this was not possible. However, in every interview, each topic was discussed. The present interviews showed that it is important to speak 'the same language'. Another difficulty in the present study was that not all informants were able to comprehend complex questions that involved opinions or recollections. However, these difficulties also reflect the complexity of communication and sometimes the difficulties of the ISP process itself. 
The current study focused solely on the experiences and perceptions of people with moderate and mild ID. In further research it would be interesting to study the involvement of people with more severe ID and of people with even more difficulties in verbal communication than the present group. Also, as informants made suggestions for improving the ISP, it would be interesting to study the effects of these suggested improvements. Another interesting question is to further study what causes the gap between vision (ideal situation) and practice in ISP. Do professional organisations have a clear vision on the function of an ISP and are they aware of the impact of good support planning on the lives of individuals? The many uncoordinated rules and expectations that different stakeholders such as the management, inspectorate, insurance companies and professionals express towards ISP may add to the complexity and difficulties of effective planning of support. Awareness of such difficulties may be a first step towards improving ISP and effectiveness of professional support to persons with ID.

\section{Acknowledgements}

We thank the participants of the study and the Dutch Self-Advocacy Federation (LFB) for their participation and collaboration in this study. Further, we are grateful to the Foundation of Intellectual Disabilities (Fonds Verstandelijk Gehandicapten), which funded part of the study. 


\section{REFERENCES}

Adams, L., Beadle-Brown, J., \& Mansell J. (2006). Individual planning: an exploration of the link between quality of plan and quality of life. British Journal of Learning Disabilities, 34, 68-76.

Alexander, M., \& Hegarty, J. R. (200 I). Measuring client participation in individual programme planning meetings. British Journal of Learning Disabilities, 29, 17-21.

Atkinson, D. (1988). Research interviews with people with mental handicaps. Mental Handicap Research, 1, 75-90.

Besluit Zorgplanbespreking AWBZ (2009) Stb., I 31 .

Burnard, P. (|99|). A method of analysing interview transcripts in qualitative research. Nurse Education Today, | I, 46 I-6.

Carnaby, S. (1997). 'What do you think?': a qualitative approach to evaluating individual planning services. Journal of Intellectual Disability Research, 41, 225-31.

Chenoweth, L., \& Clements, N. (2009). Final Report. Funding and Service Options for People with Disabilities. Griffith University, Meadowbrook.

Crocker,T. M. (1990). Assessing client participation in mental handicap services: a pilot study. British Journal of Mental Subnormality, $36,98-107$.

Dowling, S., Manthorpe, J., \& Cowley, S. (2007). Working on person-centred planning: from amber to green light? Journal of Intellectual Disabilities, 11, 65-82.

Gilbert, T. (2004). Involving people with learning disabilities in research: issues and possibilities. Correspondence. Health \& Social Care in the Community, 12, 298-308.

Greasley, P. (1995). Individual planning with adults who have learning difficulties: key issues - key sources. Disability \& Society, 10 , 353-364.

Herps, M. A., Buntinx,W. H. E., \& Curfs, L. M. G. (2010). Ontwikkelingen in het ondersteuningsplan in Nederland. [Developments in the ISP in the Netherlands]. Nederlands Tijdschrift voor de Zorg aan mensen met Verstandelijke Beperkingen, 36, I I I-36.

Herps, M. A., Buntinx,W. H. E., \& Curfs, L. M. G. (20I I). Ondersteuningsplannen in de gehandicaptenzorg: beschouwingen en perspectief. Nederlands Tijdschrift voor de Zorg aan mensen met Verstandelijke Beperkingen, 37, I 10 - 1 I 7.

Holburn, S., Jacobson, J.W., Schwartz, A. A., Flory, M. J., \& Vietze, P. M. (2004). The Willowbrook futures project: a longitudinal analysis of person-centred planning. American Journal of Mental Retardation, 109,63-76.

Lotan, G., \& Ells, C. (20I0). Adults with intellectual and developmental disabilities and participation in Decision making: ethical considerations for professional-client practice. Intellectual and Developmental Disabilities, 48, I $12-25$.

Magito-McLaughlin, D., Spinosa,T., \& Marsalis, M. (2002). Overcoming the barriers: moving toward a service model that is conducive to person-centred planning. In S. Holburn \& P. M.Vietze (Eds.), Person-Centred Planning. Research, Practice, and Future Directions (pp. 127-150). Paul H Brookes, Baltimore.

Mansell, J., \& Beadle-Brown, J. (2004). Person-centred planning or person-centred action? Policy and practice in intellectual disability services. Journal of Applied Research in Intellectual Disabilities, 17, I-9.

O'Brien, C. L., \& O'Brien, J. (2002). The origins of person- centred planning. A community of practice perspective. In S. Holburn \& P. M.Vietze (Eds), Person-Centred Planning. Research, Practice, and Future Directions (pp. 3-28). Paul H Brookes, Baltimore.

Osgood, T. (2005). Managing the tensions between the interests of organisations and service users. In P. Cambridge \& S. Carnaby (Eds). Person Centred Planning and Care Management with People with Learning Disabilities (pp. 5 I-64). London: Jessica Kingsley Publishers. 
Parley, F. F. (200 I). Person-centred outcomes: Are out- comes improved where a person-centred care model is used? Journal of Intellectual Disabilities, 5, 299-308.

Pilnick, A., Clegg, .., Murphy, E., \& Almack, K. (20I I). 'Just being selfish for my own sake ...'. balancing the views of young adults with intellectual disabilities and their carers in transition planning. The Sociological Review, 59, 304-23.

Robertson, J., Emerson, E., Hatton, C., Elliott, J., Mclntosh, B., Swift, P., ... Joyce, T. (2007). Person-centred planning: factors associated with successful outcomes for people with intellectual disabilities. Journal of Intellectual Disability Research, 5 I (3), 232-243.

Rubin, H. J., \& Rubin, I. S. (2005). Qualitative interviewing: The Art of Hearing Data. Thousand Oaks, CA: Sage Publications.

Rudkin, A., \& Rowe, D. (1999). A systematic review of the evidence base for lifestyle planning in adults with learning disabilities: implications for other disabled populations. Clinical Rehabilitation, 13, 363-72.

Schalock, R. L., Borthwick-Duffy, S. A., Bradley,V. J., Buntinx, W. H. E., Coulter, D. L., Craig, E. M., ... Yeager, M. H. (20 I 0). Intellectual disability: definition, classification, and systems of supports. Washington, D.C.: American Association on Intellectual and Developmental Disabilities.

Seidman, I. (2006). Interviewing as Qualitative Research:A Guide for Researchers in Education and the Social Sciences. New York: Teachers College Press.

Smull, M., \& Lakin, K. C. (2002). Public policy and person-centered planning. In S. Holburn, \& P. M.Vietze (Eds.), Person-Centered Planning. Research, Practice, and Future Directions (pp. 379-397). Baltimore: Paul H Brookes.

Stalker, K. (1998). Some ethical and methodological issues in research with people with learning difficulties. Disability \& Society, 13, $5-19$.

Thompson, J. R., Hughes, C., Schalock, R. L., Silverman, W., Tassé, M. J., Bryant, B. ... Campbell, E.M. (2002). Integrating supports in assessments and planning. Mental Retardation, 40, 390-405.

Thompson, J. R., Bradley, V. J., Buntinx, W. H. E., Schalock, R. L., Shogren, K. A., Snell, M. E., ... Yeager, M. H. (2009). Conceptualizing supports and the support needs of people with intellectual disability. Intellectual and Developmental Disabilities, 47(2), 135-46.

Tuffrey-Wijne, l., \& Butler, G. (20।0). Co-researching with people with learning disabilities: an experience of involvement in qualitative data analysis. Health Expectations, 13, 174-84.

Tuffrey-Wijne, I., \& Curfs, L. M. G. (2012). Research Participants with Intellectual Disabilities: Considerations for Selecting Appropriate Methodologies. Governor Kremers Center, Maastricht.

Wehmeyer, M. L. (2002). The confluence of Person-Centered Planning and Self-Determination. In S. Holburn \& P. M. Vietze (Eds.), Person-Centered Planning. Research, Practice, and Future Directions (pp. 5 I-69). Baltimore: Paul H Brookes.

Williams, V., \& Porter, S. (20I I). Your life, your choice. Qualitative research carried out as part of the 'Support Planning and Brokerage' initiative. University of Bristol: Norah Fry research centre.

Williams, V., \& Robinson, C. (2000). 'Tick this, Tick that': the views of people with learning disabilities on their Assessments. Journal of Intellectual Disabilities, 4, 293-305. 




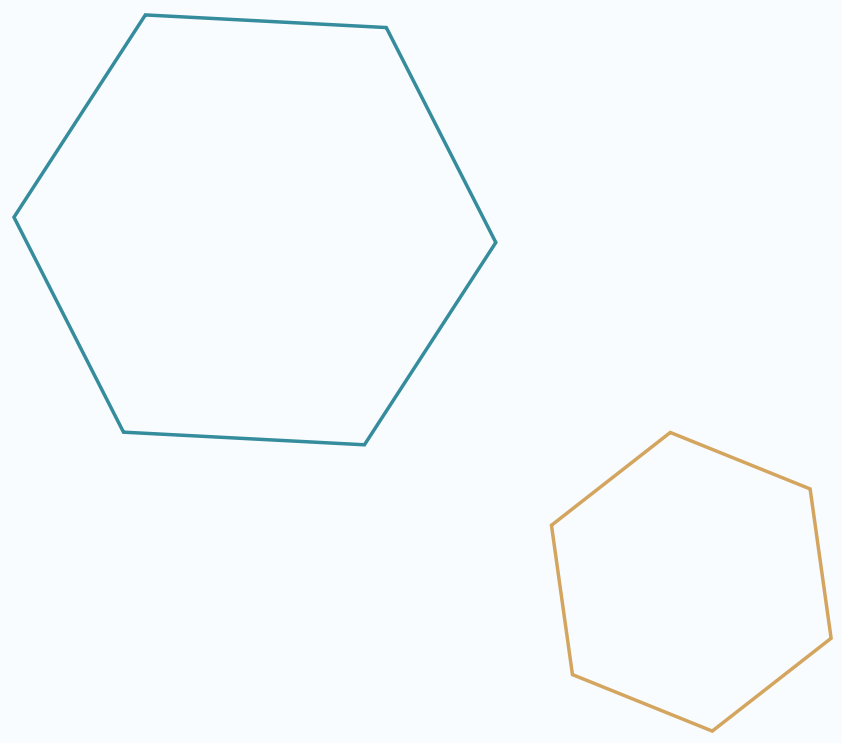

\section{Chapter 4}

Barriers and facilitators in attaining individual support plan goals

Submitted as:

Herps, M.A., Buntinx, W.H.E. \& Curfs, L.M.G. Barriers and facilitators in attaining individual support plan goals of people with intellectual disabilities. 


\section{ABSTRACT}

\section{Background}

Individual goals and objectives are a key aspect of individual support planning (ISP) for people with intellectual disabilities (ID). According to goal setting theory, goals can improve performance when people are committed to the goal, if goals are challenging and when regular feedback is provided. To be successful, goals also have to be technically adequate (e.g. specific, functional, specify a timeline and who is accountable). Although ISP for people with ID does include goal setting, previous research is inconclusive about its effects. In this study, we aim to promote understanding of barriers and facilitators in the effectiveness of goal setting within individualised support planning for people with ID.

\section{Methods}

We analysed a total of 101 individual support goals found in 34 ISP documents in individual, semi-structured interviews with staff. We developed a rating scale for the purpose of this study, which included statements derived from existing literature on ISP effectiveness and goal setting theory. We carried out statistical analyses and content analyses to determine goal quality, a relationship between client characteristics, goal quality and goal attainment and the perceived barriers and facilitators in goal attainment, according to staff.

\section{Results}

$59 \%$ of the goals were not achieved within a year. Goal attainment is related to the quality (technical adequacy) of goals. Qualitative analyses show that barriers and facilitators relate to the life and challenging the person with ID faces respectively competences of staff.

\section{Conclusion:}

The results add to the body of literature showing that the achievement of goals is related to high quality goal setting. The results further stress the need to tailor goal setting and ISP procedures to individual circumstances rather than using an organisation's one-sizefits-all approach. 


\section{INTRODUCTION}

Individual support planning (ISP) set out the strategies and resources needed to enhance the individual functioning of people with intellectual disabilities (ID). Putting these strategies into practice usually involves formulating and achieving goals. Goal setting has become a key aspect of providing professional support to people with intellectual disabilities. In fact, it is now a legal requirement to develop individual support plans that set out the individual goals for people with ID, and the agreements that are made regarding the actions needed to ensure these goals are met (Herps, Buntinx, \& Curfs, 2016).

ISP involves assessing support needs, identifying the life experiences that people would like to have and setting individual goals (Schalock et al., 20 I0). This is usually done during a meeting, after which staff writes the goals in a written or digital document (the ISP document). This process typically involves several people, including the person with ID, their relatives and professional support staff. ISP procedures involve continuously monitoring progress towards the goals, and this is a necessary aspect for working effectively on goals (Locke \& Latham, 20 I3). However, little is known about how it is carried out in ID practice. Herps et al. (20 I3) found that people with ID do not feel involved in monitoring the progress. They often only see the ISP document during the formal evaluation meeting and as such are barely aware of the goals and how things are progressing. Neither is it known how staff members monitor goals and share this feedback. Overall, studies indicate that ISP can have a positive effect on the lives of people with ID, but the body of supporting evidence is thin (Claes et al., 20 I0; Ratti et al., 20 I6; Rudkin \& Rowe, 1999).

Barriers in ISP effectiveness include the following: (I) Barriers relating to the person with ID. These include the complexity of problems (such as cognitive problems, communication problems and mental health problems (Dowling et al., 2007; Mansell \& Beadle-Brown, 2004; Robertson et al., 2007) and having a limited social network (Mansell \& Beadle-Brown, 2004). (2) Barriers relating to staff.These can include staff turnover, skills (for example, understanding of how to involve people with ID, developing a day programme based on the ISP, or goal-setting capacity), available time, and conflicting views on what support is needed (Adams, BeadleBrown \& Mansell, 2006; Dowling et al., 2007; Kinsella, 2000; Mansell \& Beadle-Brown, 2004; Robertson et al., 2007; Zijlstra, 2003). (3) Barriers relating to the service provider organisation, which may include using the ISP to serve multiple purposes, Prioritising control and uniformity over tailoring the ISP to the individual, under-resourced staff, limited collaboration and limited financial resources (Dowling et al., 2007; Kinsella, 2000; Mansell \& Beadle-Brown, 2004). (4) Barriers related to the macro level, such as budget allocation, resistance in the neighbourhood to collaboration, waiting lists, limited choice in housing or employment and problems with transport (Kinsella, 2000; Mansell \& Beadle-Brown, 2004; Robertson et al., 2007). 
Goal setting is a central aspect of ISP.According to Goal Setting Theory, goals affect performance in the following four ways: Goals direct attention and effort toward activities that are relevant to the goals and away from activities that are not relevant to the goal; goals have an energising function and goals with higher aspirations lead to greater effort than goals with lower aspirations; goals affect persistence; and goals affect action indirectly by leading to the arousal, discovery, and/or use of task-relevant knowledge and strategies (Locke \& Latham, 20।3). Furthermore, goal setting can be effective if regular feedback is provided and if people are committed to the goal.

Although goal setting theory and most of its evidence stems from the workplace, it is also used in other fields, such as the creative sector (Shalley \& Scheller, 2013), sports (Williams, 20I3), health behaviour change (Shilts, Townsend, \& Dishman, 20।3), cognitive behaviour therapy (Jostein, Dahl, Jensen, \& Nordahl, 20 I3) and academia (Morisano \& Lana, 20 I 3). However, little is known about goal setting in the context of support planning for people with ID.

Dagnan \& Sturmey ( 1994) and Zijlstra (2003) found that goals are more likely to be achieved if they are 'technically adequate': in other words, if they are specific, functional, specify a timeline and who is accountable, and if the individual being supported is committed to them (Locke \& Latham, 20 I3). Nevertheless, studies by Adams et al., (2006) and Stancliffe, Hayden, \& Lakin (1999) found that technically adequate goals are not always achieved or lead to an improved quality of life of people with ID.

This paper aims to contribute to this discussion by examining barriers in goal attainment for people with ID in the context of GST. We explore goal setting in a residential service for people with ID and the presence of barriers and facilitators in achieving these goals. The aim is to get a better understanding of ISP goal setting ISP for people with ID. Specific questions include:

I. To what extent are ISP goals achieved?

2. What is the relationship between goal quality and goal attainment, on the one hand, and characteristics of people with ID, on the other?

3. What are the perceived barriers and facilitators in goal attainment according to support staff in a residential setting? 


\section{METHOD}

\section{Participants}

We used a convenience sample consisting of direct support staff of a residential service provider organization located in the south west of The Netherlands. This relatively large organization provides residential support to around 2000 people with ID, both in community and residential settings. Staff who work in residential services for people with ID are responsible for the ISP document, which in this organization is a digital document that describes the individual goals and support strategies. Annual meetings are held to evaluate the goals and agreements and to adjust the ISP document accordingly.

We selected participants based on the date of their last ISP evaluation meeting. If a meeting had been held in the past six weeks, we included staff who had been involved. We selected a total of 50 direct support staff. In 5 cases, the person with ID or their relative did not give us permission to use their ISP information in the study, and sixteen people did not have time, or did not want to participate. As a result, 29 direct support staff participated in the study. They were responsible for the ISP documents of 34 people with ID: three were responsible for the ISP of two people with ID, and one was responsible for three ISP documents.

The majority of participants was female $(n=26)$. Their age ranged from 26 to $6 \mathrm{I}(M=42.4$, $S D=10.7)$. The years they had been working for this organization ranged from 3 to $4 \mathrm{I}(\mathrm{M}=$ 16.4, SD = 10.5). The highest level of education was high school $(n=1)$, associate degree $(n=$ 19), and bachelor or master's degree $(n=9)$.

\section{The interview}

We held individual, semi-structured interviews with each participant. We developed an interview schedule for the purpose of this study (see Table I). This schedule consisted of two sections. First, for each goal, we asked participants if the goal was achieved, before asking the following open-ended question: 'What do you think was the reason why this goal has (or has not) been achieved?' Then, based on previous literature on barriers and facilitators in ISP effectiveness and goal attainment (see introduction), we developed statements on a rating scale. We asked the participant to rate each goal according to these statements on a five-point scale ranging from I ('strongly disagree') to 5 ('strongly agree'). We repeated this procedure for each goal that was found in the ISP document. 
Table I The interview guide'

\section{Section I: Goal attainment}

What was the goal?

[Scored by the researcher] Quality of Life-domain:

Was the goal achieved?

What do you think was the reason why this goal was (not) achieved?

\section{Section 2: Goal evaluation (per goal)}

Goal quality

Specific

It is clear which actions were needed for goal attainment

Commitment

The focus person is committed to the goal

Staff is committed to work on the goal

Feedback

The goal is being monitored in a digital system

The progress of the goal is regularly discussed with the focus person/representatives

Staff regularly discusses the progress of the goal

Time line

Accountability

The roles of each actor is specified with respect to goal achievement

Functional

The goal meets the individual's needs

Individual characteristics

Complexity of the problems of the individual

Unexpected events in the life of the individual

Level of functioning, age, living arrangements?

Staff characteristics

Staff turnover

Knowledge and skills

\section{Resources}

There is enough time

There is enough staffing

There are sufficient financial resources

( I) Based on goal setting theory; Adams et al., 2006; Dowling et al., 2007; Kinsella, 2000; Mansell \& Beadle-Brown, 2004; Robertson et al., 2007; Robertson et al., 2007; Stancliffe et al., 1999; Wigham et al., 2008; \& Zijlstra, 2003. 


\section{Analysis}

Goal attainment: First, we calculated the total number of goals evaluated and the percentage that were achieved. Next, we statistically tested the relationship between client characteristics such as gender, age and level of ID and goal attainment.

Determining goal quality and its relation with goal attainment: to determine goal quality, we dichotomised the answers of respondents on the statements related to 'goal quality' (Table I, Section 2) to 'yes' (score 3-5) or 'no' (score I or 2). We then added up the scores of the goals to arrive at a 'quality score'. If a goal met all the quality criteria, it was rated as 'high quality'. However, as no goals specified a timeline, we decided to exclude the timeline criterion from the criteria of being technically adequate. If a goal did not meet all the criteria, it was rated as 'lesser quality' (Adams et al., 2006). We then carried out a chi-square test of independence to examine a relationship between the quality of goals and the achievement of goals.

Barriers and facilitators: We coded answers to the open-ended question (which focused on the reasons for the goal being achieved or not achieved) using the domains and indicators specified in Table I, Section 2. We added one category ('structural support need') since this was a specific answer that came up and did not fit into other categories. We calculated mean scores for the statements regarding barriers and facilitators that were presented to participants. 


\section{RESULTS}

\section{Goal attainment related to characteristics of the person with ID and goal content}

We identified a total of IOI ISP goals, in 34 ISP documents. Of these goals, $40.6 \%$ were achieved within the period of a year.Table 2 shows the total number of goals and the percentage of achieved goals. The table shows that goals set for people with severe disability, or for people aged between 20 and 34, are more often achieved than those set for other groups. Chi-square tests of independence revealed no statistically significant relation between goal achievement and gender $\chi^{2}(1)=.33, p=.563$, age or level of ID.

\begin{tabular}{|c|c|c|c|c|c|c|c|c|}
\hline \multirow[t]{2}{*}{ Age } & \multicolumn{2}{|r|}{$20-34$} & \multicolumn{2}{|r|}{$35-49$} & \multicolumn{2}{|r|}{$50+$} & \multicolumn{2}{|r|}{ Total } \\
\hline & $n$ & $\%$ achieved & $n$ & $\%$ achieved & $n$ & $\%$ & $N$ & $\%$ achieved \\
\hline Mild & 41 & 46.3 & 0 & 0 & 7 & 14.3 & 48 & 41.7 \\
\hline Moderate & | | & 45.5 & 8 & 25 & 8 & 37.5 & 27 & 37.0 \\
\hline Severe & 5 & 60 & 10 & 40 & 3 & 66.7 & 18 & 50 \\
\hline Profound & 0 & 0 & 6 & 0 & 2 & 100 & 8 & 25 \\
\hline Total & 57 & 47.4 & 24 & 25 & 20 & 40 & 101 & 40.6 \\
\hline
\end{tabular}

With respect to the content of the goals in terms of quality of life, most goals related to physical well-being (29\%), emotional well-being (19\%) and personal development (16\%). No goals were set in the domains of rights and $4 \%$ related to social inclusion. Table 3 shows the number and percentage of goals on the different quality of life domains that had been achieved within the past year. 
Table 3 Number of goals set and achieved goals on QoL-domains

$\begin{array}{lrr}\text { QoL-domain } & n \text { \% achieved' } \\ \text { Physical well-being } & 29 & 55.2 \\ \text { Self-determination } & 8 & 50.0 \\ \text { Inclusion } & 4 & 50.0 \\ \text { Personal development } & 16 & 37.5 \\ \text { Emotional well-being } & 19 & 36.8 \\ \text { Interpersonal relationships } & 12 & 33.3 \\ \text { Material well-being } & 13 & 15.4 \\ \text { Rights } & 0 & 0 \\ \text { Total } & 101 & 40.6\end{array}$

\section{Goal quality and its relation to goal attainment}

Fourteen goals (13.9\%) met all quality criteria. High quality goals were more often achieved (64.7\%) than goals of lower quality (35.3\%), and a statistically significant relationship was found between the quality of goals and the achievement of goals, $\chi^{2}(I)=4.25, p<.05$.

Table 4 shows the percentage of goals that met the indicators, the mean scores and standard deviation on the rating scale. It demonstrates that no goals in this study specified a timeline. This was due to the strict annual cycle: each ISP document lasts a year, irrespective of whether the goals were intended to be reached within that timescale.

The participants felt it was clear what actions needed to be taken to achieve the goal and who was accountable for this. However, feedback during the year is needed to monitor the implementation, and our results show that none of the sample group monitored progress in the digital ISP follow-up system and seldom discussed progress with the person with ID and/or their relatives. 
Table 4 Scores on the domains and indicators rating scale

Goal quality

Specific

It was clear which actions were needed for goal attainment

$95 \%$

4.39

.91

Commitment

The focus person was committed to the goal

$50 \% \quad 3.57 \quad 1.46$

Staff was committed to work on the goal

$84 \% \quad 4.09 \quad 1.10$

Feedback

The goal is monitored in a digital system

$\begin{array}{rrr}55 \% & 2.86 & 1.59 \\ 73 \% & 3.73 & 1.46 \\ 83 \% & 3.78 & 1.20 \\ 0 \% & 0 & 0 \\ & & \\ 95 \% & 4.49 & .91\end{array}$

It was specified who had which role in the achievement of the goal

Functional

The goal met the individual's needs

Individual characteristics

Complexity of the problems of the individual

$\begin{array}{lll}19 \% & 3.76 & 1.31 \\ 45 \% & 3.05 & 1.60\end{array}$

Staff characteristics

Staff turnover

Staff skills and knowledge

$91 \% \quad 4.21 \quad 1.13$

Resources

Enough time

$84 \% \quad 4.20 \quad 1.15$

Enough staffing

$85 \% \quad 4.20 \quad 1.13$

Sufficient finances

$94 \% \quad 4.76 \quad .70$ 


\section{Perceived barriers and facilitators}

In the open-ended question (which focused on the reasons for the goal being achieved or not achieved), participants attributed the achievement of goals mostly to staff characteristics (29.3\%). For example, they said that staff acquired additional knowledge or new skills that improved their support performance or that staff developed a special, individualized approach to support the individual in achieving the goal.

Where there was failure to achieve goals, the sample group attributed this most often to characteristics of the person with ID (42.1\%). This category referred to challenges facing people with ID that can make it difficult to work on goals. Another contributing factor was identified as a lack of resources (15.8\%). For example, one participant explained why they had not achieved the client's goal to learn how to cook:

'It is not possible to work on this goal during our shifts. (...) He buys microwave meals. The goal of 'learning to cook' has been postponed for now.' 
Table 5 Perceived facilitators and barriers in goal attainment

Facilitators

Staff characteristics

$12 \quad 29.3$

Individual characteristics

$8 \quad 19.5$

Specificity

$6 \quad 14.6$

Commitment $6 \quad 14.6$

Resources 49.8

Feedback $2 \quad 4.9$

Unclear

I $\quad 2.4$

Staff characteristics and individual client characteristics

Functionality

Total

Barriers

Individual client characteristics $24 \quad 42.1$

Resources

$\begin{array}{ll}9 & 15.8\end{array}$

Structural support need

$8 \quad 14.0$

Feedback

$6 \quad 10.5$

Commitment

$5 \quad 8.8$

Specificity

$4 \quad 7.0$

Functionality

। $\quad 1.8$

Feedback, resources 


\section{DISCUSSION}

This article presents an explorative study into goal setting and goal attainment in a residential service for persons with ID. We found that over a one-year period, $41 \%$ of the people' goals were achieved. We found that goals that were technically adequate were achieved more often than goals lacking one or more quality criteria, and that technical adequacy was the only aspect statistically related to the achievement of goals. Though the present study describes a relatively small number of participants and goals and further research is needed to look deeper into the barriers in goal attainment for people with ID, these findings are in line with previous studies on goal attainment for people with ID and with Goal Setting Theory.

The qualitative analyses in this study revealed that staff perceive the greatest barrier in goal attainment to be the person him or herself, with all the complexities of ID. On the one hand this may seem as an indicator that life in itself is difficult to plan, and that the time frame of a year is too big to set goals for. It then leads to a discussion of the need for goal setting for people with ID. On the other hand, this finding seems to indicate that the person with ID is being scapegoated for the failure of the intervention. If the person doesn't respond to the goals then either the wrong goals have been set, or the goals are being worked towards in the wrong way - there is no 'one size fits all' and it requires patience, curiosity and creativity to identify a goal and then find a way of working towards it that is motivating for everyone involved. How small or little steps may seem. Either way, further research is needed to better understand the parameters that are needed for goal setting to be effective for people with ID in the context of ISP (Bartholomew, Parcel, Kok, Gottlieb, \& Fernandez, 20I I).

Moreover, goal setting can itself be helpful for people with ID, for example, by providing interest and alleviating boredom (Locke \& Latham, 20 I3). Studies by McConkey \& Collins (20 I0) and Zijlstra (2003) show that goal setting is particularly effective when a 'new approach' to individualized planning is being implemented, but that it soon becomes more difficult to set new goals, until eventually the effects of goal setting wear off. When goal setting is a key aspect of ISP, it can become a routine or repetitive task - for example, among people with ID living in residential settings who may use the same service for many years. This can hinder goal attainment - even more so because goals that are challenging produce the best outcomes (Locke \& Latham, 20 I3).

As this study has shown, goal setting for people with ID requires creativity and the involvement of people who know the person very well, to set goals that are meaningful in the life of the individual, regardless of complexities related to ID. What makes a goal 'challenging', differs per person and per situation. However, life and development of the person with ID should be leading in when setting new goals, rather than an imposed requirement. The results 
of this study indicate that goal setting as part of ISP for people with ID living in residential settings requires more than just technical adequacy of goals. Future research is needed to develop a deeper understanding of how, for whom and under which conditions goal setting can be effective.

In this study, we included only one perspective (that of staff) and addressed goal setting in retrospect. This may have led to biased results, as staff knows how the process went and what outcomes were achieved. The process and outcome may have changed their perspective of, for example, how committed they were in the first place. We believe there is a need for future research that follows the process of goal setting and goal attainment and includes everyone involved.

A further challenge is in the need to set goals that are technically adequate (specific, functional, specifying a timeline and who is accountable, and with commitment from the person receiving support). Shilts, Townsend, \& Dishman (2013) studied 'guided goal setting', in which technically adequate goals were presented and the person had to choose the goal that reflected their needs. This, too, could be interesting for use in the field of ID. Future research on goal setting for people with ID could explore different goal-setting procedures.

In conclusion, this study addressed a key aspect of current support delivery to people with ID using professional services. Goal setting is a vehicle to improve personal outcomes, and as such the quality of life of people with ID. As goal setting has its roots in industrial workplaces, it is needed to understand how it is best applied in the field of (lives of people with) ID. Goal setting needs to be individually tailored to meet the rhythm of the life of the person rather than an imposed rhythm. It requires thoughtful deliberation, creativity and realism, and involvement of all people knowing and supporting the individual with ID. 


\section{REFERENCES}

Adams, L., Beadle-Brown, J., \& Mansell, J. (2006). Individual planning: an exploration of the link between quality of plan and quality of life. British Journal of Learning Disabilities, 34(2), 68-76.

Bartholomew, L. K., Parcel, G. S., Kok, G., Gottlieb, N. H., \& Fernandez, M. E. (20I I). Planning Health Promotion Programs: An Intervention Mapping Approach. 3rd edition. San Francisco: Jossey-Bass.

Claes, C., Van Hove, G.,Vandevelde, S., van Loon, J., \& Schalock, R. L. (20I0). Person-centred planning: analysis of research and effectiveness. Intellectual and Developmental Disabilities, 48(6), 432-53.

Dagnan, D. J., \& Sturmey, P. (1994).Validation of technical criteria for setting IPP goals for persons with developmental disabilities in residential settings. Behavioral Interventions, 9(1), 67-73.

Dowling, S., Manthorpe, J., \& Cowley, S. (2007). Working on person-centred planning: from amber to green light? Journal of Intellectual Disabilities, $1 /(1), 65-82$.

Herps, M. A., Buntinx, W. H. E., \& Curfs, L. M. G. (20I3). Individual support planning: perceptions and expectations of people with intellectual disabilities in The Netherlands. Journal of Intellectual Disability Research, 57( I I), 1027-1036.

Herps, M. A., Buntinx,W. H. E., \& Curfs, L. M. G. (2016). Individual support planning with people with ID in The Netherlands: official requirements and stakeholders' expectations. Alter - European Journal of Disability Research, 10(4), 281-288.

Jostein, P., Dahl, K., Jensen, R., \& Nordahl, H. M. (20 I3). Working with goals in therapy. In E. A. Locke \& G. P. Latham (Eds.), New developments in goal setting and performance. New York: Routledge.

Kinsella, P. (2000). What are the barriers in relation to Person Centred Planning? York: Joseph Rowntree Foundation.

Lawlor, D., Spitz, R., York, M., \& Harvey, B. (20I3). Using goal analysis to drive improvements in performance and outcomes. Journal of Intellectual Disabilities, 17(4), $301-13$.

Locke, E. A., \& Latham, G. P. (20।3). Goal Setting Theory. The current state. In E. A. Locke \& G. P. Latham (Eds.), New developments in goal setting and performance. New York: Routledge.

Mansell, J., \& Beadle-Brown, J. (2004). Person-Centred Planning or Person-Centred Action? Policy and Practice in Intellectual Disability Services. Journal of Applied Research in Intellectual Disabilities, 17, I-9.

McConkey, R., \& Collins, S. (20।0). Using personal goal setting to promote the social inclusion of people with intellectual disability living in supported accommodation. Journal of Intellectual Disability Research, 54(2), I35-43.

Morisano, D., \& Lana, D. (20।3). Goal Setting in the Academic Arena. In E. A. Locke \& G. P. Latham (Eds.), New developments in goal setting and performance. New York: Routledge.

Ratti,V., Hassiotis, A., Crabtree, J., Deb, S., Gallagher, P., \& Unwin, G. (2016). The effectiveness of person-centred planning for people with intellectual disabilities: A systematic review. Research in Developmental Disabilities, 57, 63-84.

Robertson, J., Emerson, E., Hatton, C., Elliott, J., Mcintosh, B., Swift, P., ... Associates, H. S. (2007). Person-centred planning : factors associated with successful outcomes for people with intellectual disabilities. Journal of Intellectual Disability Research, 5 I (3), $232-243$

Robertson, J., Hatton, C., Emerson, E., Elliott, J., Mcintosh, B., Swift, P., ... Joyce, T. (2007). Reported Barriers to the Implementation of Person-Centred Planning for People with Intellectual Disabilities in the UK. Journal of Applied Research in Intellectual Disabilities, 20, 297-307.

Rudkin, A., \& Rowe, D. (1999). A systematic review of the evidence base for lifestyle planning in adults with learning disabilities: implications for other disabled populations. Clinical Rehabilitation, 13(5), 363-372. 
Schalock, R. L., Borthwick-Duffy, S. A., Bradley, V. J., Buntinx, W. H. E., Coulter, D. L., Craig, E. M., ... Yeager, M. H. (20 I 0). Intellectual disability: definition, classification, and systems of supports. Washington, D.C.:American Association on Intellectual and Developmental Disabilities.

Shalley, C. E., \& Scheller, G. K. (20।3). Goals and creativity. In E. A. Locke \& G. P. Latham (Eds.), New developments in goal setting and performance. New York: Routledge.

Shilts, M. K., Townsend, M. S., \& Dishman, R. K. (20/3). Using goal setting to promote health behaviour change: diet and physical activity. In E. A. Locke \& G. P. Latham (Eds.), New developments in goal setting and performance. New York: Routledge.

Stancliffe, R. J., Hayden, M. F., \& Lakin, K. C. (1999). Effectiveness and Quality of Individual Planning in Residential Settings: an Analysis of Outcomes. Mental Retardation, 37(2), 104-1 16.

Wigham, S., Robertson, J., Emerson, E., Hatton, C., Elliott, J., Mclntosh, B., ... Joyce, T. (2008). Reported goal setting and benefits of person centred planning for people with intellectual disabilities. Journal of Intellectual Disabilities, 12, 143-52.

Williams, K. J. (20 I3). Goal Setting in Sports. In E. A. Locke \& G. P. Latham (Eds.), New developments in goal setting and performance. New York: Routledge.

Zijlstra, H. P. R. (2003). Dansen met olifanten, een onderzoek naar de implementatie van het opvoedingsprogramma in de zorg voor mensen met ernstig meervoudige beperkingen. Groningen: Stichting Kinderstudies. 




\section{Section 3 3

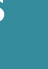

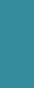

$$
\text { plans }
$$ \\ Content of individual support plans

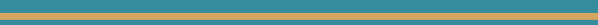

(n)
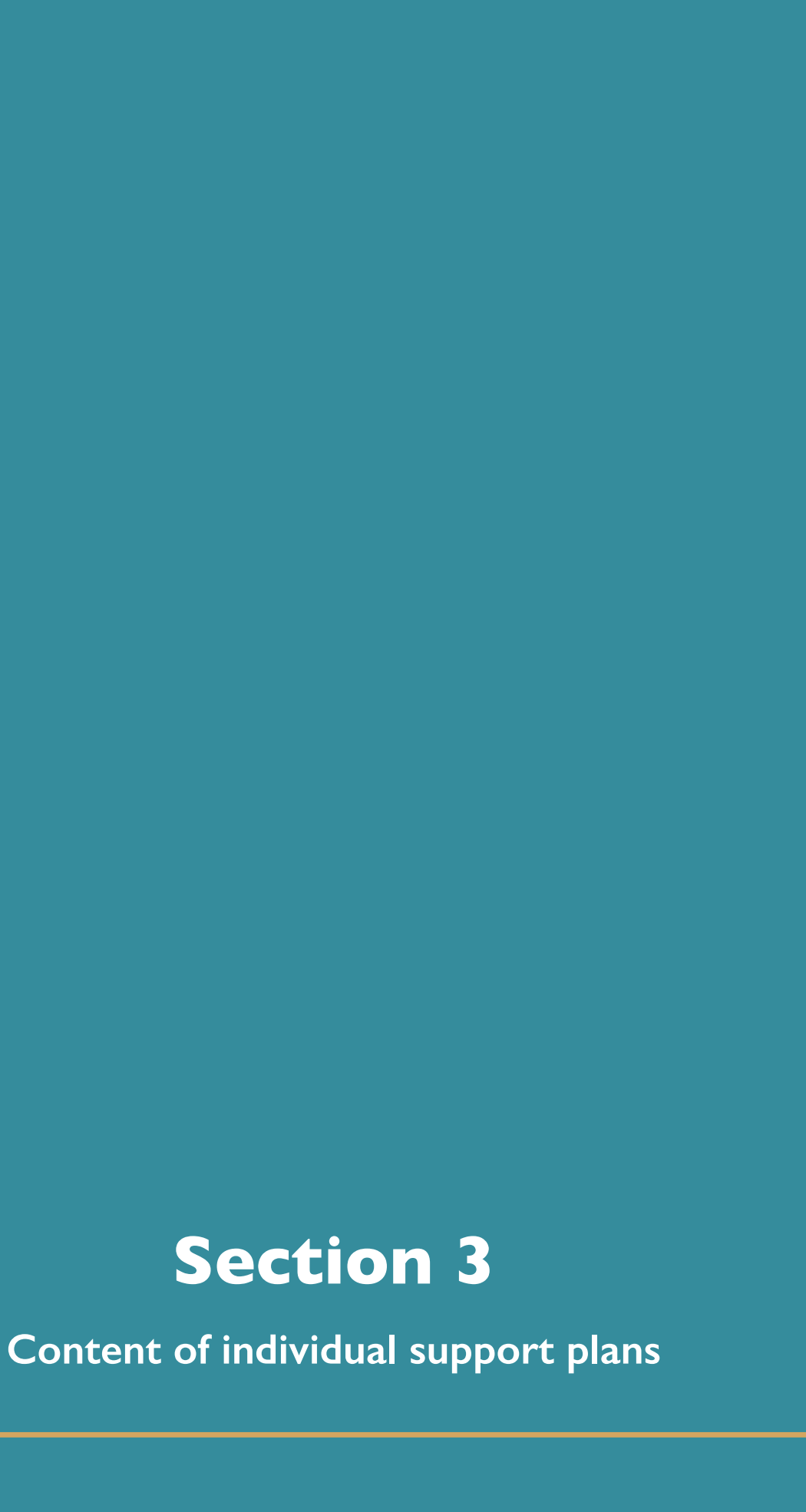

\section{(n)}

(1)

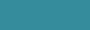

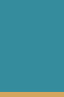

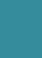





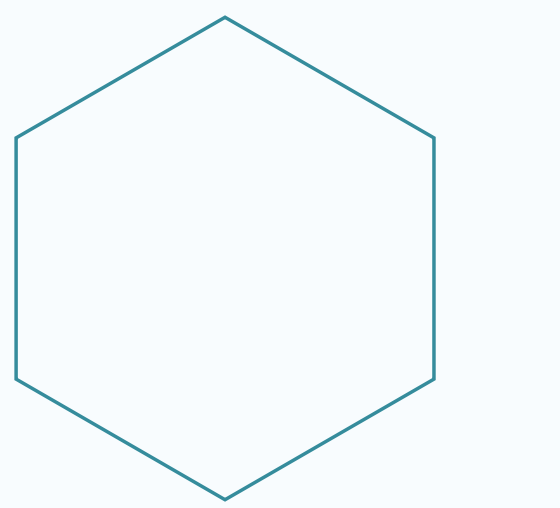

\section{Chapter 5}

\section{Content analysis of ISP documents}

\section{Published as:}

Herps, M. A., Buntinx, W. H. E., Schalock, R. L., Breukelen, G. J. P.Van, \& Curfs, L. M. G. (20 I 6). Individual support plans of people with intellectual disabilities in residential services: content analysis of goals and resources in relation to client characteristics. Journal of Intellectual Disability Research, 60(3), 254-262. 


\section{ABSTRACT}

\section{Background}

Goals and objectives as mentioned in Individual Support Plans (ISPs) were analysed to explore what domains of quality of life they are associated with, what support resources are referenced for achieving the goals, and how domains and resources are related to clients age, gender and intellectual disability (ID) level.

\section{Method}

A total of 209 ISPs for persons with ID from eight residential Dutch service provider organisations were analysed. Mixed linear regression analyses were conducted to examine the relations between client characteristics and the content of goals and support resources.

\section{Results}

Results showed that ISPs of people with mild and moderate ID had significantly more goals related to independence and social participation as compared to the ISPs of people with severe and profound ID. ISPs of clients with profound ID addressed quality of life factors related to 'well-being' more than ISPs of all other clients. ISPs of people aged 20-34 years had significantly more goals on independence than the two other age groups. ISPs of people under the age of 50 had significantly fewer goals with respect to well- being than found in ISPs of older people. Regarding the use of resources, $42.6 \%$ of the ISP goals were associated with resources from specialised services, $31.5 \%$ associated with natural resources and $25.9 \%$ associated with a combination of both natural and specialised services. In ISPs of people with mild ID, natural resources are more often mentioned, and specialised service-based resources are less often mentioned than for other people.

\section{Conclusions}

This study offers empirical feedback on ISP practices in the field of ID in the Netherlands. In light of current ISP practices, results suggest that attention should be paid to: (I) distinguishing between a 'service contract' and an ISP; (2) keeping a focus on the whole person in all age groups and levels of functioning and (3) involving the service recipient in ISP development and implementation. 


\section{INTRODUCTION}

Individual support planning refers to the process of developing personal goals, selecting resources and developing support strategies in response to support needs of persons with intellectual disability (ID).Terms that are commonly used to refer to individual support planning include person-centred planning, individualised support planning, individual programme planning, individual education planning and individual service planning (Herps et al. 2013). This article focused on the Individual Support Plan (ISP) as a digital or written document that results from individual support planning. In general, the ISP contains specific goals and objectives for the person, and includes types of support resources and strategies that are used to implement the goals and objectives. ISPs are used for different reasons, including a guiding instrument for support staff in their daily work, a tool for people with ID to have more rights and control over their lives and support processes and a tool for quality management in service provider organisations. It has become legally mandated in many jurisdictions with the aim of enhancing a person-centred approach to services and support, and to evaluate the effectiveness of individualised support (Rasheed \& Miller, 2006; Robertson et al. 2007).

A central aspect of an ISP is the individual goals and objectives. The goals and objectives prioritise the support that is currently needed for achieving personal outcomes. Ideally, these goals and objectives are developed in dialogue with the person with ID and/or their families and significant others. Research has shown that goals and objectives in ISPs are often of poor quality (Shaddock \& Bramston, 1991; Greasley, 1995; Cummins et al., 1996; Pretti-Frontczak \& Bricker, 2000; Radcliffe \& Hegarty, 200 I; Cook et al., 2006; Taylor \& Taylor, 20 I3), and that their content varies according to policy developments or the introduction of a new planning method (Wigham et al., 2008; Lawlor et al., 20 I 3). In addition, relatively little is known about the relationship between individual client characteristics and the content of ISP goals.

ISP goals and objectives are achieved through the use of resources that are organised into a system of supports. Elements within this system are natural support, technology, prosthetics, education (new skills), environmental accommodation, incentives, personal strengths/assets and professional services (Schalock \& Verdugo, 20 I2; Schalock \& Luckasson, 20 I4). Stating the intended use of resources in the attainment of goals should be a significant part of an ISP.

The present study was conducted within the context of two significant transformations that are occurring in disability organisations (Schalock \&Verdugo, 20 I4). The first is the increased consumer involvement in ISP development and the inclusion of the family in planning teams. The second transformation is the use of quality of life (QoL) domains as framework for aligning resources (i.e. support strategies) to the client's ISP goals and objectives. Though ISPs are mandated in Dutch law, little is known about ISP practices in the Netherlands. The current 
study is part of a larger project that highlights different aspects of ISPs in the Netherlands (e.g. Herps et al., 2013) so as to improve the quality and processes of ISPs. The focus of the present study is on goals and resources that are found in ISPs. The study's purpose was to explore what domains of QoL are associated with ISP-referenced goals and objectives, what support resources are referenced for achieving the goals and objectives and how domains and resources are related to demographic characteristics such as a client's age, gender and ID level. The following questions were addressed:

I. What does the ISP look like in terms of size and number of goals?

2. What support goals are mentioned in IPSs in terms of Quality of Life domains and factors?

3. What resources are being used in the achievement of support goals?

4. Is there a relationship between the client's gender, age and level of intellectual functioning and goals domains and factors in their ISP?

5. Is there a relationship between the client's gender, age and level of intellectual functioning the resources mentioned in their ISPS? 


\section{METHOD}

\section{Sample}

Stratified sampling was used for achieving a representative sample of the Dutch population of persons with ID with respect to age, gender and level of ID. Eight service provider agencies participated in the study. These organisations are geographically spread over the Netherlands and vary in size: four organisations provide services to more than 1000 people, one organisation provides services to 500-1000 people and three organisations provide services to less than 500 people with ID. All organisations provide 24-h residential care to people with all levels of ID.

Participating agencies were asked to provide a proportional number of ISPs corresponding with prevalence characteristics with respect to age group, gender and level of intellectual functioning of the Dutch population of persons with ID over 20 years (Wullink et al., 2007). Table I shows the number of documents that were supplied and how many ISPs were included in the study sample. Organisation 3 only provided services to 22 adults with ID, therefore were not able to provide more. This procedure resulted in a sample of 209 ISPS.

Participants were 104 males and 105 females, aged 20 to $83(M=4 \mid .8 ; S D=14.2)$. In eight cases the level of intellectual functioning was unknown. ISPs for these individuals were included in the sample, but are excluded from the analyses of the relationship between the level of intellectual functioning and content of goals or resources. Table I provides a description of the study's participants.

Table I Distribution of age groups and level of intellectual functioning in the study sample.

Levels of intellectual functioning

\begin{tabular}{lrrrrrr} 
Age group & Mild (\%) & Moderate (\%) & Severe (\%) & Profound (\%) & Unknown & Total (\%) \\
\hline $20-34$ & $41(19.6)$ & $14(6.7)$ & $12(5.7)$ & $3(1.4)$ & $2(1)$ & $72(34.4)$ \\
$35-49$ & $19(9.1)$ & $25(12.0)$ & $18(8.6)$ & $9(4.3)$ & $3(1.4)$ & $74(35.4)$ \\
$50+$ & $13(6.2)$ & $21(10.0)$ & $18(8.6)$ & $8(3.8)$ & $3(1.4)$ & $63(30.1)$ \\
Total & $73(34.9)$ & $60(28.7)$ & $48(23.0)$ & $20(9.5)$ & $8(3.8)$ & $209(100)$
\end{tabular}




\section{Coding of Goals and Resources}

In the present study, only goals that were explicitly described as a goal related to the personal functioning of the particular client were included. Each ISP was hand searched to identify these goals and associated resources.

Content of goals: Goals were coded according to one of the eight QoL domains proposed by Schalock et al., (2008): personal development, self-determination, interpersonal relations, social inclusion, rights, emotional well-being, physical well-being and material well-being. A ninth category was added to code goals that could not be traced to one of the domains. This was scored as 'Not related to QoL'. For example:'next December 2014, all staff members will be able to work with this person' (a support staff oriented goal). Each goal was coded to only one domain. In cases where a goal addressed more than one domain, the most dominant domain was coded.

Resources:The resources described in achieving the goal were classified along the systems of supports model including: (I) the person's own competences; (2) social network of family and friends; (3) informal supports such as neighbours, colleagues and volunteers; (4) generic agencies and (5) specialised services. If a specific goal was associated with the use of more than one resource type, combinations were coded accordingly (e.g. person's own competences and social network of family and friends).

\section{Inter-Rater Agreement}

To examine the inter-rater agreement of the scoring of goals and resources, a random sample of 43 ISPs (20.5\%) was used. For these ISPs, the goals and their corresponding resources were independently coded by two researchers. A total of 125 goals were included in this analysis, making up $19.4 \%$ of the total goals in the study. The two raters scored $(I)$ the QoL domain that the goal refers to and (2) the resources that were specified in reference to that goal. Cohen's kappa was calculated as a measure of inter-rater agreement. The percentage of corresponding items between the two raters on scoring the domains was 85\% (kappa $=.81$ ); for resources used, $92 \%$ of the scores between the two raters corresponded (kappa $=.89$ ).

\section{Statistical Analysis}

Statistical analyses were conducted with IBM SPSS (version 22). Descriptive statistics (frequencies and percentages) were used to analyse the frequency with which QoL domains, and resources were mentioned in ISPS. 
Mixed linear regression analyses were conducted to examine the relations between client characteristics as predictors and the content of goals and support resources as outcomes, taking into account outcome variation between organisations by a random intercept, because the clients included in this study (level I) are nested in organisations (level 2) that each use their own ISP formats. In these analyses, 29 ISPs were excluded since no goal statements could be found, leaving a total number of 180 ISPS.

The eight domains on QoL were reduced to three factors as described by Schalock \& Verdugo (2012): independence (composed of the domains of personal development and self-determination), social participation (composed of interpersonal relations, social inclusion and rights) and well-being (composed of emotional well-being, physical well-being and material well-being). This was done to reduce the number of dependent variables and thus reducing the chances of false positives. The resources were also reduced to three categories: natural resources, service-based resources and combined natural and service-based resources.

Dependent variables were the three QoL factors and the three categories of resources. More specifically, for each factor category, the number of times that it was mentioned in the ISP was standardised by dividing it by the total number of goals stated in the ISP. Independent variables were the client characteristics gender, age and level of intellectual functioning. The outcome variation between clients within the organisations and the outcome variation between organisations were both taken into account by mixed linear regression with a random effect of organisation. 


\section{RESULTS}

\section{Individual Support Plan Characteristics}

Table 2 shows the number of ISPs per service provider, the number of ISPs within organisations that had more than one goal, and the total, mean and standard deviation of goals found in that organisation. Goals were found in 180 (86.1\%) of the ISPs analysed. A total of 645 goals were identified $(M=3.6 ; S D=2.0)$. The number of goals in ISPs varied from I to II. The total number of pages of the 209 ISPs analysed in the study was 3,553 ( $M=17$; SD = 10.23). They varied in length from 3 to 76 pages. Statistical analysis showed the presence vs. absence of goals in an ISP were related to the organisation, but not to any client characteristic.

\begin{tabular}{|c|c|c|c|c|c|c|}
\hline Organization & $\begin{array}{l}\text { ISP } \\
(n)\end{array}$ & $\begin{array}{r}\text { Pages } \\
\text { per ISP } \\
M(S D)^{*}\end{array}$ & $\begin{array}{l}\text { Pages } \\
\text { min- } \\
\text { max* }\end{array}$ & $\begin{array}{r}\text { Number of ISP } \\
\text { documents with } \\
>0 \text { goals }\end{array}$ & $\begin{array}{r}M(S D) \text { Number } \\
\text { of goals in ISP } \\
\text { documents** }\end{array}$ & $\begin{array}{r}\text { Goals } \\
\text { min-max** }\end{array}$ \\
\hline Organization I & 18 & $22.0(10.5)$ & $9-39$ & 10 & $2.4(1.3)$ & $1-4$ \\
\hline Organization 2 & 27 & $14.6(9.6)$ & $4-29$ & 25 & $2.4(0.9)$ & $1-4$ \\
\hline Organization 3 & 22 & $5.0(1.4)$ & $3-7$ & 22 & $6.5(1.9)$ & $3-11$ \\
\hline Organization 4 & 30 & $30.7(13.5)$ & $16-76$ & 28 & $4.4(2.7)$ & $1-10$ \\
\hline Organization 5 & 30 & I $6.0(4.0)$ & $9-30$ & 26 & $3.0(1.4)$ & $1-6$ \\
\hline Organization 6 & 30 & 19.1 (2.5) & $14-23$ & 18 & $2.2(1.1)$ & I-5 \\
\hline Organization 7 & 23 & $17.5(3.4)$ & $9-23$ & 23 & $3.1(0.7)$ & $2-5$ \\
\hline Organization 8 & 29 & $9.6(1.2)$ & $7-13$ & 28 & $3.7(0.9)$ & $2-5$ \\
\hline Total & 209 & $17.00(10.23)$ & $3-76$ & 180 & $3.58(1.97)$ & $1-11$ \\
\hline
\end{tabular}

\section{Individual Support Plan goal content}

Table 3 presents the frequency with which goals refer to the eight QoL domains. The most often stated goal was in the domain of physical well-being. In II4 ISPs (63.3\%) this domain was addressed at least once, and a total of 202 goals addressed physical well-being. In only five ISPs was the rights domain addressed, with a total of five goals addressing rights. 


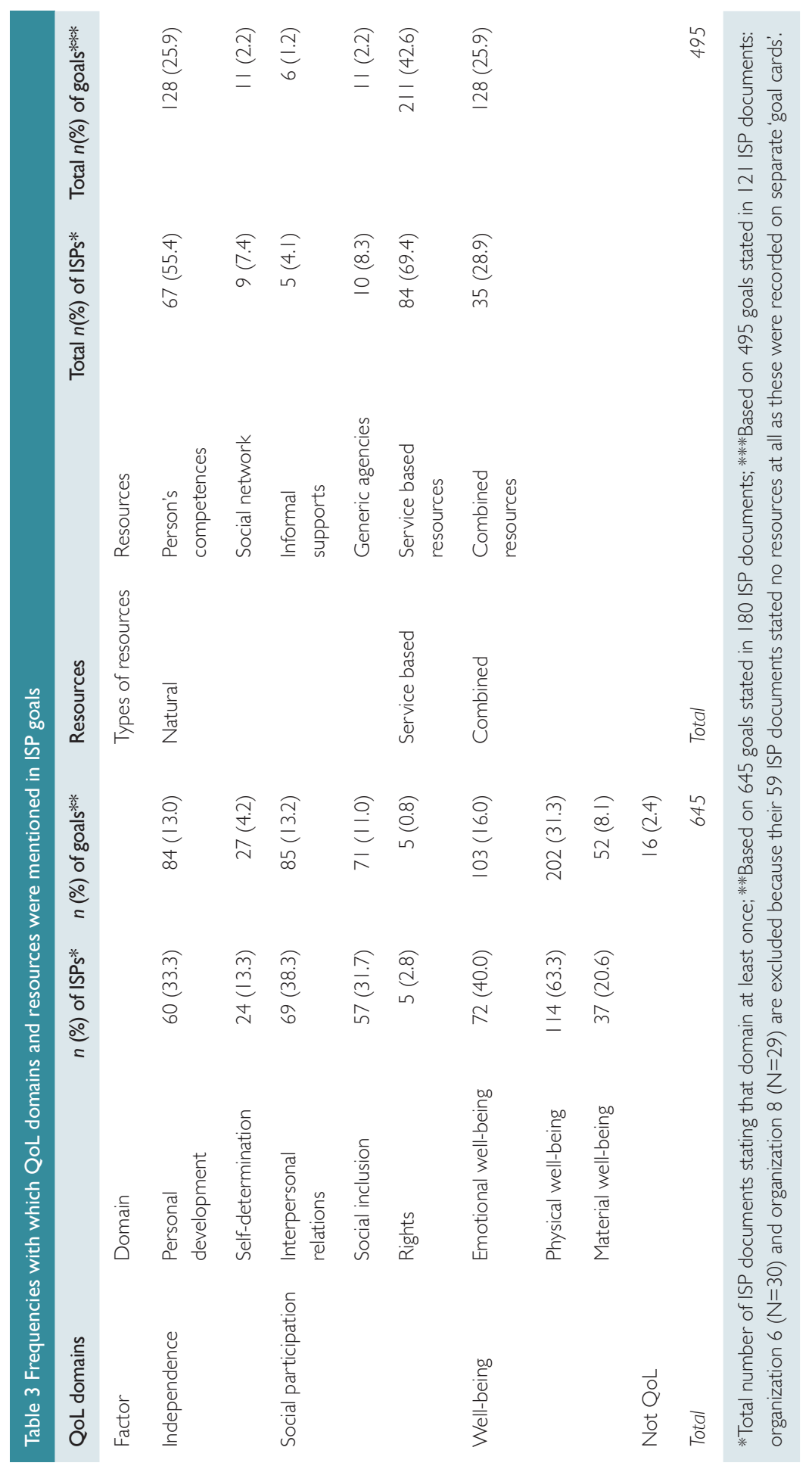




\section{Individual Support Plan listed resources}

Resources were specified in 121 of the ISPs analysed (67.2\%), for a total of 495 (76.9\%) goals. Service-based resources were mentioned in 84 ISPs (46.7\%), and specified in 21 I goals (42.6\%). In 37.2\% of the ISPs, the person's competences were mentioned as playing a role in achieving the goals. Informal supports were least often found to be resources in achieving goals, described in only 5 (2.8\%) ISPs, and in 1.2\% of the goals. In just over a quarter of the goals, a combination of different resources was used, (e.g.the person's competences and his or her social network and generic agencies).

\section{Goal-Related Correlates}

The number of goals related to each domain or resource within the ISP was analysed as an outcome variable, and regressed on the client's gender, age and level of ID with mixed linear regression. This allowed us to explore the relations between those client characteristics and the domains and resources. For every analysis a table was made representing the results. This led to six tables. Two tables are included in this chapter. The other tables are found in the appendix of this chapter.

Independence. Mixed linear regression analyses showed that younger people (20-34) and people with mild to moderate ID have significantly more goals related to the factor of independence than older people (35-49 and $>50$ ), respectively, than people with more severe or profound disabilities (Table 4).

Social participation. Mixed linear regression analyses showed that people with mild or moderate ID have significantly more goals related to social participation than people with severe or profound ID.

Well-being. Mixed linear regression analyses showed that the ISPs of the oldest clients $(>50)$ and clients with profound ID have significantly more goals related to well-being than the ISPS of younger clients respectively clients with a less severe ID.

In view of strong non-normality of the residuals of 'independence' and 'social participation', we subsequently dichotomised both outcomes as 1 = at least one goal in this domain or using this resource, vs. 0 = no such goal, and analysed these dichotomised outcomes with mixed logistic regression as a robustness check. These analyses confirmed the findings in the mixed linear regression analyses. 
Finally, we added all interactions between client characteristics to the mixed linear models, then first tested the three-way term gender $\times$ age $\times$ level (which was never significant at the $5 \%$ level), and then tested the two-way terms. These were never significant at the $5 \%$ level either. Based on this analysis, the ISPs contained more goals on independence for younger than for older clients, and more goals on independence and on participation for clients with mild or moderate ID than for clients with severe or profound ID.The opposite age and level of functioning effects are found for goals on well-being. There was no clear relation between the client's gender and the goal domains.

Table 4 Mixed linear regressions of Independence (REML) on client gender, age and level of functioning

\begin{tabular}{|c|c|c|c|c|c|c|}
\hline Fixed effect & Coefficient & SE & $T$ & $p$-value & & $95 \% \mathrm{Cl}$ \\
\hline Intercept & -.014 & .065 & -.214 & .832 & -.145 & .117 \\
\hline Gender & .021 & .035 & .598 & .551 & -.048 & .089 \\
\hline Age & & & & .083 & & \\
\hline $20-34$ & .102 & .045 & 2.252 & $.026 *$ & .012 & .192 \\
\hline $35-49$ & .050 & .044 & 1.128 & .261 & -.037 & .137 \\
\hline Level of ID & & & & .055 & & \\
\hline Mild & .157 & .064 & 2.454 & $.016 *$ & .030 & .283 \\
\hline Moderate & .141 & .063 & 2.239 & $.027^{*}$ & .017 & .265 \\
\hline Severe & .076 & .066 & 1.151 & .252 & -.054 & .206 \\
\hline Outcome variance & Coefficient & SE & Wald Z & $p$-value & & $95 \% \mathrm{Cl}$ \\
\hline Within organizations & .049 & .006 & 8.646 & $.000 *$ & .039 & .062 \\
\hline Between organizations & .002 & .004 & .469 & .639 & .000 & .119 \\
\hline
\end{tabular}

\section{Resource-Related Correlates}

In two organisations (organisation 6 and organisation 8), resources were not described in the ISP, but were described in separate 'goal cards'. These two organisations were excluded from the mixed linear analyses on resources. Results of the mixed linear regression analysis with resources as dependent variables found that clients with mild or moderate ID use natural resources more often, and service resources less often, than clients with severe or profound ID natural sources, although this difference was significant only for mild ID, not for moderate ID. No effects were found of age and gender on resources. Mixed logistic regression analyses confirmed these findings and generated no new information (Table 5). 
We then added all interactions between client characteristics to the mixed linear models, and first tested the three-way term gender $\times$ age $\times$ level (which was never significant at the $5 \%$ level), and second tested the two-way terms, which were never significant at the $5 \%$ level either. In short, mixed linear regression showed no relationship between resources and client characteristics apart from the aforementioned effect of level of ID.

Table 5 Mixed linear regression of natural resources (REML) on client gender, age, level of functioning

Fixed effect
Intercept




\section{DISCUSSION}

The ISP content analysis reported in this article has at least three implications for ISP-related policies and practices. First, there is a need for service providers to understand what constitutes an ISP. In providing support to people with ID, it is evident that a support service provider should make agreements on support goals and resources that will be used to achieve these goals. In this regard, it is remarkable that in 14\% of all ISPs analysed, no goals were specified.These ISPs contained a vast amount of descriptive and administrative information about the individual and his or her functioning, but did not reference desired outcomes of support.This points to the need for a clear understanding of what constitutes an ISP. It is crucial for staff that their management provides correct information on the key aspects of the ISP and that management coaches staff that goals and objectives are to be found in ISPs. It also points to the need for the service delivery system to differentiate between a service contract, which would contain all of the legal and regulatory requirements, and an individual support plan, which would align personal goals and assessed support needs with specific elements of a system of support. Again, these decisions and implementation are to begin at the level of the management of the service providers.

As the ISP has become a tool for 'measuring' quality performance in service provider organisations, stakeholders such as the Healthcare Inspectorate and budget allocation agencies add criteria to the content of ISPs. These criteria and the interests associated with complying with these criteria add to ISP complexity. The result is that an ISP becomes more oriented towards compliance with bureaucratic criteria than a person-centred, individualised support document (Smull \& Lakin, 2002; Osgood, 2005; Herps et al., 20 I 3). Thus, a point of focus for enhancing ISP practice should be to separate the components of a service contract from the ISP that aligns personal goals and assessed support needs with specific support strategies that focus on enhancing human functioning and personal outcomes. This de-coupling can have a significant 'unfreezing' effect and enhance changes in policies and practices (Manchester et al., 2014).

A second implication of the present study is the need to focus on the whole person as reflected in the eight QoL domains used as framework of the content analysis. Most of the goals analysed in the present study related to the domain of physical well- being, as was also found by Lawlor et al. (20 I3). This can be explained by the fact that people with ID are more at risk for health problems than the general population, and that these risks increase with age, severity of the ID and specific syndromes (Schoufour et al., 20I3; Havercamp \& Scott, 20I4; Hermans \& Evenhuis, 20I4). Therefore, it is understandable that supports for older people and people with severe/profound ID focus on aspects of physical well-being. However, other domains of the QoL framework such as personal development, selfdetermination and 
interpersonal relations are as important to persons with profound intellectual and multiple disabilities as to persons with mild or moderate ID, and that these aspects of QoL can be improved (Maes et al., 2007).

A third implication of the present study relates to the role of the individual in a horizontally structured support team (Schalock \& Verdugo, 20 I2; Schalock \& Luckasson, 20 I 4). The role and responsibility of the person with ID in achieving goals were found in a quarter of all goals analysed. A combination of both natural and service-based resources in achieving ISP goals was found in $25.9 \%$ of all goals. These findings are in line with policy developments promoting the involvement of natural resources and the persons' individual role and responsibility in working to QoL-related outcomes (Kober \& Eggleton, 2009; Lawlor, Spitz, York \& Harvey, 2013). The findings of the present study are congruent with a shift being made from a predominant specialised services approach in which these services are used to the maximum extent' to an approach in which different resources are blended into an individualised strategy of supports (Luckasson et al., 2002, p. 1 84). Still, in $42.6 \%$ of all goals, the only resources were professional and service based. One hypothesis to explain this finding is that the legal definition of ISPs in the Netherlands restricts the content of an ISP to the goals and agreements of an individual with the specific service provider.This could explain why resources outside of the facility may not have been included in the ISPs.

There are at least three limitations with regard to the present study. First, it did not include an examination of the process of the ISP development. It is unclear if the persons with ID were meaningfully involved in the development of their ISP. In future research, it would be useful to address whether the goals in the ISP are based on the individuals' preferences and wishes and if the person with ID has been actively involved in and agrees with the goals that are stated.

Second, further analyses could have been done if more characteristics of the person with ID had been collected. Robertson et al., (2007) showed for example that client characteristics (e.g. health problems) might affect ISP content. Furthermore, there were only two levels included in the present multilevel analyses. It would be informative to know who was in charge of developing and writing the ISP and what role members of a horizontally structured support team plays. In the Dutch setting, ISPs are written by direct support professionals (DSPs), and the same DSP can write ISPs for more than one person. In the present study, age and level of education of the DSP who were responsible for the ISP were unknown as was the number of years that they were working with their organisation. These factors could be related to the content of an ISP and should be included in further study. 


\section{REFERENCES}

Adams, L., Beadle-Brown, J., \& Mansell, J. (2006). Individual planning: an exploration of the link between quality of plan and quality of life. British Journal of Learning Disabilities, 34(2), 68-76.

Asselt-Goverts, A. E. van, Embregts, P. J. C. M., \& Hendriks, A. H. C. (2013). Structural and functional characteristics of the social networks of people with mild intellectual disabilities. Research in Developmental Disabilities, 34(4), 1280-1288.

Claes, C., Van Loon, J., Van Hove, G.,Vandevelde, S., \& Schalock, R. L. (2012). Predictors of quality of life in persons with intellectual disabilities. Presented at the 2012 IASSID Congres.

Cook, C.R., Crews, S.D., Wright, D.B., Mayer, G.R., Gale, B., Kraemer, B., \& Gresham, F.M. (2006). Establishing and Evaluating the Substantive Adequacy of Positive Behavioral Support Plans. Journal of Behavioral Education, 16, 191-206.

Cummins, R.A., Baxter, C., Hudson, A., \& Jauernig, R. (1996). A model system for the evaluation of Individual Program Plans. Journal of Intellectual and Developmental Disability, 21, 59-70.

Forrester-Jones, R., Carpenter, J., Coolen-Schrijner, P., Cambridge, P., Tate, A., Beecham, J., ... Wooff, D. (2006). The Social Networks of People with Intellectual Disability Living in the Community 12 Years after Resettlement from Long-Stay Hospitals. Journal of Applied Research in Intellectual Disabilities, 19(4), 285-295.

Greasley, P. (1995). Individual Planning with Adults who Have Learning Difficulties : Key issues - key Sources. Disability \& Society, 10(3), 353-364

Havercamp, S.M. \& Scott, H.M. (2014). National health surveillance of adults with disabilities, adults with intellectual and developmental disabilities, and adults with no disabilities. Disability and Health Journal, 8, 165-172.

Hermans, H. \& Evenhuis, H.M. (20 I4). Multimorbidity in older adults with intellectual disabilities. Research in Developmental Disabilities, 35, 776-783.

Herps, M. A., Buntinx, W. H. E., \& Curfs, L. M. G. (2013). Individual support planning: perceptions and expectations of people with intellectual disabilities in The Netherlands. Journal of Intellectual Disability Research, 57, 1027-36.

Hostyn, l., \& Maes, B. (2009). Interaction between persons with profound intellectual and multiple disabilities and their partners: a literature review. Journal of Intellectual \& Developmental Disability, 34(4), 296-312.

Kamstra, A., van der Putten, A. A. J., Post, W. J., \& Vlaskamp, C. (2015). Informal Social Networks of People with Profound Intellectual and Multiple Disabilities: Relationship with Age, Communicative Abilities and Current Living Arrangements. Journal of Applied Research in Intellectual Disabilities, 28(2), I59- 164.

Kober, R. \& Eggleton, I. R. C. (2009). Using quality of life to evaluate outcomes and measure effectiveness. Journal of Policy and Practice in Intellectual Disabilities, 6, 40-51.

Lawlor, D., Spitz, R., York, M., \& Harvey, B. (2013). Using goal analysis to drive improvements in performance and outcomes. Journal of Intellectual Disabilities, 17, 301-13.

Locke, E. A., \& Latham, G. P. (2002). Building a practically useful theory of goal setting and task motivation: A 35-year odyssey. American Psychologist, 57(9), 705-717.

Luckasson, R., Borthwick-Duffy, S., Buntinx, W. H. E., Coulter, D. L., Graig, E. M., Reeve, A. I. et al. (2002). Mental Retardation. Definition, Classification and Systems of Supports. Washington DC: American Association on Mental Retardation.

Maes, B., Lambrechts, G., Hostyn, I., \& Petry, K. (2007). Quality-enhancing interventions for people with profound intellectual and multiple disabilities: a review of the empirical research literature. Journal of Intellectual \& Developmental Disability, 32, $163-78$. 
Manchester, J., Gray-Miceli, D. L., Metcalf, J. A., Paolini, C. A., Napier, A. H., Coogle, C. L., \& Owens, M.G. (20।4) Facilitating Lewin's change model with collaborative evaluation in promoting evidence based practices of health professionals. Evaluation and Program Planning, 47, 82-90.

McConkey, R., \& Collins, S. (2010). Using personal goal setting to promote the social inclusion of people with intellectual disability living in supported accommodation. Journal of Intellectual Disability Research, 54(2), I35-43.

Osgood,T. (2005). Managing the tensions between the interests of organisations and service users. In P. Cambridge \& S. Carnaby (Eds.), Person centred planning and care management with people with learning disabilities (pp. 5 I -64). London: Jessica Kingsley Publishers.

Petry, K., \& Maes, B. (2007). Description of the Support Needs of People with Profound Multiple Disabilities Using the 2002 AAMR System : An Overview of Literature. Education and Training in Developmental Disabilities, 42(2), | $30-143$.

Pretti-Frontczak, K. \& Bricker, D. (2000). Enhancing the Quality of Individualized Education Plan (IEP) Goals and Objectives. Journal of Early Intervention, 23, 92-105.

Radcliffe, R. \& Hegarty, J.R. (200 I). An Audit Approach to Evaluating Individual Planning. The British Journal of Development Disabilities, 47, 86-97.

Robertson, J., Hatton, C., Emerson, E., Elliott, J., Mcintosh, B., Swift, P., ... Joyce, T. (2007). Reported Barriers to the Implementation of Person-Centred Planning for People with Intellectual Disabilities in the UK. Journal of Applied Research in Intellectual Disabilities, 20, 297-307.

Schalock, R. L., Bonham, G. S., \& Verdugo, M. A. (2008). The conceptualization and measurement of quality of life: implications for program planning and evaluation in the field of intellectual disabilities. Evaluation and Program Planning, 31, |8|-90.

Schalock, R. L., \& Luckasson, R. (20 I4). Clinical Judgment (2nd Edition). Washington, D.C.: American Association on Intellectual and Developmental Disabilities.

Schalock, R. L., \& Verdugo, M. A. (2012). A leadership guide for today's disabilities organizations: overcoming challenges and making change happen. Baltimore: Paul H. Brookes Pub.

Schoufour, J.D., Van Wijngaarden, J., Mitnitski, A., Rockwood, K., Evenhuis, H.M., \& Ecteld, M. A. (20 I3). Characteristics of the least frail adults with intellectual disabilities: A positive biology perspective. Research in Developmental Disabilities, 35, 27-I36.

Shaddock, A.J. \& Bramston, P. (199|). Individual service plans: the policy-pratice gap. Australia and New Zealand Journal of Developmental Disabilities, 17, 73-80.

Smull, M., \& Lakin, K. C. (2002). Public policy and person-centered planning. In S. Holburn, \& P. M.Vietze (Eds.), Person-Centered Planning. Research, Practice, and Future Directions (pp. 379-397). Baltimore: Paul H Brookes.

Taylor, J.E. \& Taylor, J.A. (20।3). Person-centered planning: evidence-based practice, challenges, and potential for the 2 I st century. Journal of social work in disability \& rehabilitation, 12, 213-35.

Vlaskamp, C., \& van der Putten, A. (2009). Focus on interaction: the use of an Individualized Support Program for persons with profound intellectual and multiple disabilities. Research in Developmental Disabilities, 30(5), 873-83.

Wigham, S., Robertson, J., Emerson, E., Hatton, C., Elliott, J., Mclntosh, B., ... Joyce, T. (2008). Reported goal setting and benefits of person centred planning for people with intellectual disabilities. Journal of Intellectual Disabilities, 12, 143-52.

Wullink, M., Van Schrojenstein Lantman-de Valk, H. M., Dinant, G. J., Metsemakers, J.F. (2007). Prevalence of people with intellectual disability in the Netherlands. Journal of Intellectual Disability Research, 51,51 I-519. 


\section{APPENDIX}

\section{Appendix A}

Mixed linear regressions of content of goals on client gender, age and level of functioning

Table A Mixed linear regression of social participation (REML) on client gender, age and level of functioning

\begin{tabular}{|c|c|c|c|c|c|c|}
\hline Fixed effect & Coefficient & SE & $T$ & $p$-value & & $95 \% \mathrm{Cl}$ \\
\hline Intercept & .116 & .071 & 1.638 & .107 & -.026 & .259 \\
\hline Gender & -.076 & .040 & -1.909 & .058 & -.154 & .003 \\
\hline Age & & & & .138 & & \\
\hline $20-34$ & .029 & .051 & .575 & .566 & -.072 & .130 \\
\hline $35-49$ & .098 & .050 & 1.942 & .054 & -.002 & .198 \\
\hline Level of ID & & & & .088 & & \\
\hline Mild & .162 & .072 & 2.255 & $.026 *$ & .020 & .304 \\
\hline Moderate & .148 & .071 & 2.076 & $.040 *$ & .007 & .289 \\
\hline Severe & .078 & .075 & 1.040 & .300 & -.070 & .226 \\
\hline Outcome variance & Coefficient & SE & $T$ & $p$-value & & $95 \% \mathrm{Cl}$ \\
\hline Within organizations & .066 & .007 & 8.921 & $.000 *$ & .053 & .083 \\
\hline Between organizations & .000 & .002 & .195 & .845 & .000 & 9.586 \\
\hline
\end{tabular}


Table B Mixed linear regression of Well-being (REML) on client gender, age, level of functioning

\begin{tabular}{|c|c|c|c|c|c|}
\hline Fixed effect & Coefficient & SE & $T$ & $p$-value & $95 \% \mathrm{Cl}$ \\
\hline Intercept & .799 & .093 & 8.594 & $.000 *$ & $.613-.984$ \\
\hline Gender & .092 & .047 & 1.973 & .050 & $-.000-.184$ \\
\hline Age & & & & $.007 *$ & \\
\hline $20-34$ &.$-|3|$ & .062 & -2.097 & $.038 *$ & $-.254--.008$ \\
\hline $35-49$ & -.186 & .060 & -3.114 & $.002 *$ & $-.304--.068$ \\
\hline Level of ID & & & & $.000 *$ & \\
\hline Mild & -.358 & .088 & -4.078 & $.000 *$ & $-.531--.185$ \\
\hline Moderate & -.375 & .086 & -4.375 & $.000 *$ & $-.544--.206$ \\
\hline Severe & $-.27 \mid$ & .090 & -3.021 & $.003^{*}$ & $-.448--.094$ \\
\hline Outcome variance & Coefficient & SE & $T$ & $p$-value & $95 \% \mathrm{Cl}$ \\
\hline Within organizations & .089 & .010 & 8.868 & $.000 *$ & $.07|-|||$. \\
\hline Between organizations & .009 & .008 & 1.048 & .294 & $.001-.055$ \\
\hline
\end{tabular}

Reference category in gender: females; reference category in Age: age group 50+; reference group in level of ID: Profound ID. * $p<.05$ 


\section{Appendix B}

Mixed linear regressions of content of goals on client gender, age and level of functioning

Table C Mixed linear regression of service based resources (REML) on client gender, age, level of functioning

\begin{tabular}{|c|c|c|c|c|c|c|}
\hline Fixed effect & Coefficient & SE & $T$ & $p$-value & & $95 \% \mathrm{Cl}$ \\
\hline Intercept & .546 & .137 & 3.981 & .001 & .255 & .837 \\
\hline Gender & .048 & .058 & .816 & .416 & -.068 & .163 \\
\hline Age & & & & .377 & & \\
\hline $20-34$ & .107 & .077 & 1.403 & .163 & -.044 & .259 \\
\hline $35-49$ & .050 & .076 & .660 & .511 & -.100 & .201 \\
\hline Level of ID & & & & $.003^{*}$ & & \\
\hline Mild & -.293 & .101 & -2.907 & $.004 *$ & -.493 & -.093 \\
\hline Moderate & -.154 & .098 & -1.565 & .120 & -.348 & .041 \\
\hline Severe & .014 & .103 & .133 & .895 & -.191 & .219 \\
\hline Outcome variance & Coefficient & SE & $T$ & $p$-value & & $95 \% \mathrm{Cl}$ \\
\hline Within organizations & .097 & .013 & 7.646 & .000 & .075 & .126 \\
\hline Between organizations & .055 & .039 & 1.414 & .157 & .014 & .220 \\
\hline
\end{tabular}

Reference category in gender: females; reference category in Age: age group 50+; reference group in level of ID: Profound ID. * $p<.05$ 
Table D Mixed linear regression of combined resources (REML) on client gender, age, level of functioning

\begin{tabular}{|c|c|c|c|c|c|c|}
\hline Fixed effect & Coefficient & SE & $T$ & $p$-value & \multicolumn{2}{|c|}{$95 \% \mathrm{Cl}$} \\
\hline Intercept & .150 & .128 & 1.175 & .277 & -.150 & .451 \\
\hline Gender & -.032 & .034 & -.962 & .338 & -.099 & .034 \\
\hline Age & & & & .841 & & \\
\hline $20-34$ & -.013 & .044 & -.296 & .768 & $-.10 \mid$ & .075 \\
\hline $35-49$ & -.040 & .044 & -.922 & .358 & -.127 & .046 \\
\hline Level of ID & & & & .582 & & \\
\hline Mild & .081 & .058 & 1.380 & .170 & -.035 & .196 \\
\hline Moderate & .026 & .057 & .458 & .648 & -.086 & .138 \\
\hline Severe & .051 & .060 & .860 & .391 & -.067 & .169 \\
\hline Outcome variance & Coefficient & SE & $T$ & $p$-value & & $5 \% \mathrm{Cl}$ \\
\hline Within organizations & .032 & .004 & 7.648 & .000 & .025 & .042 \\
\hline Between organizations & .079 & .051 & 1.539 & .124 & .022 & .282 \\
\hline
\end{tabular}

Reference category in gender: females; reference category in Age: age group 50+; reference group in level of ID: Profound ID. * $p<.05$ 


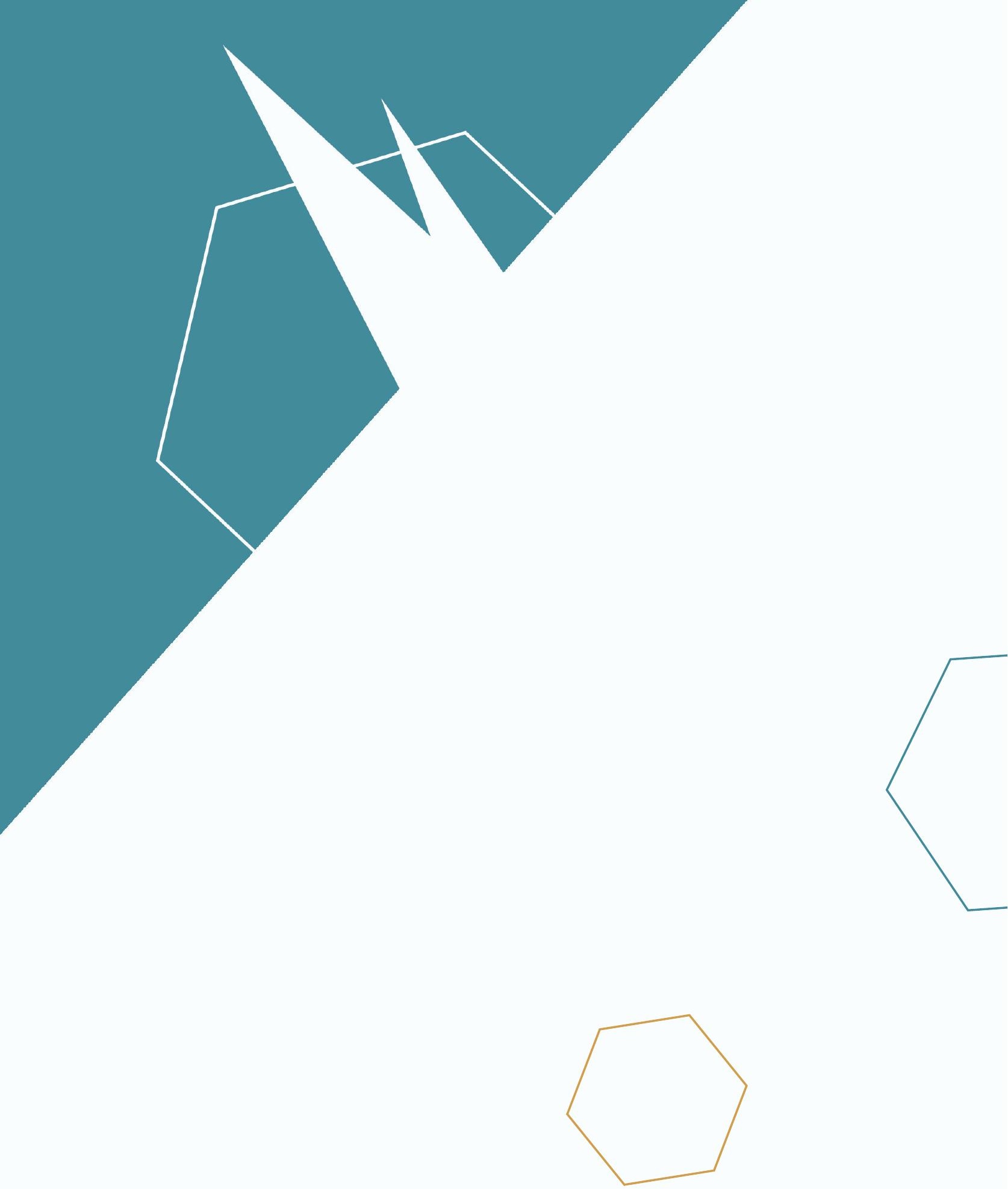


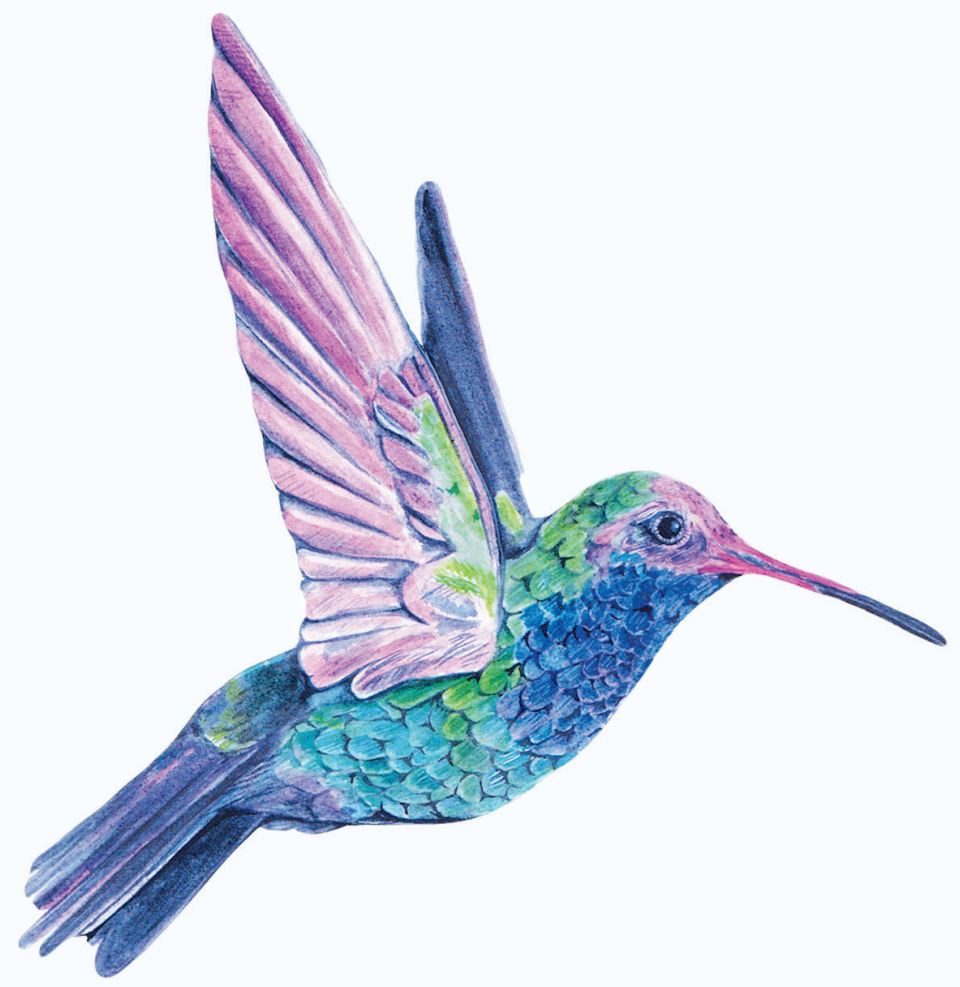

\section{Chapter 6}

\section{Sexual health and sexual rights in individual support plans.}

Accepted for publication as:

Stoffelen, J.M.T., Herps, M.A., Buntinx, W.H.E., Schaafsma, D., Kok, G. \& Curfs, L.M.G. Sexuality and Individual Support Plans for People With Intellectual Disabilities. Journal of Intellectual Disability Research. 


\section{ABSTRACT}

\section{Introduction}

Sexual rights and sexuality are important aspects of Quality of Life, including for people with intellectual disabilities (ID). However, providing support in this area to people with ID poses some challenges. In this study, the content of individual support plan (ISP) documents was analysed to determine the extent to which sexuality and sexual rights are addressed in part of the ISP documents.

\section{Method}

Content analysis was carried out on a sample of 187 ISP documents from seven different service provider organisations in the Netherlands. First, we conducted a lexical search using terms related to sexuality and sexual health. The retrieved segments were then analysed.

\section{Results}

A total of 159 ISP documents (85\%) of 60 men and 99 women contained some reference to aspects of sexuality. However, these references were mostly descriptive and offered little guidance in terms of providing support. Moreover, these notations mostly described negative or problematic aspects of sexuality. References to sexual education, treatment, intervention programs or support strategies were rarely found in the ISP documents.

\section{Discussion}

Although sexuality is addressed in most ISP documents, there is little information available about the provision of professional support in this area, that would give people the opportunity to exert sexual rights. As sexuality and exerting sexual rights is important for people with ID as well as for other people, it is recommended that issues surrounding proactive sex education, shared decision making and the implementation of sexual health care plans are addressed in the ISP. 


\section{INTRODUCTION}

\section{Individual support planning}

Individual support planning (ISP) has become a key aspect of support for people with intellectual disabilities (ID) in many countries around the world (Robertson et al., 2007; Schwartz, Holburn, \& Jacobson, 2000), and is regarded as a key aspect of person-centered support (Robertson et al., 2007). It refers to the process of developing, implementing and evaluating individual goals and objectives in terms of personal outcomes. The ISP document is the written or digital document that describes these goals and objectives (Thompson et al., 2009; Herps, Buntinx, \& Curfs, 20 I 3), and thus should reflect the current support that is provided to enhance personal outcomes (Thompson et al., 2009). The content of the ISP document should be based on an ongoing dialogue between staff and the person regarding the individual's wishes and preferences, but research has shown that people with ID are not always meaningfully involved in this process (Williams \& Robinson, 2000, Herps et al., 20 I3; Herps, Buntinx \& Curfs, 2016).

Balancing different perspectives and developing an ISP document that incorporates the provision of professional support can be difficult when conflicting interests arise, or when sensitive subjects are addressed (Tuffrey-Wijne, Bernal, Butler, Hollins, \& Curfs, 2007; Wagemans, van Schrojenstein Lantman-de-Valk, Tuffrey-Wijne, Widdershoven, \& Curfs, 20 I0). For the purpose of this study, we chose the topic of 'sexuality' as an example of a sensitive and perhaps difficult subject in terms of providing support for people with ID, and studied the extent to which this topic is addressed in ISP documents. We are aware of only one other study that has researched the topic of sexuality in ISP documents. Stancliffe, Hayden, \& Lakin (1999) studied the content of I 26 ISP documents and found no individual goals on sexuality.

\section{Sexuality and sexual rights of persons with ID}

People with ID have human rights (Stainton \& Clare, 20I2), including sexual rights. The World Association for Sexual Health (2014) has specified the number of sexual health rights, including the right to privacy, the right to sexual health, the right to marriage and to start a family, the right to decide on the number of children, the right to information and education, the right to freedom of opinion and expression, and the right to protection of these rights. According to the American Association on Intellectual and Developmental Disabilities (AAIDD),'These sexual rights and needs must be affirmed, defended, and respected' (in 'Position Statement Sexuality' AAIDD; 2008). 


\section{Definitions of sexual rights}

Three authoritative organisations have defined sexual rights from the perspective of human rights: the WHO (20I5), The World Association for Sexual Health (WAS, 20I4) and The International Planned Parenthood Federation (IPPF, 2003). Though not specifically written for people with ID, people with ID also have sexual needs, wishes and questions, as well as sexual rights that need to be addressed (AAIDD, 2008; UNCRPD, 2006, article 25), and sexuality and sexual health are as such important and constitute a part of the concept of Quality of Life (Schalock, Keith,Verdugo \& Gomez, 2010). Nussbaum (2014, pp. 57) describes sexuality as an essential human capability: 'Having the opportunity for sexual satisfaction and choices about reproduction', and states that it is important to protect this.

\section{Sexual rights and people with ID}

However, understanding sexual rights and exercising these rights in daily life is not always straightforward for people with ID. Richards, Miodrag, Watson, Feldman, Aunos, Cox-Lindenbaum, \& Griffiths (2009, p.2 I I) conclude that 'sexuality is a complex and unresolved issue due to the imposition of a social construct and the continued pathologizing of the disability itself. People with an ID experience a variety of problems in the area of sexuality. They do not always get the respect and support that is needed (Watson, Venema, Molloy \& Reich, 2002; Ignagni, Schormans, Liddiard \& Runswick-Cole, 20I 6). Issues such as overprotection - along with a lack of skills and knowledge - can make people with ID vulnerable to sexual abuse (O'Callaghan \& Murphy, 2007; Murphy, O'Callaghan \& Clare, 2007; Hollomotz, 20 I I). Individuals with ID are more likely than the general population to have had negative sexual experiences, or to have been sexually abused (Abbott \& Howarth, 2005; Reiter, Bryen \& Shachar, 2007; Hickson, Khemka, Golden \&Chatzistyli, 2008; Van Berlo et al., 20I I; Eastgate, Van Driel, Lennox \& Scheermeyer, 201 I; Stoffelen, Kok, Hospers \& Curfs, 20 I 3). People with ID often face resistance in their direct surroundings when it comes to exerting their sexual rights (Bernert, 20 I I; McGuire \& Bayley, 20 I I) and the need for privacy in residential settings is often badly recognised (Hollomotz, 2008). Family members and other support providers set different norms for themselves (or other people without disabilities) than for people with ID (Christian, Stinson \& Dotson, 2002; Yool, Langdon \& Garner, 2003; Swango-Wilson, 2008). Information about sexual rights is often not easy to understand by people with ID (Abbott, 2013), and they receive less sexual education than people without disabilities (Schaafsma, Kok, Stoffelen \& Curfs, 20I 3). Furthermore, some people with ID have difficulties memorising the information that is presented during sexual education (Löfgren-Mårtenson, 2012). Having had less sexual education or not having had tailor made sex education, can result in people with ID having less knowledge about topics such as masturbation, pregnancy, safe sex, reproduction and sexual diversity, as compared to peers without an ID (Leutar \& Mihokovic, 2007; Healy, McGuire, Evans \& Carley, 2009; Kelly, Crowley \& Hamilton, 2009; McCarthy, 2009; Schaafsma, Kok, Stoffelen \& Curfs, 2017). Moreover, the social, communicative and decision- 
making competences of some individuals with ID are limited (Hayahsi, Arakida \& Ohashi, 20 I I). Finally, although sexual education materials for people with ID have been developed, people with ID and their caregivers are rarely or not involved in the development of such materials (Schaafsma, Kok, Stoffelen \& Curfs, 20 15). This is in spite of research which shows that active involvement of the target population is one of the conditions for the development of effective health promotion or education programs (Bartholomew Eldredge, Markham, Ruiter, Fernandez, Kok \& Parcel, 2016). An example of research involving people with an intellectual disability is the study of Frawley and Bigby (2014).

\section{Aim and research questions}

The complexities surrounding sexuality and sex education, alongside issues regarding sexual rights, suggest that sexuality is an important issue for people with ID, and should, as such be addressed in ISP documents. Furthermore, Dutch policy requires sexuality to addressed in ISP documents (Herps, Buntinx \& Curfs, 2016).

In line with this, the aim of the present study is to understand to what extent sexuality, sexual health and sexual rights are mentioned in such documents. The study has an exploratory and descriptive design. The research questions are outlined below:

I. To what extent are 'sexual health' and 'sexual rights' mentioned in the ISP documents of people with ID?

2. When references are made to sexuality in ISP documents, what subjects or issues are covered?

3. How is support provided to people with ID with regard to aspects related to sexual health and sexual rights described in terms of individual support goals? 


\section{METHODS}

\section{Procedure}

For the purpose of this study, we used data that were collected by Herps et al. (2016). From the original sample of eight organisations, data of one organisation could not be used because the authors could not consult the full ISP document but rather only an excerpt of individual goals and resources as described in those excerpts. This resulted in a sample of I 87 ISP documents of people with ID from seven service providers in the Netherlands. These organisations all provide residential support to people with intellectual disabilities and are located in the north $(n=2)$, the middle $(n=1)$ and south $(n=4)$ of the Netherlands. Two organisations provide residential support to more than 2.000 people with ID, four provide between 1.000 and 2.000 people with ID support and one organization provides less than I.000 people support.

The ISP documents constituted a total of 3,444 pages with individual ISP documents ranging between 4 and 76 pages; $M=18.42, S D=9.88)$. The ISP documents belonged to 95 men with ID and 92 women with ID, aged between 20 and 83 years $(M=43.14, S D=13.97)$. Table I shows the demographic characteristics of the present sample. Information regarding the degree of the disabilities was either found in the ISP document or, when the information was not found in the ISP document, was provided by the organization.

\begin{tabular}{|c|c|c|c|c|c|c|c|c|c|}
\hline \multirow{2}{*}{$\begin{array}{l}\text { Level ID } \\
\text { Age }\end{array}$} & \multirow[t]{2}{*}{ Mild(\%) } & \multicolumn{2}{|c|}{ Moderate (\%) } & \multirow[t]{2}{*}{ Severe(\%) } & \multicolumn{2}{|c|}{ Profound ID } & \multirow[t]{2}{*}{ Unknown (\%) } & \multirow[t]{2}{*}{ Total } & \multirow[t]{2}{*}{$\%$} \\
\hline & & & & & & & & & \\
\hline $20-34$ & $25(13.4)$ & 13 & $(7.0)$ & $12(6.4)$ & 3 & $(1.6)$ & $2(1.1)$ & 55 & (29.4) \\
\hline $35-49$ & $16(8.6)$ & 25 & (13.4) & $18(9.6)$ & 9 & $(4.8)$ & $3(1.6)$ & 71 & (38.0) \\
\hline $50+$ & II (5.9) & 20 & $(10.7)$ & $18(9.6)$ & 8 & $(4.3)$ & $4(2.1)$ & 61 & (32.6) \\
\hline Total & $52(27.8)$ & 58 & $(31.0)$ & 48 (25.7) & 20 & $(10.7)$ & $9(4.8)$ & 187 & $(100)$ \\
\hline
\end{tabular}

\section{Analysis}

Content analysis was completed on all 187 ISP documents. The definitions of sexual rights were used to develop search terms (see Appendix A). A lexical search using these search terms was carried out on all ISP documents using the qualitative data software program MaxQDA. The lexical search identified paragraphs in which at least one of the search terms was present. 
The lexical search resulted in 6,185 segments being identified, of which 270 segments were found to be relevant in the context of the research questions. Selection of relevance was assessed by carefully reading the segment, determining if it was related to the research questions, and then coding it using a codebook. For example, 3,979 segments were found in the lexical search for 'relations'. Many segments in which this term was found were, however, not related to sexual relations, but rather referred to interpersonal relationships with, for example, family or friends. Search terms that included 'education', 'privacy' and 'rights' led to segments being identified that were unrelated to the topic of this study. These segments were not relevant in the context of our research questions and therefore not included in the analysis.

We identified eight themes on which segments were coded. These themes were: sexuality; sexual health; information and sexual education; developing and maintaining relationships; physical contact; parenting or the desire to be a parent; privacy; and joining an advocacy group related to sexuality. The relevant segments were then independently coded on these themes by two researchers with an agreement rate of 99\%. The researchers discussed any differences until consensus was reached. By using a structured coding system, all paragraphs were coded. The results of our analyses are shown in Table 2.

Finally, any goals that were found in ISP documents (Herps et al., 20 I 6) were read and coded as to whether they were related to the topic of the present study or not.

\section{Table 2 Quantitative results of the original lexical search}

\begin{tabular}{|c|c|c|c|c|}
\hline \multirow[b]{2}{*}{ Themes } & \multicolumn{2}{|r|}{ Results } & \multicolumn{2}{|c|}{ Relevant segments } \\
\hline & ISP documents (\%) & Hits (n) & ISP documents (\%) & $n$ \\
\hline Sexuality & $92(49.19)$ & 236 & $56(29.95)$ & 87 \\
\hline Sexual health & I I 6 (63.04) & 761 & $31(16.58)$ & 53 \\
\hline Information and sexual education & $15(8.02)$ & 17 & $4(2.14)$ & 4 \\
\hline Developing and maintaining relationships & $184(98.39)$ & 3.979 & $20(10.70)$ & 64 \\
\hline Physical contact & | | | (59.36) & 404 & $18(9.63)$ & 23 \\
\hline Parenting/ desire to be a parent & I I 5 (6 |.49) & 321 & $27(14.44)$ & 36 \\
\hline Privacy & $55(29.4 I)$ & 86 & $3(1.60)$ & 3 \\
\hline Joining advocacy groups & $10 \mid(54.01)$ & 381 & 0 & 0 \\
\hline Total & $187 *$ & 6.185 & $156(84.61)$ & 270 \\
\hline
\end{tabular}




\section{RESULTS}

\section{Relevant segments in ISP documents}

Relevant segments were found in 85.0\% $(n=159)$ of the ISP documents. In 77 ISP documents, segments related to one topic/domain/search term were found; in 54 ISP documents we found segments on two search topics; in 27 ISP documents we found segments related to three different search topics; and in I 5 ISP documents we found segments related to four different search topics.

\section{Content and nature of references to sexuality in ISP documents}

Table 3 presents the eight themes that we found, relating to demographic information of the people with ID whose files contained information related to these themes (age, gender and level of ID). The most striking findings regarding the eight themes are described below.

\section{Sexuality}

We describe the following aspects regarding sexuality: (non)sexual behaviour (a description of behavior of the individual with ID that may look sexual, but is interpreted as non-sexual behavior); sexual preferences. We also describe findings that indicate that the individual has been sexually abused. We found these results in 56 ISP documents.

\section{(non)sexual behaviour}

Eight ISP documents described how the individual expresses his or her sexual needs (in some documents we found information about more than one expression); masturbation was found in six (3.21\%) ISP documents; the use of specialised sexual service provision in one ISP document (0.53\%); and the use of porn and chat rooms in three ISP documents ( I.60\%). One ISP document described that the person had used an alternative dating service but that this has not been followed-up as his parents and group home could not agree upon it. It did not state how the person is expressing his sexual needs instead.

Furthermore, several findings relate to a description of behaviour of the individual with ID that may look sexual, but is interpreted as non-sexual behaviour. See for example these two quotes:

'The individual is aware of her body. She is not sexually active. She does like to be touched and tickled, but this carries no sexual meaning for her.' (woman, 45 years old, profound ID)

'He has a girlfriend in his group home. This is expressed in holding hands and often sitting together. He likes to cuddle; this is not something sexual for him but rather has to do with attention and attachment' (man, 52 years old, moderate ID) 


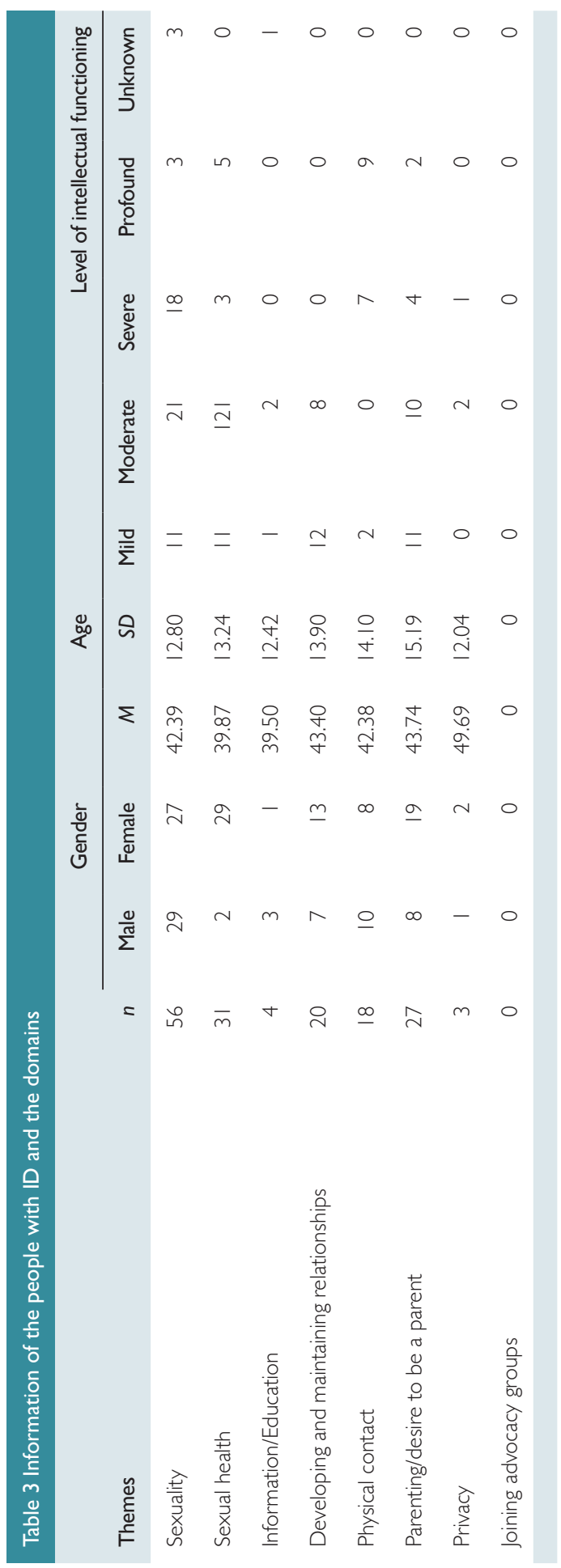


In 13 ISP documents (6.95\%), reference was found to the individual showing inappropriate or inhibited sexual behaviour. In three cases, this behaviour was linked to the individual having been sexually abused. Yet none of these ISP documents contained information about treatment or support regarding these issues, nor was there any reference to other (professional) treatment plans.

\section{Sexual preferences}

With regard to sexual diversity, two ISP documents (1.06\%) noted that the individual concerned has interest in a partner of the same sex.

\section{Sexual abuse}

In 12 ISP documents (6.24\%), reference was made to sexual abuse of the individual. Four ISP documents disclosed that sexual abuse of the individual had led to trauma. In two ISP documents, treatment of this trauma was mentioned.

'Individual has had PsychomotorTherapy in 2006 and 2007. The reason for this was a posttraumatic stress disorder stemming from alleged sexual abuse. She shows signs of impulse control disorder.' (woman, 46 years, level of ID unknown)

\section{Sexual health}

Sexual health refers to the (access to and use of) contraceptives. Table 3 shows that results were mostly found in ISP documents of women. In most instances, contraceptives were used as a remedy for premenstrual syndrome or problem behaviour during menstruation. In one ISP document it was made explicit that contraceptives were used to prevent pregnancy. In six ISP documents it was reported that the person had been sterilised.

'She occasionally fainted (see: Medical). She has had abdominal pains for a longer period of time. She has been examined, but no clear answers emerged. She kept complaining about abdominal pains, leading to adjustments in her medication and for quite a long time she used Provera. When she kept complaining about abdominal pains, she got some extra Naproxen. Finally, the gynecologist decided with her parents to operate and remove her uterus. This has been successful, she no longer menstruates and so does not suffer from abdominal pains.' (woman, 34 years old, moderate ID)

\section{Information and sexual education}

A reference to sexual education or information was found in four ISP documents (2.14\%). These were mostly statements of whether or not the person had been educated sexually, but most of these ISP documents (three) did not explain how this is relevant in current support provision or how follow-up is provided. For example: 
'He has had sexual education at school. He is interested in the other sex, age accordingly.' (man, 20 years old, level of ID unknown)

\section{Developing and maintaining relationships}

Table 3 shows that we found segments of developing and maintaining relationships in 20 ISP documents. This could be that the person with ID has expressed that he or she wants to have a boy- or girlfriend or that the person has a boy- or girlfriend. Two ISP documents reported that a legal commitment had been made. In four ISP documents it wasn't clear whether the boy- or girlfriend was a regular friend or a sexual partner.The ISP documents did not state how people with ID are supported in their relationship: they describe that the person is in a relationship and how it is expressed (e.g. by holding hands or seeing each other weekly), and only in 5 ISP documents we found minimal information about the support that is given.

'She has been in a relationship since 2003. This is a friendly relationship and sometimes they kiss. Her boyfriend is often at her flat, he often cleans it for her.' (woman, 63 years old, mild ID)

The lack of a description of support is also found in ISP documents in which the person with ID is described to be 'vulnerable' in social contacts or when he or she is in a relationship but is experiencing difficulties in this area. Most ISP documents describe this risk or problem, but do not provide an account of how support is then being provided.

'He is regarded as vulnerable and easily influenced. He easily feels pressured by others and has the need to prove himself. There is a risk that he is overburdened by his environment.' (man, 26 years old, mild ID)

$\therefore$ when they see each other and sleep together but also when they take time to do things for themselves. He finds it difficult to give his girlfriend space if she - for example - wants to go out with a friend or family member.' (man, 36 years old, level of ID unknown)

This description of the risk or problem is also found with respect to the wishes of individuals, with the exception of four ISP documents, in which a support goal was described in the area of finding a girlfriend.

\section{Physical contact}

Table 3 shows that information regarding physical contact is mostly found in ISP documents of people with severe or profound ID. It then often relates to how the individual responds to physical contact such as cuddling or during physical care. The reaction to physical contact can be interpreted as a means of making contact with others, as this citation illustrates: 'Person likes to cuddle with staff' (woman, 47 years old, severe ID), but it can also be an expression 
of affection and sexual feelings.

'He sometimes likes to have contact with other residents. He can laugh at what is happening around him, but he also seeks physical contact (with his hand) with other residents. Residents respond in different ways, depending on the moment and the person. Some people like it, and keep the physical contact, other people pull their hand back.' (man, 2 I years old, severe ID)

'He doesn't like it when you touch him a lot, for example when getting dressed and shaved. He lets you know by whining and grabbing you.' (man, 47 years old, severe ID)

\section{Parenting or the desire to be a parent}

As is shown in table 3, in 27 ISP documents we found information related to 'children', mostly of women with mild to moderate ID. In two case (1.07\%), it was reported that the person with ID has or had children. In one cases the ISP only reported that there were two children and one child died. The only information given about this child is that it lives abroad. In the other cases the ISP reported that the person with ID is mother of seven children. She sees them every two weeks. All her children have an intellectual disability and live with a foster family or in an institution.

Often, it is stated in more general terms that the person is aware of his or her disability and how this influences his or her life.

'He thinks about it sometimes, what if he didn't have this disability. How would his life be?

Would he be married and have children?' (man, 46 years old, mild ID)

One ISP document stated explicitly that the person with ID wants to be a parent and is frustrated that she is not.

'She likes her brother's children, but at the same time experiences the frustrations of not being able to raise children herself.' (woman, 36 years old, mild ID)

In one ISP document (0.53\%) it was made clear that the individual does not want to get married or have children:

'She has a boyfriend. They give each other kisses, but there is no sexual relationship. If her boyfriend talks about marriage or children, she says she does not want that.' (woman, 63 years old, mild ID)

\section{Privacy}

Three ISP documents (1.60\%) provided information on privacy in relation to sexuality. 
'She does not talk about sexual feelings, she finds this private. She does however talk and giggle about cuddling and kissing with X.' (woman, 64 years old, moderate ID)

'He needs guidance in order to respect the privacy of others. It has happened that the privacy of other group members was violated. This was caused by his disability and/or sexual needs.' (man, 42 years old, severe ID)

\section{Joining an advocacy group regarding sexual rights}

No segments were found regarding the wish to meet up or join an interest or advocacy group regarding sexual rights. In 30 ISP documents ( $6.04 \%$ ), all from one service provider organisation, a standard reference was made: "She/he can not stand for her/his own rights and interests".

\section{Provision of professional support}

As is described throughout the results, little information about the attitude of staff and the use of sexual education, treatment or other support strategies was found in the ISP documents. In only eight ISP documents (4.28\%), was the attitude of staff with regard to sexuality described. Reference to the use of interventions or programs regarding sexuality was not found in any of the ISP documents.

'She can 'test' new people to see how they react. For example, taking her shirt off in a public area. This rarely happens now. She does say things like: "I wet my pants" or "I don't feel so good" (when this is not true). Respond casually on this, change the subject or ignore it. That is the best way to deal with it. If you stick to this for a few weeks, this behaviour will fade away.' (woman, 27 years old, mild ID)

In working with her you need to take into account that she has had bad experiences with men. It is therefore inappropriate for a male to provide support in this area. In supporting her, you should also take her vulnerability into account. Support staff should listen to her talking about her relationship and the feelings she has about this. Support staff need to help her in realising her dream of living together with someone. It is important to keep the relationship with her father and family a subject of conversation.' (woman, 43 years old, mild ID)

Support goals describe the areas in which and the way in which support is provided. A total of 475 goals were found in the 187 ISP documents. Four of these goals $(0.84 \%)$ concerned sexuality or (intimate) relationships, see for example this goal:

I want to build my relationship with S. I want to explore the possibilities of getting married or living together. I need support to stand up for myself and make my own choices (in my 
relationship).' (man, 56 years old, mild ID)

\section{CONCLUSIONS}

In this study, we examined ISP documents of people with ID using residential support services in the Netherlands. We were interested in the extent to which 'sexual health' and 'sexual rights' were mentioned in ISP documents; what subjects or issues regarding sexuality were covered; and how support is being provided to people with ID regarding aspects related to sexual health and sexual rights. To our knowledge, no such study has been carried out before.

With respect to the extent to which sexual health and sexual rights were found in ISP documents, we found that $85 \%$ of the ISP documents provided information in this area. This high number may be the result from Dutch policy requiring that sexuality is addressed in ISP documents (Herps et al., 2016).

Most often, information in the ISP documents regarding sexuality-related topics were sexuality (sexual or non-sexual behaviour, sexual abuse, sexual preferences), sexual health, and parenting / desire to be a parent. This concerns a limited number of parts of the overall concept of sexuality and sexual rights.

In ISP documents, there should be congruence between the individual's support needs and the support agreements and goals that are set (Thompson et al., 2009). The third research question concerned how support is being provided on sexual health and sexual rights. The results of the present study show that there is a large discrepancy between the amount of information that describes aspects of sexuality of individuals with ID, and the amount of support strategies, agreements or goals in this area. We found little references to counselling or indications for support provision in instances of negative sexual experience or abuse (Abbott \& Howarth, 2005; Hollomotz, 2008). Furthermore, little reference was made to the use of sex education programs or other interventions related to sexuality and relationships (Löfgren-Mårtenson, 2012; Schaafsma et al., 2013, 2015).

There are several possible explanations for the lack of support goals or strategies regarding sexuality being found in the ISP documents. First, it is possible that the individual with ID or their relatives do not want this to be written in the ISP document. Herps et al. (2013) reported that people with ID prefer negative life experiences not to be included in the ISP document. However, this does not fully explain the high number of ISP documents that did describe aspects related to sexuality did not include an account of support in this area. Another possibility is that more information can be found in individual treatment plans or medical files, for example when sexual abuse has led to trauma, or with regard to the moti- 
vation for using contraceptives or performing sterilisation. Though we did not find reference to such files, this does not mean that they do not exist. Third, previous research has shown that support staff can feel inhibited in talking about this subject (Abbott \& Howarth, 2007; Richards et al., 2009) and that family members and other support providers set different norms for themselves (or other people without disabilities) than for people with ID (Christian, Stinson \& Dotson, 2002; Yool, Langdon \& Garner, 2003; Swango-Wilson, 2008). The results of our study show that sexuality is being talked about, but it may well be that staff feels inhibited in making agreements about supporting the individual in this area or that differences in opinions and attitudes is reflected in the absence of specific support agreements (Christian, Stinson \& Dotson, 2002; Yool, Langdon, \& Garner, 2003; Swango-Wilson, 2008; Schaafsma et al., 2013, 2014,2015). A lack of support agreements in the area of sexuality may result in people with ID not being able to exercise their sexual rights, to satisfy their needs or for them to feel less able to talk about it.

It is important to note, when interpreting the results of this study, that a lack of information regarding sexuality in the ISP documents does not necessarily reflect a lack of support with respect to sexuality in daily practice. Paper plans do not necessarily reflect the individual's life in the fullest, and previous studies indicate that developing ISP documents can be a rather bureaucratic exercise, which is done simply because it is required (Mansell \& Beadle-Brown, 2004; Osgood, 2007; Herps et al., 2016).

\section{Implications for providing professional support}

The results of our study have at least three important implications for providing professional support to people with ID in relation to sexuality. First, sexuality, sexual health and sexual rights are important subjects to talk about with people with ID. It should be part of the support needs assessment that addresses the individual's needs and wishes (Thompson et al., 2009; Schaafsma et al., 20 17). Second, talking about sexuality, specifically with people with ID, is not easy for many people (Abbott \& Howarth, 2007; Stoffelen et al., 20 I 3; Schaafsma et al., 20 17; Richards et al., 2009). Not only the individual support staff should be provided with support to talk about sexuality and other sensitive topics with people with ID, their relatives and their colleagues. The whole system (government, schools, agencies, advocacy groups, families) should be set up to create respect and recognition of rights for the sexuality of people with an intellectual disability (Richards et al., 2009). Third, sexuality is a subject that needs more attention. Individuals with ID, their relatives, and staff need to be given guidance on how to address this subject in a respectful manner: by talking about it in a way that takes into account the vulnerability and sensitivity of the individuals involved, by increasing knowledge about the topic, and by increasing the support available in this area. Furthermore, the wishes of people with ID should determine the strategy of support. The search for the cause and meaning of behaviour, must be leading for professional support providers. And 
assuming that every human being is a sexual being, professional support providers need to be more sensitive about behaviour, whether or not it is sexual. An open mind is required instead of acting from their own standards and values. We endorse the view of Richards et al. (2009). They advocate a holistic approach 'in which all systems and supports work cohesively, simultaneously, seamlessly, and in harmony to ensure that persons with developmental disability achieve equality in sexual rights'.

\section{Strengths and limitations of this study}

When interpreting the results, the following strengths and limitations should be considered.A relative strength of the present study is the number of ISP documents we analysed, and the fact that these were sourced from different service provider organisations. In the Netherlands, every service provider organisation develops and implements their own ISP procedures and forms. When the protocol of the ISP document does not mention the topic 'sexuality', the chances are that it gets forgotten or ignored. By including different organisations in this study, we incorporated different kinds of forms, and, in doing so, reduced the chance of potential biases influencing the data.

There are also several limitations in this study. First we used only one source in this study: ISP documents. The results raise different questions which could have been answered if other sources were used, e.g. interviews with people with ID, their family and staff. The use of other sources such as medical documents can also provide more information. This would be interesting for further research.

This is the first article that looked into how sexuality is described in ISP documents. The study was exploratory and as such, did not focus on finding differences between groups within this set of data. However, further research could be done to explore the results in more depth by examining differences in gender, age and level of ID.

As described above, future research that involves multiple sources and analysis of differences between groups could be done to get a better understanding of sexuality in ISP documents. Furthermore, international comparison is recommended. It contributes to a better understanding of sexuality of people with ID and their quality of live, to compare how sexual health and sexual rights are addressed in ISP in other countries. And finally, it would be interesting to investigate the whole system of government, schools, agencies, advocacy groups, families, and their vision, role and opportunities on sexuality of people with an intellectual disability. 


\section{Recommendations}

The ISP document should be a document that can be used as a practical guide to put into practice the wishes and preferences of individuals with ID, also in relation to sexual health. It's important to talk to people with ID and taking their views seriously to find out what place and value sexuality has in their lives, what specific support they need and wish for, and to practice the concept of shared decision-making. As such, we recommend the use of clear language and the setting out of realistic and achievable goals, alongside a description of the type of support needed and how this should be achieved. Because the ISP is personcentered, the person with ID and people important to him or her, should be involved in decision making. The whole ISP document should reflect that serious consideration has been given to sexuality -including different aspects of sexual rights, the need for proactive sex education, and how goals related to this can be implemented. 


\section{REFERENCES}

AAIDD (2008). Sexuality. Joint Position Statement of AAIDD and The Arc. Retrieved May 20, 20 I 6, from https://aaidd.org/newspolicy/policy/position-statements/sexuality

Abbott D. \& Howarth J. (2005). Secret loves, hidden lives? Exploring issues for people with learning difficulties who are gay, lesbian or bisexual. Bristol:The Policy Press.

Abbott D. (2013). Nudge, nudge, wink, wink: love, sex and gay men with intellectual disabilities - a helping hand or a human right? Journal of Intellectual Disability Research, 57, 1079- 1087.

Bartholomew Eldredge L.K., Markham C.M., Ruiter R.A.C., Fernandez, M.E., Kok G., \& Parcel, G.S. (2016). Planning Health Promotion Programs: An Intervention Mapping Approach, 4th Edition. San Francisco: Jossey-Bass.

Bernert, D. (201 I). Sexuality and disability in the lives of women with intellectual disabilities. Sexuality and Disability, 29, I29- |41.

Christian L., Stinson J., \& Dotson L.A. (2002). Staff values regarding the sexual expression of women with development disabilities. Sexuality and Disability, 19, 283-292.

Eastgate G., Van Driel M.L., Lennox N., \& Scheermeyer E. (201 I) Women with intellectual disabilities. A study of sexuality, sexual abuse and protection skills. Australian Family Physician, 40, 226-229.

Frawley P., \& Bigby C. (2014). "I'm in their shoes": Experiences of peer educators in sexuality and relationship education. Journal of Intellectual \& Developmental Disability, 39, 167-176

Hayashi M., Arakida M., \& Ohashi K. (201 I). The effectiveness of a sex education program facilitating social skills for people with intellectual disability in Japan. Journal of Intellectual \& Developmental Disability, 36, 1 I - 19.

Healy E., McGuire B.E., Evans D.S., \& Carley S.N. (2009). Sexuality and personal relationships for people with an intellectual disability. Part I: Service-user perspectives. Journal of Intellectual Disability Research, 53, 905-912.

Herps M. A., BuntinxW. H. E., \& Curfs L. M. G. (20I3). Individual support planning: perceptions and expectations of people with intellectual disabilities in The Netherlands. Journal of Intellectual Disability Research, 57, 1027-1036.

Herps M.A., Buntinx W.H.E., \& Curfs L.M.G. (20I6). Individual support planning with people with ID in The Netherlands: official requirements and stakeholders' expectations. ALTER - European Journal of Disability Research/Revue Européenne de Recherche sur le Handicap, 10, 281-288.

Herps M. A., Buntinx W. H. E., Schalock R. L., Breukelen G. J. P.Van, \& Curfs L. M. G. (20 I 6). Individual support plans of people with intellectual disabilities in residential services: content analysis of goals and resources in relation to client characteristics. Journal of Intellectual Disability Research, 60, 254-262.

Hickson L., Khemka I., Golden H., \& Chatzistyli A. (2008). Profiles of women who have mental retardation with and without a documented history of abuse. American Journal on Mental Retardation, I 13, I33-142.

Hollomotz A. (2008). 'May we please have sex tonight?'- people with learning difficulties pursuing privacy in residential group settings. British Journal of Learning Disabilities, 37, 91-97.

Hollomotz A. (201 I). Learning Difficulties And Sexual Vulnerability. A Social Approach. London: Jessica Kingsley Publishers.

Ignagni E., Schormans A., Liddiard K., \& Runswick-Cole K. (2016). 'Some people are not allowed to love': intimate citizenship in the lives of people labelled with intellectual disabilities. Disability \& Society, 31, | 3 |- 135.

International Planned Parenthood Federation (2003). IPPF Charter on Sexual and Reproductive Rights. London.

ISBN 086089 I 09 7. https://www.sm.ee/sites/default/files/content-editors/eesmargid_ja_tegevused/Tervis/Tervislik_eluviis/ ippf_charter_srh_rights_2003.pdf 
Kelly G., Crowley H., \& Hamilton C. (2009). Rights, sexuality and relationships in Ireland: 'It'd be nice to be kind of trusted'. British Journal of Learning Disabilities, 37, 308-315.

Leutar Z. \& Mihoković M. (2007). Level of knowledge about sexuality of people with mental disabilities. Sexuality and Disability, 25, $93-109$.

Löfgren-Mårtenson L. (20।2). "I Want to Do it Right!" A Pilot Study of Swedish Sex Education and Young People with Intellectual Disabilities. Sexuality and Disability, 30, 209-225.

Mansell J. \& Beadle-Brown J. (2004). Person-Centred Planning or Person-Centred Action? Policy and Practice in Intellectual Disability Services. Journal of Applied Research in Intellectual Disabilities, 17, 1-9.

McCarthy M. (2009). 'I have the jab so I can't be blamed for getting pregnant': Contraception and women with learning disabilities. Women's Studies International Forum, 32, 198-208.

McGuire B.E., \& Bayley A.A. (20I I). Relationships, sexuality and decision-making capacity in people with an intellectual disability. Current Opinion in Psychiatry, 24, 398-402.

Murphy G.H., O'Callaghan A. C., \& Clare I.C.H. (2007). The impact of alleged abuse on behaviour in adults with severe intellectual disabilities. Journal of Intellectual Disability Research, 51, 741-749.

Nussbaum M.C. (2014). Mogelijkheden scheppen. Een nieuwe benadering van de menselijke ontwikkeling. [Creating Capabilities. The Human Development Approach]. Amsterdam: Ambo/Anthos uitgevers.

O'Callaghan A.C., \& Murphy G.H. (2007). Sexual relationships in adults with intellectual disabilities: understanding the law. Journal of Intellectual Disability Research, 51, 197-206.

Osgood, T. (2005). Managing the tensions between the interests of organisations and service users. In P. Cambridge \& S. Carnaby (Eds.), Person centred planning and care management with people with learning disabilities (pp. 5 I-64). London: Jessica Kingsley Publishers.

Reiter S., Bryen D.N., \& Shachar I. (2007). Adolescents with intellectual disabilities as victims of abuse. Journal of Intellectual Disabilities, 11,371-387.

Richards D., Miodrag N.,Watson S.L., Feldman M., Aunos M., Cox-Lindenbaum D., \& Griffiths D. (2009). Sexuality and Human Rights of Persons with Intellectual Disabilities. In: Challenges to the Human Rights of People with Intellectual Disabilities (eds F. Owen \& D. Griffiths), pp. 184-219. Jessica Kingsley Publishers, London and Philadelphia.

Robertson J., Emerson E., Hatton C., Elliott J., Mcintosh B., Swift P., ... Associates H. S. (2007). Person-centred planning : factors associated with successful outcomes for people with intellectual disabilities. Journal of Intellectual Disability Research, 5 I, $232-243$.

Schaafsma D., Kok G., Stoffelen J.M.T., \& Curfs L.M.G. (20/3). People with intellectual disabilities about sexuality: important implications for the development of sex education. Journal of Applied Research in Intellectual Disabilities, 26, 157-I66.

Schaafsma D., Kok G., Stoffelen J. M.T., van Doorn P., \& Curfs L. M. G. (20।4). Identifying the important factors associated with teaching sex education to people with intellectual disability: A cross-sectional survey among paid care staff. Journal of Intellectual and Developmental Disability, 39, 157-166.

Schaafsma D., Kok G., Stoffelen J.M.T. \& Curfs L.M.G. (20I5). Identifying Effective Methods for Teaching Sex Education to Individuals with Intellectual Disabilities: A Systematic Review. Journal of Sex Research, 52, 4 I2-432.

Schaafsma D., Kok G., Stoffelen J. M.T., \& Curfs L.M.G. (20 I7). People with intellectual disabilities talk about sexuality: implications for the development of sex education. Sexuality and Disability, 35, 21-38.

Schalock R. L., Keith K. D., Verdugo M. A., \& Gomez L. E. (20।0). Quality of life model development and use in the field of intel- 
lectual disability. In: Quality of life:Theory and implementation (eds. R. Kober), pp. 17-32. Sage: New York.

Schwartz A. A., Holburn S. C., \& ]acobson J.W. (2000.) Defining Person Centeredness: Results of Two Consensus Methods. Education and Training in Mental Retardation and Developmental Disabilities, 35, 235-249.

Stancliffe R. J., Hayden M. F., \& Lakin K. C. (1999). Effectiveness and Quality of Individual Planning in Residential Settings: an Analysis of Outcomes. Mental Retardation, 37, 104-1 16.

Stainton T. \& Clare I. C. H. (20I2). Human rights and intellectual disabilities: an emergent theoretical paradigm? Journal of Intellectual Disability Research, 56, 1011-1013.

Stoffelen J., Kok G., Hospers H., \& Curfs L.M.G. (2013) Homosexuality among people with a mild intellectual disability: an explorative study on the lived experiences of homosexual people in the Netherlands with a mild intellectual disability. Journal of Intellectual Disability Research, 57, 257-267.

Swango-Wilson A. (2008). Caregiver perception of sexual behaviours of individuals with intellectual disabilities. Sexuality and disability, 26, 75-81.

Thompson J. R., Bradley V. J., Buntinx W. H. E., Schalock R. L., Shogren K. A., Snell M. E., .. Yeager M. H. (2009) Conceptualizing supports and the support needs of people with intellectual disability. Intellectual and Developmental Disabilities, 47, I35-46.

Tuffrey-Wijne I., Bernal J., Butler G., Hollins S., \& Curfs L. M. G. (2007) Using Nominal Group Technique to investigate the views of people with intellectual disabilities on end-of-life care provision. Journal of Advanced Nursing, 58, 80-9.

Van Berlo W., De Haas S., Van Oosten N.,Van Dijk L., Brants S., Tonnon S., \& Storms O. (20I I). Beperkt weerbaar. Een onderzoek naar seksueel geweld bij mensen met een lichamelijke, zintuiglijke of verstandelijke beperking [Sexual violence among individuals with a physical, sensory, or intellectual disability]. Utrecht: Rutgers WPF.

UNCRPD (2006). Convention on the Rights of Persons with Disabilities. New York. http://www.un.org/disabilities/convention/conventionfull.shtml

Wagemans A., van Schrojenstein Lantman-de-Valk H., Tuffrey-Wijne I.,Widdershoven, G., \& Curfs L. (20।0). End-of-life decisions: An important theme in the care for people with intellectual disabilities. Journal of Intellectual Disability Research, 54, 5I 6-524.

Watson S.L.,Venema T., Molloy W., \& Reich M. (2002). Sexual rights and individuals who have a developmental disability. In: Ethical dilemmas: sexuality and developmental disability (eds. D.M. Griffits, D. Richards, P. Fedoroff \& S.L. Watson), pp. 19-53. New York: NADD Press.

Williams V., \& Robinson C. (2000). "Tick this, Tick that": The views of people with learning disabilities on their assessments. Journal of Intellectual Disabilities, 4, 293-305.

World Association for Sexual Health (2014). Declaration of Sexual Rights. http://www.worldsexology.org/wp-content/ uploads/2013/08/declaration_of_sexual_rights_sep03_2014.pdf

World Health Organization (2015). Sexual health, human rights and the law. Geneva:WHO. http://apps.who.int/iris/ handle//0665/175556

Yool L., Langdon P.E., \& Garner K. (2003). The attitudes of medium-secure unit staff toward the sexuality of adults with learning disabilities. Sexuality and Disability, 21, 137-151. 
Appendix A. Search terms based on three definitions of sexual rights (table I)

\section{Common subjects in the three documents on sexual rights (table I)}

The right to life

The right to equality, be free of discrimination

The right to sexual health care

The right to information and education

The right to bodily integrity

The right to choose their partner, to choose whether or not to marry (based on equality and consensual)

The right to privacy

The right to be sexually active or not

The right to decide whether or not, and when, to have children

The right to pursue a satisfying, safe and pleasurable sexual life

The right to the freedom of thoughts, opinions, and expression

The right to enjoy the benefits of scientific progress and its application

The right to be free from torture, violence and coercion

The right to freedom of assembly and political participation

The right ro access to justice, remedies en redress

Search terms related to*

Search terms*

Safety

Sexual freedom, homosexuality, sexual diversity

sexual health; treatment; contraceptives.

Sexual information; eduction; training

Touching; stroking; setting boundaries

Partner; boyfriend/girlfriend; dating; relationship; marriage; friend.

Privacy

Sexually active

Children

Sexual satisfied, safe sex and sexual pleasure,

Sexual fantasies, sexual desires, sexual expression

Sexual research

Sexual abuse, sexual violence, sexual coercion

Advocacy group

Sexual abuse, declaration seks* ${ }^{*}$, sex $^{*}$

seks* ${ }^{*}, \mathrm{se}^{*}$

voorbehoed*, pil, condoom*, sterilisatie, spiraal*

(contraceptive, contraceptive pill, condom, sterilization, contraceptive coil)

voorlichting, educatie

(information, education)

lichaam*, aanraken

(body, contact)

vriend*, partner, man, vrouw, verkering, relatie, trouwen (friend, partner, man, woman, engagement, relation, marriage)

priv*

seks* ${ }^{*}, \mathrm{sex}^{*}$

kind* (child)

seks* ${ }^{*}, x^{*}$

seks* ${ }^{*}$, sex $^{*}$

seks* ${ }^{*}, \mathrm{se}^{*}$

seks* ${ }^{*}, \mathrm{sex}^{*}$

belangen* (interests)

seks* ${ }^{*}, x^{*}$

*The terms that were used were the Dutch words and synonyms. 

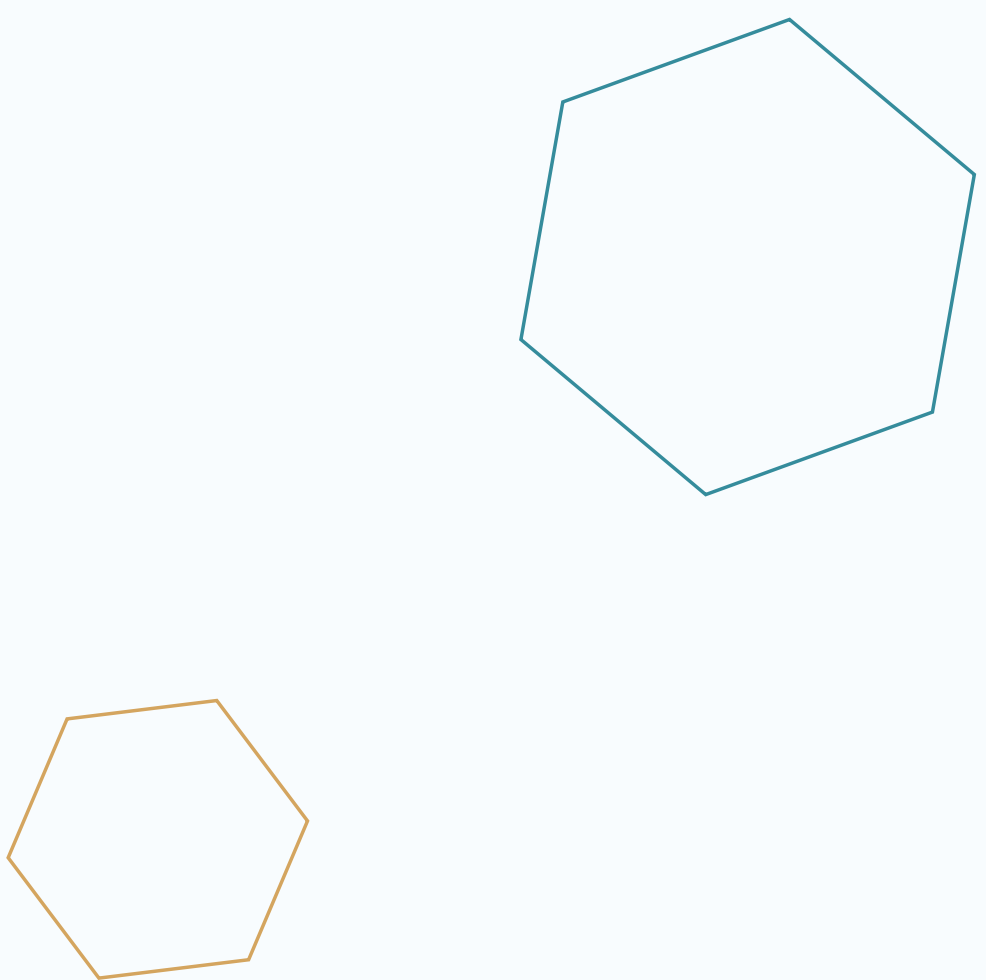


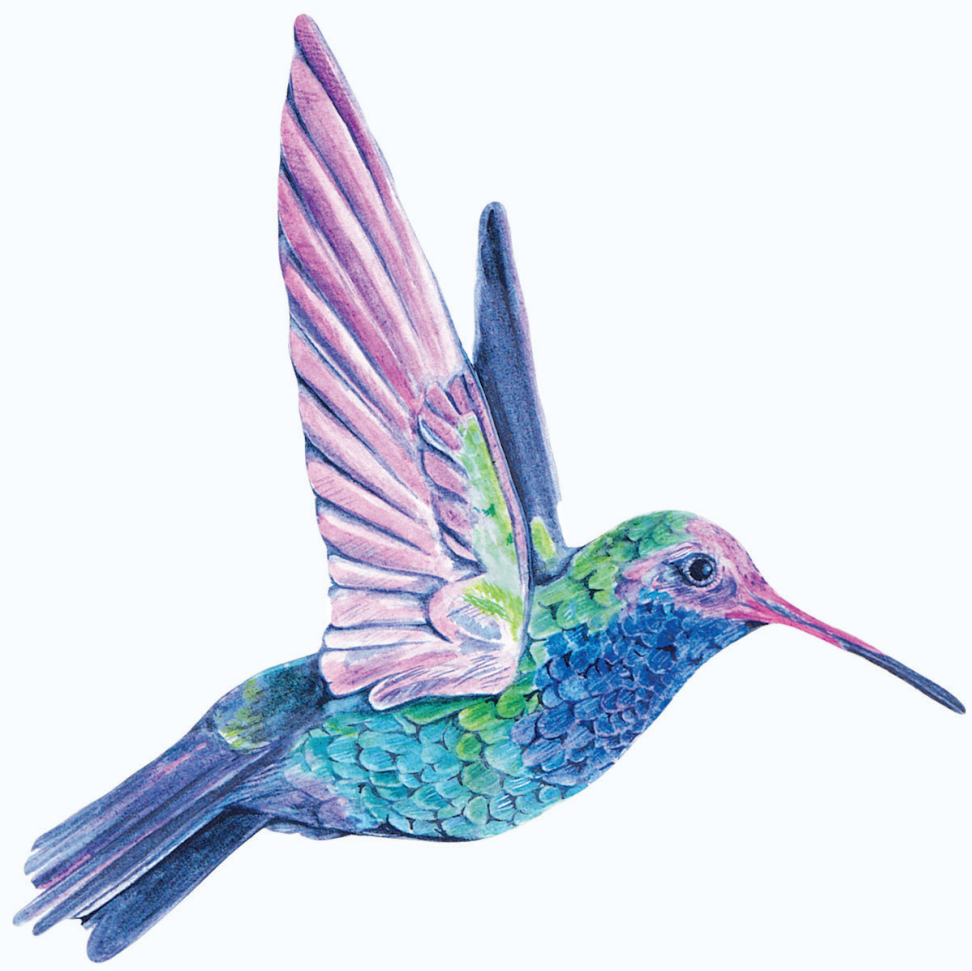

Chapter 7

Discussion 



\section{INTRODUCTION}

Individual support planning (ISP) is regarded as a key factor in professional and personcentred support for people with intellectual disabilities (ID). In the Netherlands, the Chronic Care Act requires that service provider organisations develop and implement ISP for each of their service users as a way of enhancing person-centred support. In this thesis, we aimed at improving our understanding of how ISP functions in practice and how it impacts on support processes. This thesis consists of three parts, each addressing a different area of ISP practice. The first part focuses on nationwide ISP policy and stakeholders' expectations regarding ISP.The second part focuses on ISP use in daily practice and the third part examines the content of ISP documents. This chapter draws on five studies that we conducted to address the following research questions (explained in chapter I):

\section{ISP policy}

I. What are the formal requirements impacting on ISP content and procedures formulated in Care Acts and national policy documents, and what are the expectations of stakeholders such as self-advocate organisations, the Dutch Association of Service Providers, quality management officers working for ID service providers and legal advisers specialised in Care Acts regarding ISP in the Netherlands? (chapter 2)

\section{ISP in daily practice}

2. What are experiences and expectations of persons with ID with respect to their ISP? (chapter 3)

3. What are barriers and facilitators to ISP goal attainment? (chapter 4)

\section{Content of the ISP document}

4. What are ISP features with respect to the number and content of goals and the nature of support resources in relation with client characteristics? (chapter 5)

5. How is sexuality addressed in ISP documents? (chapter 6)

This final chapter presents and discusses the main findings of these studies. It then highlights implications and recommendations for future research, policy and practice, before drawing final conclusions. 


\section{PRESENTATION AND DISCUSSION OF THE MAIN FINDINGS}

\section{ISP policy \\ Formal requirements}

Policies on high quality ID care and support are developed by a range of organisations, including legislative bodies, budget allocation agencies, the Healthcare Inspectorate and Dutch Association of Service Providers (VGN). These organisations develop requirements that must be met by service providers in their ISP practices. To explore these requirements, we studied relevant Care Acts and policy documents. We identified requirements relating to ISP content and procedures, person-centredness and ISP policy (as developed by service providers).

With respect to content, the Exceptional Medical Expenses Act (which was active during this study) demands that the ISP document sets out the needs and wants of the individual, their support goals, the agreements on resources and strategies that will be used and, finally, a named person in provider organisation who is responsible for the individual's ISP.The Healthcare Inspectorate adds that the ISP document should set out the diagnosis, strengths and weaknesses, an overview of medication, the use of restrictive interventions and a risk analysis. The VGN quality framework requires that the subject of sexuality should be addressed in the ISP document. Budget allocation agencies, the VGN and the Healthcare Inspectorate require that the individual with ID should agree with the content of the ISP document.

When it comes to ISP procedures, it is required that the person with ID is involved in developing the ISP, that the ISP follows a Plan-Do-Check-Act cycle, and that the ISP document is reviewed each year. The Healthcare Inspectorate adds that a multidisciplinary team should be involved.

Care Acts, the VGN and budget allocation agencies also set requirements of organisational ISP policy. Care Acts state that ISP should form part of the individual's wider file, which should also contain elements including administrative information and treatment plans. The VGN and budget allocation agencies require each organisation to have an ISP policy document that is reviewed regularly.

With respect to person-centredness, Care Acts require ISP documents to be understandable to the person with ID and state that he or she should be actively involved in all components of the ISP process. People with ID must also have access to their ISP and should be 'in control' - having choices with respect to its content and procedures. Similarly, the Healthcare Inspectorate and VGN require the person with ID to be actively involved in all ISP components. 


\section{Consulting stakeholders}

After exploring official requirements, we asked key people at self-advocate organisations, VGN representatives, quality management officers working at service provider organisations and specialised legal advisors what they find important in working with ISP, and for their expectations regarding ISP.As well as confirming the importance of the official requirements, they expected organisations to do the following in their ISP policy: (I ) develop a vision on ISP that guides ISP procedures and format; (2) protect the privacy of people with ID; (3) clarify who is responsible for ISP procedures within an organisation. They also added requirements related to person-centredness of ISP: (4) ensure that the annual review meeting is based on equality between the individual, their representatives and professionals; (5) inform the person with ID about the development and evaluation of ISP policy; (6) provide the individual with a copy of their ISP document (either that it is in their possession or through having direct access to it); (4) consider the individual in the context of his/her social network.

There are at least three implications that come with these requirements. First, meeting requirements can become a priority for service provider organisations, especially since not meeting requirements of the Healthcare Inspectorate and the budget allocation agencies can lead to being placed 'under surveillance' or risking a budget cut. This could lead to the ISP document becoming used as proof that requirements are being met, rather than a tool for individual support, and thus becoming a bureaucratic exercise.

Second, because requirements change frequently (for example, budget allocation agencies and the VGN change or renew their policy and ISP requirements yearly) and stakeholders add 'new' requirements to ISP, service providers face the challenge of keeping up with current requirements and demands, and implementing them while maintaining workable ISP procedures. Implementing requirements in practice takes time, and there is a risk of service providers losing focus on current ISP requirements.

Third, requirements are set at a high level for a defined group: people with ID using professional services. However within this 'group' there is enormous diversity and variation. Tensions arise when individual preferences, circumstances or needs require adaptability from service provider organisations in form, processes and content of the ISP, since organisations are inclined to standardise support delivery (Claes et al., 20 I0; Kinsella, 2000; Osgood, 2005) This adds to the risk of ISP becoming a paper exercise with a main focus on requirements rather than on the people being supported. 


\section{ISP in daily practice}

\section{Experiences and expectations of people with ID}

Chapter three (research question 2) describes the experiences and expectations of 61 people with ID with regard to their ISP.The majority (69\%) found their ISP important, saying it ensures that the agreements are written down, it keeps everything together, and serves as a tool to remember what to work on. However, others were not well informed about the aims, procedures, roles and content of ISP, and this prevented people from participating actively and meaningfully. As a result, these people regarded ISP as the business of 'professionals' with no added value to the quality of their own life. This is in line with previous research finding that people with ID have little control over ISP procedures and formats (Carnaby, 1997; Crocker, 1990; Williams \& Robinson, 2000). The interviews further revealed issues with respect to the development, evaluation and ISP document.

\section{Involvement in development and evaluation}

Multidisciplinary meetings are held to evaluate current ISP documents and to set new goals and agreements for the coming year. The majority of people we interviewed (57\%) were present at this meeting. However, staff decide when and where the meeting is held, who attends it and what is discussed. As a result, it is possible that topics are discussed without the person with ID knowing why, such as traumatic past experiences. This makes it difficult for people with ID to participate in the meeting. Furthermore, they often experience difficulties with communication or reading, so ensuring that people can actively participate in the meeting may require some adjustments. However, our research revealed that little effort is made to meet these needs. This leads to people with ID being present at the meeting, but not feeling, or being, actively involved.

A quarter of the respondents are not present at the meeting but are involved in other ways. For example, a person might be invited to talk to their direct support staff, who can then use the conversation as input for the multidisciplinary meeting, or they might answer a standardised questionnaire. Our research found that I8\% of people with ID believed they had not been involved in developing and evaluating their ISP.

Issues with active and meaningul involvement of people with ID have been described in previous literature. For example, Carnaby (1997) found that people with ID did not know the purpose of the ISP meeting, and that many found it an uncomfortable experience. Williams \& Robinson (2000) found similar results, with people with ID having difficulties understanding the meeting and finding it disempowering. 


\section{The ISP document}

One-third of the informants had direct access to their ISP documents. For the remainder, the ISP document was either physically inaccessible (the document is usually kept in staff offices or in electronic reports that only staff have access to) or inaccessible because of the language used, with little effort made to avoid jargon or, for people with difficulty reading, to use alternative communication techniques. Those who did access their documents reported often finding irrelevant or old information in ISP documents, and were unclear why this was, or how to change it.

The ISP document is not often used in the regular meetings or conversations between support staff and people with ID. As a result, people only see their ISP document during the formal evaluation meetings. Lack of access to the ISP documents, and thus the support agreements, prevents people with ID to fully participate in ISP implementation and followup of the agreements. Lotan \& Ells (2010) describe this phenomenon as an 'asymmetrical relationship' and warn about the impact that this can have on support and decision making, as it can hinder (although very subtly and unintentionally) the extent to which the person truly agrees with decisions or makes choices.

\section{Barriers and facilitators to ISP goal attainment}

In chapter 4 (research question 3), we describe a study on barriers and facilitators in ISP goal attainment. In this study, we analysed I 0 I goals, identified in 34 ISP documents, through semistructured interviews with staff. Participants were asked whether the goal was achieved and the reason for their answer. Based on literature on ISP effectiveness and goal-setting theory, we also showed the participants statements related to goal quality, individual characteristics, staff characteristics and resources, and we asked them to rate the extent to which these applied to each specific goal.

The results showed that $41 \%$ of the goals were achieved within the allotted timeframe of the goal (one year). Success in attaining a goal was related to the quality of that goal. This meant that goals that were 'technically adequate' were achieved more often than goals that were not. The participants also identified the greatest barrier in goal attainment as being the person with ID, and their complexity of their needs. This finding indicates that individual differences could exist with respect to the use and effectiveness of goal setting.

In present policy, goal setting is a mandatory aspect of ISP, and it is questionable whether goal setting can still be effective when it becomes routine, or 'care as usual' (Locke \& Latham, 20 I3). More insight is needed into these differences and into what parameters need to be in place for goal setting to be effective. This could also entail competences of staff. It also adds to existing criticism on mandating standardised ways of individualised planning for all 
people with ID (Mansell \& Beadle-Brown, 2004; Osgood, 2005; Smull \& Lakin, 2002), or even all people who fall under the reach of the Chronic Care Act.

\section{Content of the ISP document}

The final two studies in this thesis addressed more closely the content of ISP documents. Chapter 5 (research question 4) described a study that looked into general characteristics of ISP documents and explored which quality of life domains are associated with ISP goals, which resources were used, and how domains and resources are related to demographic characteristics of service users. For the final study in this thesis, we analysed the content of ISP documents for information about sexuality (research question 5, chapter 6).

\section{ISP features}

With respect to ISP features, we looked at the number of pages and the number of goals. The ISP documents we studied (chapter 5) varied in length from three to 76 pages, with an average of 17 A4 pages. The difference in length could not be explained by individual characteristics of the person with ID (such as age or complexity of need). Instead, it related only to the service provider's rules and procedures.

The number of goals per ISP document ranged from 0 to II, with I4\% of the documents not specifying any goals at all. This finding was striking, since it is legally required that ISP documents describe the support goals and agreements to achieve these goals (chapter 2). Instead, these ISP documents provided only administrative and descriptive information about the individual and his or her functioning. These findings indicate that service providers differ in their interpretation of what constitutes an ISP, and that the ISP document is often used to store information that should be saved elsewhere in the individual's file.

\section{Goal domains}

In the sample, most goals $(31 \%)$ in the ISP documents relate to the quality of life domain of 'physical well-being' and a small portion of goals (0.8\%) referred to the domain of 'rights'. Goals related to physical well-being were found more often in the ISP documents of people with profound ID and older people.

It is known that the chance of physical problems increases with age and that people with severe or profound ID often have more and more severe physical problems (Havercamp \& Scott, 2014; Hermans \& Evenhuis, 2014; Schoufour et al., 2013). The focus on physical wellbeing is therefore not surprising, although other quality of life domains are also important and need attention (see, for example, Maes, Lambrechts, Hostyn, \& Petry, 2007). Goals related to independence and social participation were more often found in ISP documents of people with mild-to-moderate ID. 


\section{Support resources}

Support resources can include: the person's own competences; social network of family and friends; informal support such as neighbours, colleagues and volunteers; generic agencies; and finally, specialised services. Achieving ISP goals may involve pulling all these resources together. However, we found that the resource most frequently referred to in achieving the goal was specialised services. In $43 \%$ of all goals, a specialised service was the only support resource, while $26 \%$ of the goals cited a combination of specialised services and natural resources (such the social networks and informal support) as achieving the ISP goals. In 31\%, achieving the goals involved the use of natural and generic resources.

The emphasis on specialised services as a main support resource can be explained by the definition of ISP being used in the Netherlands. Based on health care law, Dutch ISP documents describe support goals and agreements as being between the service user and the support provider.This is based on a view of support as being provided solely by professional organisations. However, in current thinking, support is regarded as strategies and resources to enhance personal outcomes using multiple resources, including the person's social network and generic as well as specialised resources (Schalock et al., 2010). This calls for a shift in thinking. While in the past, 'support teams' may have comprised only of paid care professionals, today theyare becoming dynamic groups of professionals and non-professionals, working together to providing the support needed.

\section{Sexuality}

Sexuality is an important aspect of life, and people with ID have sexual needs, wants and rights just as anyone else. We explored the extent to and the way in which sexuality is addressed in ISP documents and found that $85 \%$ of the ISP documents mentioned one or more aspects related to sexuality. This finding was unexpected, as previous research showed that staff members have difficulties talking about sexuality with people with ID (Abbott \& Howarth, 2005). However, Dutch policy states that sexuality is a mandatory item of the ISP document, as shown in chapter 2 , and in this light, this result is less surprising.

The information in ISP documents related mostly to starting or maintaining a relationship.The ISP documents contained very little goals or references to treatment on this topic, indications for support provision in instances of negative sexual experience or abuse, or references to sex education programmes or other interventions. The gap between the quantity of sexualityrelated information included in the ISP document and the small number of support goals or agreements found in the same documents raises questions as to why, or for whom, that descriptive information is included at all. This supports the findings of our study described in chapter 5, where we noted that the ISP document is used as a personal file and as such is storage for all kinds of information. 
We chose the topic of sexuality for this study because in professional support provision it can be considered a sensitive topic. It incorporates ethical aspects, is a very private subject, and for some people, the very issue of sexuality in people with ID is a taboo. It is not the only sensitive topic when it comes to supporting people with ID. Other examples include substance use or misuse and use of restrictive interventions, force or coercion. Topics as these require a dialogue between everyone involved to seek a balance between the rights of the individual (such as choice, self-determination and privacy) and the obligations of the service provider organisation (providing sound, ethical and responsible care). 


\section{IMPLICATIONS AND RECOMMENDATIONS}

\section{Implications for practice}

\section{Inform people about ISP aims, procedures, roles and responsibilities}

Our research showed that people with ID are often poorly informed about ISP purposes, procedures and responsibilities, and this hinders active participation in the process. It is therefore important that service providers inform people with ID about what ISP is for and how to prepare and follow up the ISP process, in a way that is meaningful to them. Furthermore, as many people with ID have difficulties with communication, memory and information processing (Schalock et al., 20 I 0), information needs to be accessible and presented as many times as necessary.

\section{Improve involvement of people with ID and their relatives}

Often, people with ID do not feel involved (chapter 3). Active involvement of the service user is an essential element when developing interventions (Bartholomew, Parcel, Kok, Gottlieb, \& Fernandez, 20I I). The person with ID has a responsibility in achieving personal outcomes in terms of quality of life, alongside his or her social network and other actors in the support process (Schalock et al., 20 I0).

We recognise the difficulties that can arise in involving people with ID in their ISP due to cognitive or communication problems (Mansell \& Beadle-Brown, 2004). However, there are several ways of enhancing meaningful involvement. For example, 'chunking down' information into small pieces of information can be an effective strategy that helps people understand an issue that requires a decision (Tuffrey-Wijne, 2013), thus enhancing involvement.

It can also be helpful to create ISP meetings that refer to the person's future (rather than the past) and that are easy to follow for people with ID (for example, by using visual communication and avoiding jargon). This too can improve involvement (chapter 3).

Finally, referring to the goals and agreements during informal contacts (for example, during an activity) can help improve active involvement and responsibility in achieving goals (chapter 3 ).

\section{Provide accessible ISP documents}

The ISP document was often inaccessible to people with ID. Individuals do not have direct access to their ISP document, and the ISP is almost always a written document that may be difficult to understand (chapter 3).

Because the ISP document addresses the agreements concerning the individual's life, it is important that people with ID have access to it and understand the content. It is recom- 
mended that staff and the person with ID agree on the format of the ISP and on the way to keep it and to consult it. Electronic portals may provide one answer, but this will not be suitable for everyone with ID, and an understandable and accessible ISP document for people with ID will be quite different to the files that staff use for storing information (including the person's ISP) for professional communication and for accountability (the so-called 'electronic client file').

\section{Differentiate between a service contract, personal file and ISP}

Based on the definition of ISP given in the Dutch Chronic Care Act, an ISP document should set out the support goals and agreements on how to achieve these goals. However, we found that ISP documents tend to contain a lot of additional information as well, either demanded by other stakeholders (the inspectorate or insurance agencies, for example) or added by the provider organisation as part of its internal rules and practices. As a result, ISP documents often contain a vast amount of information, much of which may not be necessary for actually providing support (chapter 5, chapter 6). This appeared to include information that should have formed part of the service contract (related to terms of service and administration) or clinical files (such as diagnostic and treatment information).

It is necessary to make a clear distinction between 'files' and 'documents', so that the ISP document can be used for its intended purpose and does not become an all-purpose destination for every piece of information that needs to be kept.

\section{Align support needs with interventions}

Information presented in the ISP document should be congruent. This means that its objectives and goals should be derived from the individual's support needs, and in the context of what is actually available (Lombardi, Croce, Claes, Vandevelde, \& Schalock, 20 I 6). The ISP document should describe only the information needed for providing support now and in the nearby future. Other information regarding issues can then be saved in the individual's record file.

\section{Usage of technology}

In the context of ISP, information and communication technology can be used for several purposes: (I) to facilitate involvement of people with ID in their ISP; (2) as an information source when considering goals and agreements; and (3) to enhance accessibility of the ISP document.

New forms of communication make it possible for participants to be involved in ISP meetings while not being physically present, or to be in touch with other during the execution of the plan. Technology, such as wearable devices that measure activity or sleep, and eHealth 
can also support decision-making about what support is needed and enhance involvement of the focus person (Barello et al., 20।6).

Technology can also be used to enhance ISP accessibility. Our research showed that the ISP is usually a digital document, accessible only by staff. Providers can give service users and their relatives online access to their ISP document and other resources - for example through the use of so-called portals, so they can monitor the progress towards goals.

\section{Make ISP a continuous, dynamic process}

The studies in this thesis show that life events and disability complexities can act as barriers to goal attainment. However, strict ISP procedures within a service-provider organisation may also prevent ISP documents and goals from being up to date or relevant to the lives of people with ID (chapter 4). Procedures need to be flexible and organised around the individual's needs and wants. ISP is a continuous process of matching support needs with resources and strategies. As such, it should be easy to adjust the ISP whenever needed, and ISP 'meetings' may vary in format, agenda and participants. ISP refers primarily to an interaction between the person with ID and the professionals providing support. The interpersonal aspect of ISP is far more important than any bureaucratic procedure.

\section{Collaborative learning and developing}

Service-provider organisations develop their own ISP procedures and formats. This leads to a wide diversity in ISP formats and documents (chapter 5). A number of approaches may be useful, including collaborative learning, sharing knowledge and good practices, developing ISP formats and procedures collaboratively, and improving ISP practices as a joined activity between different service providers. Furthermore, since ISP is also being used for people with other long-term health conditions (for example in nursing homes, psychiatric services and for people with visual or auditory impairments), it will be important to explore, share, exchange and learn beyond the field of ID.

\section{Improve staff competences}

Throughout this thesis, we stress that tailoring the ISP process and content to individual people with ID and their relatives is crucial for planning to be person centred. This requires frontline staff to be flexible and accountable - which, in turn, means they need to be well equipped with relevant knowledge and competencies (Mansell \& Beadle-Brown, 2004; Robertson et al., 2005). Important competencies include being able to: facilitate a meeting or communication process that meaningully involves people with ID and their significant others; develop support goals that meet quality criteria and fit the individual's needs and life (see chapter 4); provide feedback during ISP implementation to the person with ID and others involved in their support; plan and organise how goals are going to be achieved. 
It may be more effective to improve the competency of direct support staff to facilitate individualised and person-centred ISP through training than to create highly standardised and bureaucratic procedures that are supposed to serve all service users in exactly the same way.

\section{Policy}

\section{Develop a coherent set of requirements}

Official requirements for ISP can motivate service users to move towards more personcentred support, but regulations can also put pressure on them to respond in a way that is bureaucratic rather than person centred. This may result in ISP procedures and documents that are formally correct but that in practice fail to enhance person-centred outcomes, and the resulting document may disappear into a drawer. Overcoming this difficulty is not easy, as different policymakers set different requirements according to their vision on good quality care and good quality ISP.There needs to be coordinated development of requirements and criteria, with coherence between different policy makers, and these requirements should not change too often.

\section{Distinguish between ISP, personal file and service contract}

Policy makers and managers in provider organisations are also recommended to make a clear distinction between the service contract (business information), personal record file (clinical information) and ISP document (goals and agreements on the individual's support) when developing requirements and standards applying to ISP. These different documents serve different purposes, and criteria for administrative or clinical information should not be mixed up with criteria for person-centred ISP.

\section{Differentiation in ISP procedures}

ISP is legally mandated for a large population of health and disability service users who greatly vary in age, level of ID and comorbidity. The requirements from the Chronic Care Act also stretch beyond people with ID to include, for example, older people or those with severe psychiatric problems (chapter I). ISP is used to promote individualised support, and this thesis has shown in several studies that individualised support requires individualised approaches to planning. For example, the study in chapter 4 shows that the likelihood of goal attainment is affected by the complexity of individual problems, which may indicate the need for different approaches for different people.

Conditions under which ISP is effective are highly individual and hence differentiated. Even within one service provider, ISP formats and procedures might need to vary in order to be effective. This presents a challenge to service providers since in certain units or divisions it may be more person-centred and effective to use procedures tailored to individuals rather than standardised, uniform procedures across the whole organisation. 


\section{Research}

\section{Alternative models}

This thesis focuses on provision in the Netherlands, where ISP is an obligation for service providers under the Chronic Care Act.This may lead service providers to develop ISP documents that strongly focus on promoting their own services, focusing on disability support mainly as a professionally driven activity. However, there are other possible models where the ISP process considers the full spectrum of support strategies and resources (see for example Schalock et al., 20 I0). Here, from the very first assessment of an individual's support needs and resources, the scope is not restricted to specialised and paid services alone but considers wider resources such as family, informal support and generic services (school, health care, work, leisure, community services).

Under the United Nation Convention on the Rights of Persons with Disabilities (UN, 2007), also ratified by the Netherlands, there is a formal obligation to facilitate inclusion and participation of people with disabilities. So, although specialised services are needed as centres of knowledge and facilities for people with ID, they also need to become facilitators for personal well-being and participation across a far broader playing field than the horizon of their own organisation. This requires staff and other professionals to have strategies, knowledge and the skills to communicate and work alongside other support resources in the community.

It is worth exploring the role of independent 'support brokers' in ISP. These brokers act independently from a service provider organisation, and research shows that they can help provide a high degree of personalisation of support and for shifting the balances between service provider and service user (Colla \& Maes, 2013; Dowson \& Greig, 2009; Wullink, Widdershoven, Van Schrojenstein Lantman-deValk, Metsemakers, \& Dinant, 2009).The Long Chronic Care Act provides for such a mediating role, but evaluation studies have shown that neither service providers nor service users are aware of this possibility and their right to use it (Van Bergen, Van de Maat \& Hurkmans, 20I6). Moreover, though such a role may be useful, it should be beneficial and not added bureaucracy. As such, research is needed into the effectiveness of independent assessment of support needs and independent support planning on the one hand (for example in degree of personalisation, effectiveness of goal attainment and cost-effectiveness), and the conditions under which this may work without adding to bureaucracy.

\section{The role of technology in ISP}

A final suggestion for future research concerns the use and role of technology in developing, implementing and evaluating ISP. Research in patient portals used in primary care shows that electronic records and patient portals can serve as important tools for managing and understanding patients' health status and improving patient participation, satisfaction and 
outcomes (Jilka, Callahan, Sevdalis, Mayer, \& Darzi, 20I5; Kruse, Argueta, Lopez, \& Nair, 20 I5; Kruse, Bolton, \& Freriks, 20 I 5). However, no similar studies have been found regarding people with ID. The use of electronic systems was briefly addressed in this thesis as these are used by staff to store ISP documents and monitor progress (chapter 4), but more work is needed to develop a better understanding of the role of modern technology in person-centred support for people with ID. 


\section{FINAL REMARKS}

In this thesis, we have addressed different aspects of ISP through five studies. The results show that although the idea behind ISP is self-evident and straightforward, in real life it is a complex, multifaceted intervention that comes with several challenges. In practice, ISP is supposed to serve multiple purposes for multiple stakeholders. It was intended as a tool for enhancing individualised, person-centred support, but the results of our studies show that several key purposes are still not self-evident and need our special attention. They are: involving people with ID in their ISP; applying user-friendly formats for understandable information; tailoring the ISP process and content to the individual; and avoiding bureaucratic approaches.

It can be argued that the relative simple concept of the ISP has not been transposed into practice and that ISP risks becoming more important for 'the system' than for 'the person'. The idea of ISP is based on a utilitarian model in which outcomes are plannable and predictable. In practice, people's lives are far too complex to reduce to an almost mechanical, one-dimensional, linear process in which input determines outcomes. By attempting to reducing the complexity of people's realities, ISPs may create the illusion that outcomes are being controlled when this is not the case. For those professionals and organisations that need to account for the use of public resources and have to account for a methodical, professional approach to support, ISP is a valuable instrument. But as this thesis has shown, it is not the ISP document itself, but the ongoing dialogue between professionals and service users, that is key for delivering effective, person-centred support. 


\section{REFERENCES}

Abbott, D., \& Howarth, J. (2005). Secret loves, hidden lives? Exploring issues for people with learning difficulties who are gay, lesbian or bisexual. Bristol:The Policy Press.

Barello, S., Triberti, S., Graffigna, G., Libreri, C., Serino, S, Hibbard, J., \& Riva, G. (20 I 6). eHealth for Patient Engagement: A Systematic Review. Frontiers in Psychology, 6, 1-13.

Carnaby, S. (1997). "What do you think?": a qualitative approach to evaluating individual planning services. Journal of Intellectual Disability Research, 4 I (3), 225-3I.

Claes, C., Van Hove, G., Vandevelde, S., van Loon, J., \& Schalock, R. L. (20 I0). Person-centred planning: analysis of research and effectiveness. Intellectual and Developmental Disabilities, 48(6), 432-53.

Colla, S., \& Maes, B. (20।3). Evaluatie van de Diensten Ondersteuningsplan. Leuven: Steunpunt Welzijn, Volksgezondheid en Gezin.

Crocker, T. M. (1990). Assessing client participation in mental handicap services: a pilot study. The British Journal of Mental Subnormality, 36(2), 98-107.

Dowson, S., \& Greig, R. (2009). The emergency of the independent support broker role. Journal of Integrated Care, 17(4), 22-30.

Havercamp, S. M., \& Scott, H. M. (20।4). National health surveillance of adults with disabilities, adults with intellectual and developmental disabilities, and adults with no disabilities. Disability and Health Journal, 8(2), 165-172.

Hermans, H., \& Evenhuis, H. M. (20 I 4). Multimorbidity in older adults with intellectual disabilities. Research in Developmental Disabilities, 35(4), 776-783.

Jilka, S. R., Callahan, R., Sevdalis, N., Mayer, E. K., \& Darzi, A. (20I5). "Nothing About Me Without Me": An Interpretative Review of Patient Accessible Electronic Health Records. Journal of Medical Internet Research, 17(6), el 61 .

Kinsella, P. (2000). What are the barriers in relation to Person Centred Planning? York: Joseph Rowntree Foundation.

Kruse, C. S., Argueta, D. A., Lopez, L., \& Nair, A. (2015). Patient and Provider Attitudes Toward the Use of Patient Portals for the Management of Chronic Disease: A Systematic Review. Journal of Medical Internet Research, $17(2)$, e40.

Kruse, C. S., Bolton, K., \& Freriks, G. (20I5). The Effect of Patient Portals on Quality Outcomes and Its Implications to Meaningful Use: A Systematic Review. Journal of Medical Internet Research, 17(2), e44.

Locke, E. A., \& Latham, G. P. (20।3). Goal Setting Theory.The current state. In E. A. Locke \& G. P. Latham (Eds.), New developments in goal setting and performance. New York: Routledge.

Lombardi, M., Croce, L., Claes, C., Vandevelde, S., \& Schalock, R. L. (2016). Factors predicting quality of life for people with intellectual disability: Results from the ANFFAS study in Italy. Journal of Intellectual \& Developmental Disability, 4 I (4), 338-347.

Lotan, G., \& Ells, C. (20।0). Adults with intellectual and developmental disabilities and participation in decision making: ethical considerations for professional-client practice. Intellectual and Developmental Disabilities, 48, I $12-25$.

Maes, B., Lambrechts, G., Hostyn, I., \& Petry, K. (2007). Quality-enhancing interventions for people with profound intellectual and multiple disabilities: a review of the empirical research literature. Journal of Intellectual \& Developmental Disability, 32(3), 163-78.

Mansell, J., \& Beadle-Brown, J. (2004). Person-Centred Planning or Person-Centred Action? Policy and Practice in Intellectual Disability Services. Journal of Applied Research in Intellectual Disabilities, 17, I-9.

Osgood, T. (2005). Managing the tensions between the interests of organisations and service users. In P. Cambridge \& S. Carnaby (Eds.), Person centred planning and care management with people with learning disabilities (pp. 5 I -64). London: Jessica Kingsley Publishers. 
Robertson, J. M., Emerson, E., Hatton, C., Elliott, J., Mclntosh, B., Swift, P., ... Joyce, T. (2005). The impact of person centred planning. Lancaster University.

Schalock, R. L., Borthwick-Duffy, S. A., Bradley, V. J., Buntinx, W. H. E., Coulter, D. L., Craig, E. M., ... Yeager, M. H. (20 I 0). Intellectual disability: definition, classification, and systems of supports. Washington, D.C.: American Association on Intellectual and Developmental Disabilities.

Schoufour, J. D., van Wijngaarden, J., Mitnitski, A., Rockwood, K., Evenhuis, H. M., \& Echteld, M. A. (20I3). Characteristics of the least frail adults with intellectual disabilities: A positive biology perspective. Research in Developmental Disabilities, 35(I), I27-136.

Smull, M., \& Lakin, K. C. (2002). Public policy and person-centered planning. In S. Holburn, \& P. M.Vietze (Eds.), Person-Centered

Planning. Research, Practice, and Future Directions (pp. 379-397). Baltimore: Paul H Brookes.

Tuffrey-Wijne, I. (20।3). A new model for breaking bad news to people with intellectual disabilities. Palliative Medicine, 27(I), 5-12.

United Nations (2007). United Nations Convention on the Rights of Persons with Disabilities.

Van Bergen, A., Van de Maat, J., \& Hurkmans, M. (2016). Onafhankelijke cliëntondersteuning. Een kwalitatief onderzoek naar de ervaringen van onafhankelijke cliëntondersteuners. Utrecht: Movisie.

Van de Wouw-Van Dijk, E, Evenhuis, H.M. \& Echteld, M.A. (20I3). Comparison of two types of Actiwatch with polysomnography in older adults with intellectual disability: A pilot study. American Journal on Intellectual and Developmental Disabilities, 38(3), $265-273$.

Williams, V., \& Robinson, C. (2000). "Tick this, Tick that": The views of people with learning disabilities on their assessments. Journal of Intellectual Disabilities, 4(4), 293-305.

Wullink, M., Widdershoven, G., Van Schrojenstein Lantman-de Valk, H., Metsemakers, J., \& Dinant, G. J. (2009). Autonomy in relation to health among people with intellectual disability: a literature review. Journal of Intellectual Disability Research, 53, 8I 6-826. 

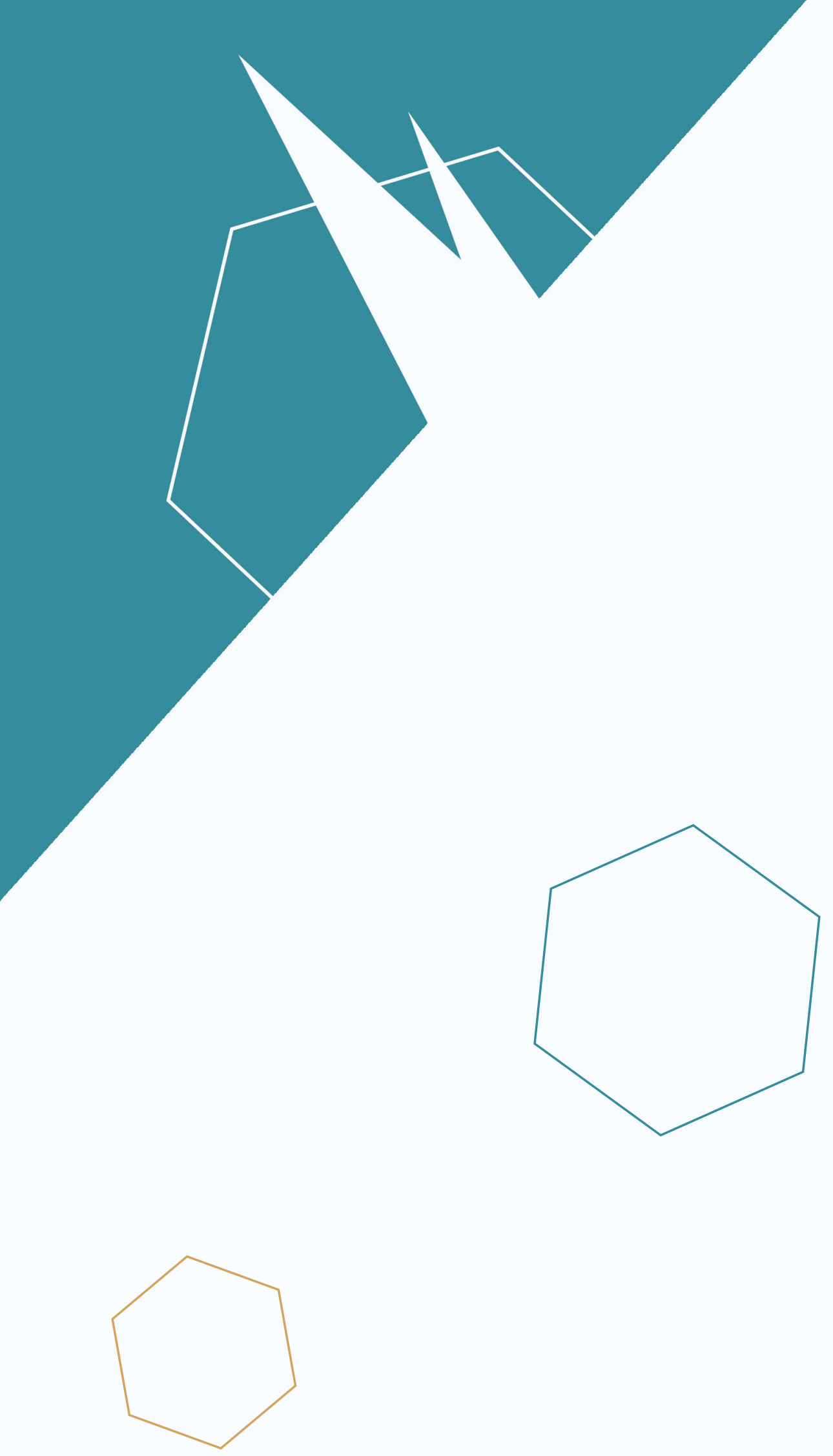


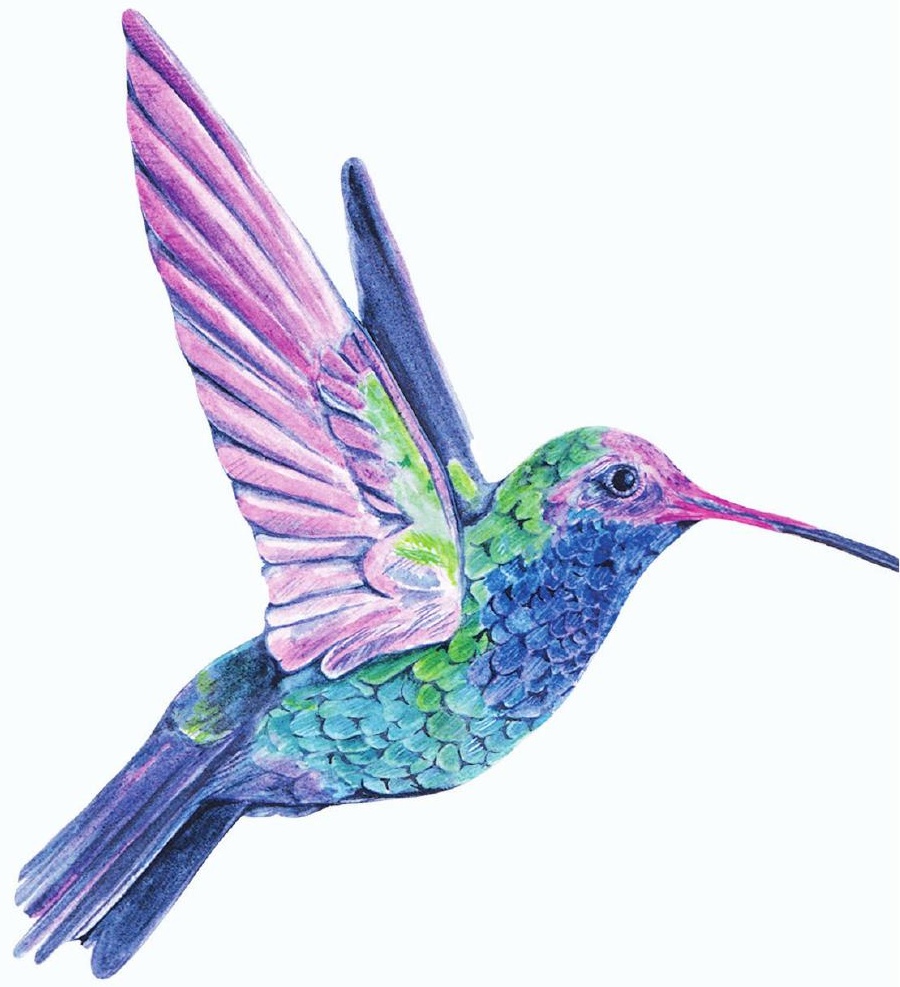




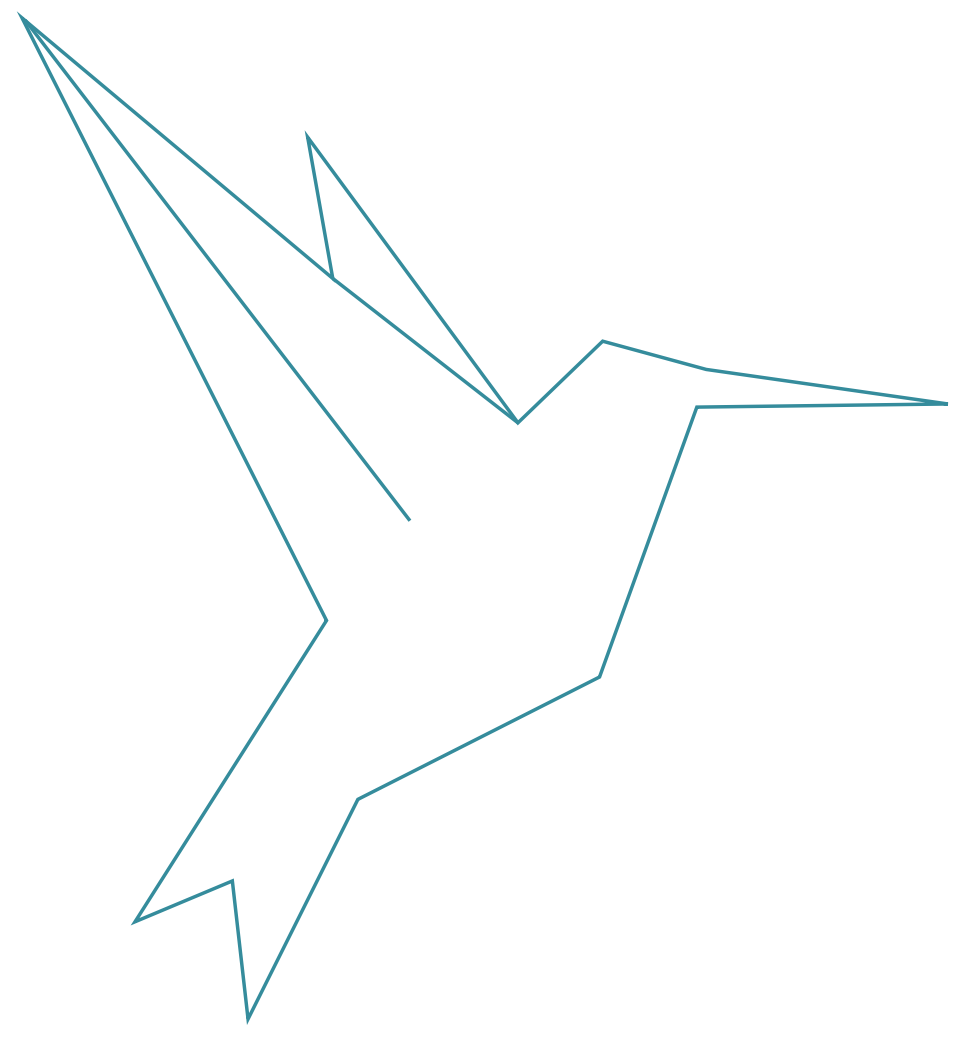




\section{SUMMARY}

Individualised support planning (ISP) is regarded as an important tool for enhancing person-centred support and high quality care. It usually takes the form of a written or digital document, that describes individual goals set for (and by) the person with intellectual disabilities (ID), and the agreement with the service provider to help realise these goals. ISP has been a legal requirement in the Netherlands since 2009, under the ISP amendment ('Besluit Zorgplanbespreking AWBZ-zorg') and became fully legally required in 20 I5, when the Exceptional Medical Expenses Act (AWBZ) was replaced by the Chronic Care Act. The ISP amendment and the Chronic Care Act require that an ISP meeting should be organised in which the individual's wishes, strengths and disabilities form the basis for selecting individual support goals and how (with what actions, by whom and when) these goals are supposed to be achieved. The aim of this meeting is enhancing person-centred care and improving the quality of life of individuals.

Besides the Chronic Care Act, different stakeholders develop their own policies regarding ISP practices. These include budget allocation agencies, the Healthcare Inspectorate and the service provider organisations (from now on referred to as 'service providers'), represented by the Dutch Association of Service Providers. These stakeholders regard ISP as important for enhancing and controlling quality of care and person-centred care. They set requirements accordingly, which influence ISP content and procedures.

This thesis starts in Chapter I by describing ISP in the context of supporting people with ID. ISP is a process consisting of several components, approaches, use and potential outcomes. Generally, the process starts with assessing the individual's support needs, to determine the types and intensity of support that is needed. An ISP meeting brings together the perspectives of different people (the person with ID, their relatives and professionals) to help prioritise support needs and determine goals for the next period. Afterwards, the ISP document is written, usually by staff, and implementation begins. Monitoring and evaluation are carried out during the implementation, and after a set period of time, the next ISP meeting is organised and the cycle continues.

ISP has been in place for several decades, and during this time has undergone a shift from a merely professional instrument to a person-centred tool. This shift is most visible in the literature from, among others, the UK and US, resulting in 'person-centred planning' approaches. These approaches to planning are characterised by a focus on individuals as people rather than bearers of diagnostic labels; the use of common language rather than jargon; a focus on the person's gifts and capacities; and a strong voice of the person and those who know the person best. In the Netherlands, ISP evolved from a tool merely for professional account- 
ability to a tool used to promote person-centredness and enhance quality of life, as well as quality of services. Currently, these functions co-exist. This may cause tensions, and several authors worry about the balance between these functions, as they tend to lean mostly towards accountability.

There have been a number of studies on the effectiveness of ISP. However, these have mostly been carried out in the UK and the US, with a focus on implementing person-centred planning.The studies show that these approaches can be effective, but they use different outcome measures and differ from Dutch ISP. Furthermore, research on ISP effectiveness is difficult as it has become common and (legally) required practice, which makes it difficult to compare the 'before and after'. In this thesis, we reflected on the policy and practice of ISP and content of ISP documents for people with intellectual disabilities (ID) in the Netherlands. The chapter closes by setting out the research questions addressed in the thesis.

Chapter 2 describes a study of the formal requirements impacting on the content and process of ISP, as well as the expectations of stakeholders (including self-advocate organisations, the Dutch Association of Service Providers, quality management officers working at service providers and legal advisers specialising in Care Acts) of this approach. First, we studied relevant Care Acts and policy documents to explore the requirements. Then we asked 56 stakeholders to reflect on these and express their expectations with respect to ISP.

We found several requirements with respect to ISP content. For example, the ISP has to contain the individual's needs, wants and goals; a diagnosis; a risk analysis; and an overview of the medication. There were also requires of the process. The ISP document has to be evaluated annually and it should follow a plan-do-check-act cycle), person-centredness (for example, the document has to be easy to read and accessible for the person with ID). Service-providers are also required to develop an ISP policy and review it regularly.

Different policy documents and stakeholders have different requirements and expectations regarding ISP. Some requirements are changed every year and differ regionally, resulting in a comprehensive and colourful mix of criteria. Service providers thus need to be continuously up to date and may need to implement new requirements each year. Since not meeting criteria can have severe consequences (such as budget cuts), there is a risk that meeting criteria becomes the priority, which can influence the quality of ISP and its usefulness in practice. There is also a risk of criteria being met for the purpose of avoiding consequences. Though it is important that ISP documents and procedures meet certain criteria, having all boxes ticked does not in itself ensure high quality ISP. 
The next chapter (Chapter 3) sets out the results of a qualitative study in which 6 I people with ID, using services from different service providers in the Netherlands, were interviewed. The purpose of the study was to collect information about the experiences and expectations of Dutch people with ID with respect to their involvement in their ISP. We developed a topic list for the interviews and collaborated with the self-advocate organisation LFB. The results indicated that 'presence' is not the same as 'involvement': although people with ID are present at their ISP meeting, they are often not involved in developing, executing and evaluating the ISP document. Indeed, people with ID are not always aware of the purpose of ISP. Little is done to make the ISP document and procedures easy to understand: most people cannot access their ISP document without having to ask permission, and the ISP document is difficult to understand because of the use of jargon, and the way it describes disabilities and negative life experiences. Though most people found it important to have a document that described the agreements, they also felt that the ISP document was a professional formality and not connected to their everyday life. Participants offered suggestions for improvement. These related to accessibility, developing ISP documents and procedures that were easier to understand and tailoring ISP content and procedures to individual needs.

The definition of ISP used in the Netherlands requires that each ISP document contains the individual's goals, along with agreements between client and service provider about how these goals will be achieved. Chapter 4 describes a study that we carried out to look at the barriers and facilitators in goal attainment. Goal-setting theory states that goals can be highly effective in achieving outcomes as long as certain conditions are met. These conditions include providing feedback on progress towards the goal and making sure the people involved are committed to the goal. The goal itself needs to be, among others, specific and measurable.

To study whether goals are achieved and identify barriers and facilitators, we interviewed direct support staff of a service provider that had recently evaluated an ISP document. We analysed IOI goals found in 34 ISP documents, using a set of questions based on the literature on ISP effectiveness and goal-setting theory. The results showed that approximately half of the goals were achieved within one year. None of the goals specified a timeline, but the goals were maintained over a one-year period, because the meetings to evaluate the ISP documents were annual.

After assessing the quality of goals using a goal rating scale, we found a relationship between the quality of goals and the extent to which they were achieved, indicating that high quality goals were achieved more often than goals of lesser quality. However, the question of whether this relationship was causal was beyond the scope of this study; more research is needed. Another important finding was that staff perceived the individual with ID, and the 
complexity of their problems, as the greatest barrier in goal attainment. This raises a question as to whether the art of goal setting for people with ID, with all complexity involved, is present in service providers and whether goal setting is needed and effective in all individual situations.

The next two chapters describe two studies that we carried out on the content of ISP documents collected from different service providers.

The first, described in Chapter 5, examined the general characteristics of ISP documents, and the support goals and resources to achieve these goals. We linked each support goal to one of the quality of life domains (personal development, self-determination, interpersonal relations, social inclusion, rights, emotional well-being, physical well-being, and material wellbeing) and subsequently used multi-level analyses to study whether particular domains were particularly related to client characteristics such as age, gender, level of intellectual functioning or service provider.

With respect to the general characteristics, the results showed that ISP documents vary in size, with the number of pages ranging from 3 to 76, with an average of 17 pages. The size of the ISP document was not related to client characteristics, such as age or level of ID, but to which service provider had produced it. This is because all the service providers develop their own ISP forms and procedures. We also found that I 4\% of the ISP documents had not specified any support goals at all.This finding was unexpected, as Dutch policy requires support goals to be present in the ISP document. These documents contained a vast amount of administrative and descriptive information about the person with ID. This indicates that it is unclear to service providers what should constitute the ISP document and what information should be stored elsewhere in the individual's file.

In terms of the content of support goals, we found that most goals related to the domain of physical well-being. Multi-level analyses revealed that goals relating to the domains of independence and social participation were more common in in ISP documents of people with mild-to-moderate ID than in those of people with severe or profound ID. In contrast, ISP documents of people with profound ID contained more goals in the domain of wellbeing. Finally, ISP documents of people aged 20-34 contained more goals in the domain of independence. This is a concern, as ISP documents need to pay attention to all domains of quality of life in order to provide individualised support and enhance personal outcomes.

Finally, this study looked at what resources were described in helping achieving the individual support goals. Resources were classified along the systems of support model and included the person's own competences, the social network of family and friends, informal support such as neighbours, colleagues, volunteers, generic agencies, and specialised services. In $23 \%$ 
of the goals, no resources were specified. In most goals that did describe the support resources, the resource that achieved the individual goal was named as professional support staff. In one third of the support goals, named resources in achieving goals included natural resources such as social network or generic care settings. Statistical analysis revealed that natural resources were mentioned more often in the ISP documents of people with mild ID than in those of others. In a quarter of support goals, a combination of natural and specialised resources were mentioned.

Chapter 6 describes our second study on the content of ISP documents. This one asked how, and to what extent, the topic of sexuality is addressed within the ISP documents of people with ID. We used the same sample of ISP documents as the study in Chapter 5. We performed a lexical search in all ISP documents using search words derived from accepted definitions on sexual rights. The searches resulted in fragments of text that were coded and then analysed.

The results showed that aspects of sexuality were found in almost all ISP documents, but that the information did not provide directions for individualised support in this area. There were hardly any support goals found in this area and no references were found for support providers, care plans or other support strategies. Although it is positive that sexuality does not seem to be avoided in ISP, the results indicate a lack of clarity about what information should be written in the ISP document to be of use in everyday practice. However, this result does not necessarily mean that no support is being provided in this area; it could be that the person with ID does not want to have these details recorded in their ISP document.

Chapter 7 summarises and discusses the main results of the previous chapters. It then provides some implications and recommendations of the studies on practice, policy and research.

With respect to practice, service providers can take several actions to enhance a more person-centred use of ISP. First, they need to inform people with ID and their relatives about the purpose of ISP, roles, procedures and responsibilities, making sure the information is easy to understand. Second, they need to ensure the active involvement of the person with ID in all ISP components. Third, they need to provide accessible and easy-to-understand ISP documents.

At an organisational level, service providers need to distinguish between an ISP document, the individual's file and a service contract. Information needs to be structured logically, so that no detail is lost and the document is clear and concise. Technology can assist in this. Within the documents, there needs to be a clear line between the individual's support needs and the support that will actually be provided, and ISP procedures should allow for the content 
to be changed when needed. Because each service provider develops its own forms and procedures, the different providers can learn from each other. Moreover, as ISP is used in a broader setting than ID, learning can also be shared between providers in different fields. A final recommendation for practice is that service providers need to make sure that staff have the required competencies to develop ISP.

Policy makers at national and regional level need to be aware of the impact of their requirements and expectations on day-to-day practice. It is recommended that policy makers develop a coherent set of requirements that stand the test of time. Furthermore, as with service providers, policy makers need to make a clear a distinction between the information that is needed in an ISP document, other aspects of the individual's file and a service contract.

The findings of this thesis also indicate directions for future research. Individualised support planning is legally required for a large and diverse population. However, individual differences need to be reflected in ISP procedures and content of ISP documents, as well as in expected outcomes of ISP. More research is needed to achieve a better understanding of these individual differences. In addition, it is worth studying different innovative approaches to ISP. Finally, the role of technology in different ISP components needs to be studied further, and can increase involvement of people with ID and their relatives in ISP.

This thesis examines several aspects of ISP in the field of ID. It shows that although the idea of ISP seems straightforward and self-evident, it actually is a complex, multi-faceted intervention. ISP is a legal requirement to enhance person-centred support, but our research shows that several aspects of the approach are not consistent with this purpose. This poses a risk that ISP can be used to serve the system rather than the individual. 



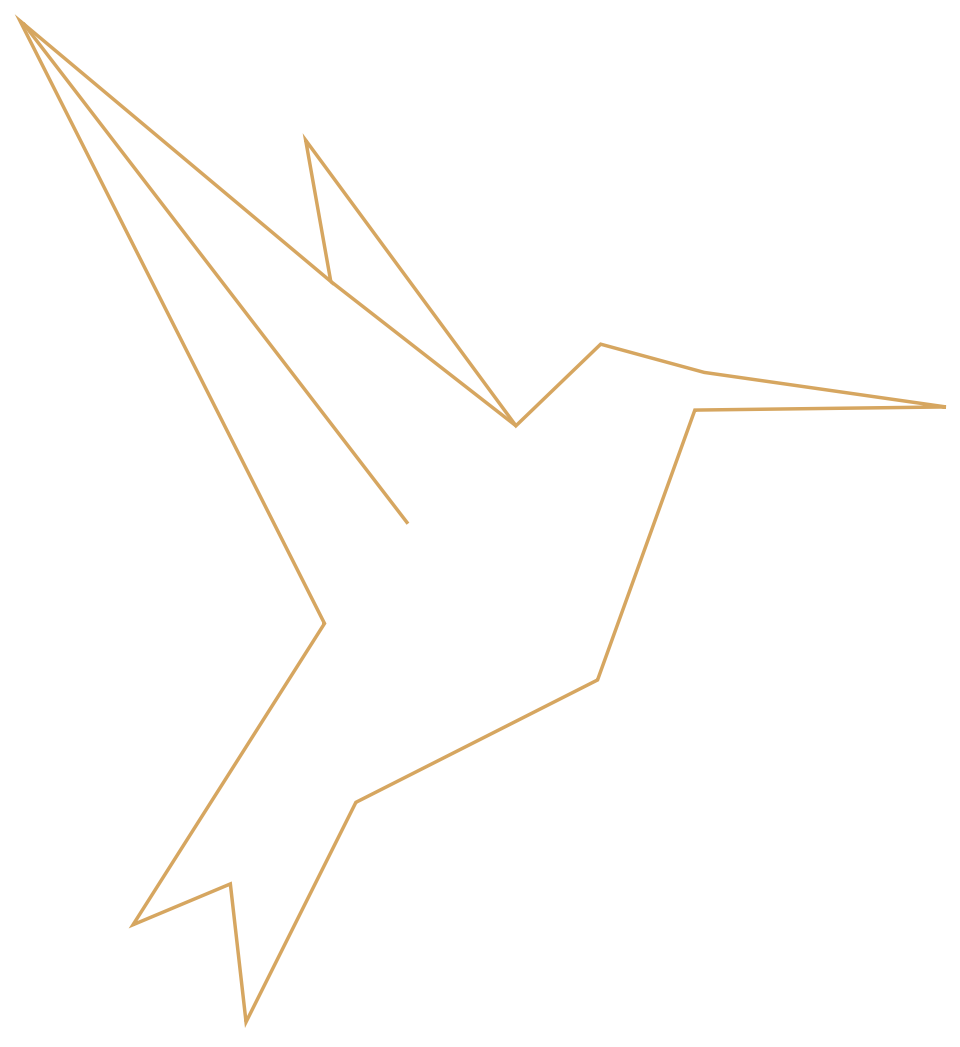




\section{SAMENVATTING}

Het werken met individuele ondersteuningsplannen is belangrijk voor het bevorderen van cliëntgerichte ondersteuning en een goede kwaliteit van zorg. Een ondersteuningsplan is, over het algemeen, een geschreven of digitaal document. Het beschrijft de individuele doelen van mensen met een verstandelijke beperking en de afspraken die de persoon met de zorgaanbieder heeft gemaakt om deze doelen te realiseren. In Nederland is het werken met ondersteuningsplannen sinds 2009 verplicht middels het Besluit Zorgplanbespreking AWBZ-zorg en in 2015 onderdeel geworden van de Wet langdurige zorg.

Het Besluit zorgplanbespreking AWBZ-zorg had tot doel om persoonsgerichte ondersteuning te bevorderen en de kwaliteit van bestaan van mensen te verbeteren. Het Besluit verplichtte dat voor elke persoon een zorgplanbespreking georganiseerd moest worden, waarin de wensen, behoeften, mogelijkheden en beperkingen de basis vormden voor bepalen van de ondersteuningsdoelen en hoe (met welke acties, door wie en wanneer) deze doelen bereikt gaan worden. In 2015 is de AWBZ vervangen door, onder andere, de Wet langdurige zorg. Het Besluit zorgplanbespreking AWBZ-zorg is in deze wet opgenomen met enkele aanvullende verwachtingen om zo de rol en positie van cliënten te versterken.

Behalve deze wet ontwikkelen andere stakeholders beleid ten aanzien van het werken met ondersteuningsplannen. Dit zijn de zorgkantoren, de Inspectie voor de Gezondheidszorg en de vereniging van zorgaanbieders in de gehandicaptenzorg in Nederland. Deze stakeholders beschouwen het werken met ondersteuningsplannen als belangrijk hulpmiddel voor het verbeteren van en het kunnen bewaken van de kwaliteit van zorg. Deze partijen stellen eisen aan de inhoud en werkwijze van het ondersteuningsplan, passend bij hun rol.

In hoofdstuk I beschrijven we hoe het werken met ondersteuningsplannen in de ondersteuning aan mensen met een verstandelijke beperking. Het werken met ondersteuningsplannen is een proces dat verschillende componenten, benaderingen, gebruik en mogelijke uitkomsten omvat. In het algemeen begint het proces met het onderzoeken van iemands' ondersteuningsbehoefte, zodat het type en de intensiteit van de benodigde ondersteuning kan worden vastgesteld.Tijdens een ondersteuningsplanbespreking komen de perspectieven van verschillende betrokkenen (de persoon zelf, verwanten en professionals) samen om de ondersteuningsbehoeften te prioriteren en doelen voor de komende periode te stellen. De uitkomsten van deze bespreking worden, meestal door zorgmedewerkers, vastgelegd in het ondersteuningsplan. Hiermee begint de implementatie in de praktijk, waarbij de voortgang continu gemonitord wordt. $\mathrm{Na}$ een bepaalde periode vindt de volgende ondersteuningsplanbespreking plaats en zet de cyclus zich voort. 
Het werken met ondersteuningsplannen gebeurt al tientallen jaren, waarbij een verschuiving heeft plaatsgevonden van een voornamelijk professioneel instrument naar een persoonsgericht hulpmiddel. Deze verschuiving is sterk zichtbaar in internationale literatuur, waarbij een omslag wordt beschreven van een meer'systeemgerichte' aanpak naar een 'persoonsgerichte' aanpak. Deze persoonsgerichte aanpakken worden gekenmerkt door een sterke focus op de individu in zijn geheel, in plaats van als dragers van diagnostische labels; het gebruik van gewone taal in plaats van jargon; nadruk op iemands' mogelijkheden en talenten; en een sterke invloed van de persoon zelf en de mensen die hem of haar het best kennen. In Nederland is het werken met ondersteuningsplannen ontwikkeld van een instrument voor professionele verantwoording naar een hulpmiddel in het bevorderen van persoonsgerichte ondersteuning en het verbeteren van individuele kwaliteit van bestaan, alsook voor het toetsen van de kwaliteit van ondersteuning. Deze drie functies bestaan momenteel naast elkaar. In de praktijk kan dit spanningen veroorzaken en verschillende auteurs waarschuwen dan ook voor het borgen van de balans tussen deze functies, omdat in de praktijk de meeste nadruk kan komen te liggen op het afleggen van verantwoording.

Verschillende studies beschrijven de effectiviteit van het werken met ondersteuningsplannen. Echter, deze studies zijn met name uitgevoerd in Groot-Brittannië en de Verenigde Staten, waarin de implementatie van een persoonsgerichte ondersteuningsplanmethodiek onderzocht werd. Deze studies laten zien dat persoonsgerichte methodieken effectief kunnen zijn. Echter, in deze worden verschillende uitkomstmaten gehanteerd en de werkwijze die onderzocht wordt verschilt van de Nederlandse situatie. In Nederland wordt onderzoek naar de effectiviteit van het ondersteuningsplan bemoeilijkt omdat het inmiddels een vast onderdeel is van de ondersteuning en zelfs wettelijk verplicht is. Hierdoor is het niet mogelijk om een voor- en nameting uit te voeren of om een situatie waarin wel en geen ondersteuningsplannen worden gebruikt, vergeleken kan worden. We reflecteren in dit proefschrift op het beleid rond ondersteuningsplannen, het werken in de praktijk van ondersteuning en op de inhoud van ondersteuningsplannen van mensen met een verstandelijke beperking in Nederland. Het hoofdstuk sluit af met de onderzoeksvragen die in het onderzoek aan bod komen.

In hoofdstuk 2 beschrijven we een studie naar de formele eisen die gesteld worden aan het werken met ondersteuningsplannen in Nederland en naar verwachtingen die verschillende stakeholders (belangenorganisaties, de VGN, kwaliteitsmedewerkers en gezondheidsjuristen) hebben ten aanzien van het werken met ondersteuningsplannen. Hiervoor is allereerst een deskresearch gedaan naar relevante wetgeving en zijn beleidsdocumenten bestudeerd van de Inspectie voor de Gezondheidszorg, het kwaliteitskader dat de branchevereniging VGN hanteert en inkoopbeleid vanuit de zorgkantoren in Nederland. Vervolgens is aan 56 stakeholders gevraagd om te reflecteren op deze formele eisen. 
We vonden een veelheid aan formele eisen en verwachtingen ten aanzien van de inhoud van een ondersteuningsplan en de werkwijze rond ondersteuningsplannen bij zorgorganisaties. Eisen ten aanzien van de inhoud van een ondersteuningsplan zijn bijvoorbeeld dat het de wensen, behoeften en doelen beschrijft; diagnose; risicoanalyse; medicatieoverzicht. Eisen ten aanzien van de werkwijze zijn bijvoorbeeld dat het frequent geëvalueerd moet worden en gewerkt moet worden volgens een Plan-Do-Check-Act cyclus. Ook worden eisen gesteld aan het beleid van zorgorganisaties (bv dat er beleid is en dit geregeld wordt herzien) en persoonsgerichtheid (bv dat het plan begrijpelijk en toegankelijk moet zijn) van het ondersteuningsplan.

De verschillende bronnen hanteren eigen criteria en verwachtingen, waardoor een omvangrijk geheel ontstaat. Daarbij geldt dat een aantal stakeholders hun criteria jaarlijks verandert en dat er regionale verschillen kunnen ontstaan. Dit vraagt van zorgorganisaties om continu up-to-date te zijn én om nieuwe verwachtingen binnen een jaar te implementeren. Het niet voldoen aan bepaalde criteria, kan daarnaast forse consequenties hebben voor zorgaanbieders (zoals gekort worden op budgetten). Hiermee ontstaat het risico dat het voldoen aan externe eisen de prioriteit wordt, wat weer van invloed is op de kwaliteit van het ondersteuningsplan en het werken in de praktijk. Tot slot zit er spanning op het feit dat standaard eisen aan een zeer brede en diverse populatie worden gesteld. Hoewel het van belang is dat het werken met ondersteuningsplannen aan een aantal criteria voldoet, betekent het voldoen aan alle eisen niet automatisch dat het ondersteuningsplan een goede kwaliteit heeft.

Het volgende hoofdstuk (hoofdstuk 3) geeft de resultaten van een kwalitatieve waarin 6 I mensen met een verstandelijke beperking die een ondersteuningsplan hebben, geïnterviewd zijn. Het doel van deze studie was de ervaringen en verwachtingen van mensen met een verstandelijke beperking te onderzoeken met betrekking tot hun ondersteuningsplan. Specifiek voor het doel van dit onderzoek is een topiclijst ontwikkeld en is in de uitvoer nauw samengewerkt met de LFB, belangenvereniging voor en door mensen met een beperking. Uit de resultaten blijkt dat 'aanwezigheid' niet hetzelfde is als 'betrokkenheid': hoewel mensen aanwezig zijn bij de ondersteuningsplanbespreking, ervaren ze weinig betrokkenheid in de ontwikkeling, uitvoer en evaluatie van het plan. Ze weten niet altijd wat het doel is van de jaarlijkse ondersteuningsplanbespreking. Er wordt weinig gedaan om het plan en de werkwijze begrijpelijk te maken voor cliënten zelf: de meerderheid van de mensen heeft zijn of haar plan niet in eigen bezit en kan er niet zonder tussenkomst van derden bij. Het plan zelf bevat veel jargon en vaak een opsomming van problemen die in het leven van de persoon hebben plaatsgevonden, waardoor het voor de meeste mensen ook geen document was waar ze positieve associaties mee hebben. Hoewel mensen het belangrijk vinden dat er afspraken worden gemaakt en worden opgeschreven, voelt het ondersteuningsplan als een professionele formaliteit die niet in verbinding staat met hun eigen leven. Mensen hadden 
ook een aantal suggesties voor verbetering. Deze hadden betrekking op de toegankelijkheid van hun eigen plan, het vergroten van flexibiliteit om beter af te kunnen stemmen op de individu en op de begrijpelijkheid van het ondersteuningsplan zelf.

De definitie die in Nederland gehanteerd wordt maakt zichtbaar dat de kern van het ondersteuningsplan bestaat uit doelen en de afspraken om deze doelen te behalen. In hoofdstuk 4 beschrijven we een onderzoek naar het behalen van doelen in individuele ondersteuningsplannen en de bevorderende en belemmerende factoren daarin. Goal setting theory stelt dat het werken met doelen uiterst geschikt kan zijn om resultaten te behalen, mits voldaan wordt aan een aantal voorwaarden is voldaan. Bijvoorbeeld dat er commitment is van de betrokkenen, er geregeld feedback over de voortgang wordt gegeven en het doel zelf voldoet aan aspecten als dat het specifiek en meetbaar is.

Om te kunnen onderzoeken of doelen in ondersteuningsplannen behaald zijn en wat daarin heeft mee- en tegengewerkt, hielden we interviews met begeleiders die onlangs een ondersteuningsplan geëvalueerd hebben. Op deze manier analyseerden we I0I doelen uit 34 verschillende ondersteuningsplannen. Elk doel is met hen besproken aan de hand van een aantal vragen gebaseerd op eerder onderzoek naar effectiviteit van ondersteuningsplannen en goal setting theory. Het onderzoek liet zien dat ongeveer de helft van de doelen behaald was binnen de looptijd van het ondersteuningsplan. Opvallend daarbij was dat geen enkel doel een deadline omvatte: elk doel duurde een jaar, omdat de evaluatiegesprekken jaarlijks plaatsvinden.

Verder bleek er een relatie te bestaan tussen de kwaliteit van het doel en het behalen ervan, namelijk dat doelen van een hoge kwaliteit eerder behaald lijken te worden dan doelen van lagere kwaliteit. We onderzochten niet of dit een causale relatie is. Tevens zijn er meer factoren om rekening mee te houden bij het werken aan doelen dan de technische aspecten. Een andere belangrijke uitkomst was namelijk dat respondenten de (complexiteit van de problemen van de) persoon met een beperking als grootste hindernis in het behalen van doelen ervaren. Dit roept de vraag op of de kunst van het goed stellen van de juiste doelen voor deze doelgroep aanwezig is in zorgorganisaties en of het werken met doelen in alle situaties wenselijk en effectief is.

De twee hieropvolgende hoofdstukken beschrijven twee onderzoeken naar de inhoud van ondersteuningsplannen die we bij verschillende zorgaanbieders verzamelden.

De eerste, beschreven in hoofdstuk 5, onderzocht de algemene kenmerken van ondersteuningsplannen en de doelen en hulpbronnen (wie wordt ingezet om het doel te kunnen behalen) die in het plan beschreven zijn. We codeerde elk doel op inhoud aan de hand van de 
domeinen van kwaliteit van bestaan (persoonlijke ontwikkeling, zelfbepaling, interpersoonlijke relaties, sociale inclusie, rechten, emotioneel welbevinden, lichamelijk welbevinden, materieel welbevinden). Vervolgens is middels multi-level analyses onderzocht of het voorkomen van doelen op bepaalde domeinen samenhing met cliëntkenmerken zoals leeftijd, geslacht en het niveau van functioneren.

Uit deze studie bleek dat de omvang van een ondersteuningsplan varieert tussen de 3 en 76 pagina's, met een gemiddelde van 17 pagina's. De omvang van het document hing niet samen met cliëntkenmerken (leeftijd en niveau van functioneren), maar wel met de zorgorganisatie waar het plan geschreven is. Omdat elke zorgorganisatie in Nederland een eigen format ontwikkelt, is dat het meest van invloed op de omvang en hoeveelheid tekst in het ondersteuningsplan. Daarnaast vonden we in 14\% van de ondersteuningsplannen geen individuele ondersteuningsdoelen. Dit is onverwacht, omdat landelijk beleid stelt dat er doelen in het plan staan. Deze plannen bevatten veelal administratieve en beschrijvende informatie over (het functioneren van) de persoon. Tevens lijkt daarbij onduidelijkheid te bestaan bij zorgorganisaties over wat er in het ondersteuningsplan thuis hoort en wat op andere plekken in het dossier.

Ten aanzien van de inhoud van de doelen bleek dat de meeste doelen betrekking hebben op het domein van lichamelijk welbevinden. Multi-level analyses lieten zien dat er in ondersteuningsplannen van mensen met een lichte tot matige verstandelijke beperking significant meer doelen staat over onafhankelijkheid en sociale participatie dan in plannen van mensen met een lager niveau. Plannen van mensen met een zeer ernstige verstandelijke beperking bevatten daarentegen significant meer doelen op het domein van welbevinden. Ook in plannen van mensen in de leeftijd van 20 tot 34 zijn er meer doelen op het terrein van onafhankelijkheid. Om goede ondersteuning te kunnen bieden, is het nodig om naar alle domeinen van kwaliteit van bestaan te kijken.

Tot slot onderzochten we welke hulpbronnen worden ingezet in het behalen van doelen. Hiermee wordt bedoeld welke personen of instanties betrokken worden bij het behalen van de doelen. Hulpbronnen werden gecodeerd als de persoon zelf; het sociale netwerk van de persoon; informele ondersteuning zoals buren, collega's, vrijwilligers; algemene diensten; en gespecialiseerde ondersteuning (geleverd door zorgaanbieders). Bij 23\% van de doelen stonden geen hulpbronnen beschreven. Bij het merendeel van de doelen stond een rol voor de (medewerkers van de) zorgorganisatie beschreven, in ongeveer een derde van de plannen werden ook natuurlijke hulpbronnen benoemd (zoals het sociale netwerk van de persoon of het gebruik van reguliere voorzieningen zoals het ziekenhuis). Statistische analyses lieten zien dat in de ondersteuningsplannen van mensen met een licht verstandelijke beperking, vaker natuurlijke hulpbronnen beschreven staan dan bij mensen met een lager niveau. In 
een kwart van de doelen zijn zowel natuurlijke als gespecialiseerde hulpbronnen beschreven.

Hoofdstuk 6 beschrijft de tweede studie naar de inhoud van ondersteuningsplannen. In deze studie onderzochten we de wijze waarop en de mate waarin het thema 'seksualiteit' aan bod komt in ondersteuningsplannen. Hiervoor maakten we gebruik van de ondersteuningsplannen die voor het onderzoek in hoofdstuk 5 gebruikt zijn. We voerden een lexicale search uit in deze ondersteuningsplannen met zoekwoorden ontleend aan definities over seksuele rechten. De fragmenten tekst die dit opleverde, zijn gecodeerd en geanalyseerd.

De resultaten lieten zien dat 'seksualiteit' in bijna alle plannen aan bod komt, maar dat dit meestal geen aanwijzingen bevat voor de ondersteuning die op dit vlak geboden moet worden. Er zijn slechts enkele doelen op dit thema geformuleerd en geen, referenties naar behandelplannen of beschikbare methodes te vinden. Hoewel het positief is dat seksualiteit aan bod komt in een ondersteuningsplan, lijkt het erop dat er onduidelijkheid is over de aard van de informatie die nodig is om te gebruiken in de dagelijkse praktijk. De uitkomsten van deze studie hoeven echter niet te betekenen dat er in de daadwerkelijke ondersteuning geen aandacht voor het onderwerp is. Vanwege de gevoeligheid van het onderwerp kan besloten zijn om er in het ondersteuningsplan geen specifieke aandacht aan te besteden, of heeft de persoon met een verstandelijke beperking hier zelf een keuze in gemaakt.

In hoofdstuk 7 vatten we de belangrijkste resultaten uit de voorgaande hoofdstukken samen en reflecteren we op deze resultaten. Vervolgens beschrijven we implicaties en aanbevelingen voor de praktijk, beleid en verder onderzoek. Het hoofdstuk sluit af met een algemene conclusie.

Zorgorganisaties kunnen verschillende acties ondernemen om ervoor te zorgen dat ondersteuningsplannen persoonsgerichter ingezet worden. Een eerste stap is dat cliënten, en hun naasten, goed geïnformeerd zijn over waarom een ondersteuningsplan gebruik wordt en hoe procedures, rollen en verantwoordelijkheden verdeeld zijn. Ten tweede dienen zij ook te zorgen voor actieve betrokkenheid van cliënten in alle fasen van het werken met het ondersteuningsplan. In de derde plaats is een voor individuele cliënten toegankelijk en begrijpelijk ondersteuningsplan nodig.

Op organisatieniveau is het van belang om een helder onderscheid te maken tussen een ondersteuningsplan, zorgverlenersovereenkomst en persoonlijk dossier. Door informatie op een goede manier te ordenen wordt geen informatie 'verloren' en kan het ondersteuningsplan kort en overzichtelijk blijven. Technologie kan daarin een belangrijke rol spelen. In het ondersteuningsplan zelf, is het dan van belang dat er een duidelijke samenhang is tussen de ondersteuningsbehoefte en de ingezette ondersteuning, en dat de werkwijze voldoende 
flexibel is om zich aan te passen wanneer nodig. Bij het ontwikkelen of verbeteren van de ondersteuningsplansystematiek kunnen zorgorganisaties veel van elkaar leren, ook vanuit verschillende sectoren. Om bovenstaande te bereiken, is het nodig dat medewerkers over voldoende en juiste competenties beschikken.

Beleidsmakers op landelijk en lokaal niveau dienen zich bewust te zijn van de impact die hun eisen of verwachtingen hebben op het werken met ondersteuningsplannen in de praktijk. Een aanbeveling is dan ook om de verschillende eisen en verwachtingen op elkaar af te stemmen, het eisenlijstje kort te houden en deze niet te frequent veranderen. Daarnaast is het ook voor beleidsmakers van belang om een goed onderscheid te maken tussen dossierinformatie, informatie die in een zorgverleningsovereenkomst hoort en informatie die in het feitelijke ondersteuningsplan hoort.

De studies in dit onderzoek geven ook richting aan vervolgonderzoek. Het werken met ondersteuningsplannen is verplicht voor een zeer diverse populatie (divers in leeftijd, ondersteuningsvragen, bijkomende problematieken, etc.). Individuele verschillen lijken nodig in zowel de aanpak, de inhoud van het plan als in de te verwachten uitkomsten van het ondersteuningsplan. Verder onderzoek is nodig om hier meer zicht op te krijgen. Daarbij aansluitend kan onderzoek van belang zijn om nieuwe, innovatieve modellen te onderzoeken. Bijvoorbeeld door het ondersteuningsplan te laten maken door een onafhankelijke partij, waarbij voorkomen dient te worden dat dit een bureaucratische exercitie wordt. Tot slot bieden technologische ontwikkelingen kansen voor het werken met ondersteuningsplannen. Denk aan de inzet van technologie bij het nemen van beslissingen, bij het stellen van doelen of bij het betrekken van de cliënt en zijn of haar naasten bij de ondersteuning.

In deze thesis zijn verschillende aspecten van het werken met ondersteuningsplannen aan de orde gekomen. Het laat zien dat hoewel het idee van een ondersteuningsplan vanzelfsprekend lijkt, de werkelijkheid laat zien dat het een complexe interventie is die bestaat uit meerdere facetten. De reden waarom het werken met ondersteuningsplannen verplicht is geworden, is het bevorderen van cliëntgericht werken. Ons onderzoek liet echter zien dat dit door verschillende redenen bedreigd wordt. Het risico bestaat dat het ondersteuningsplan ten behoeve staat van 'het systeem', in plaats van 'de cliënt'. 


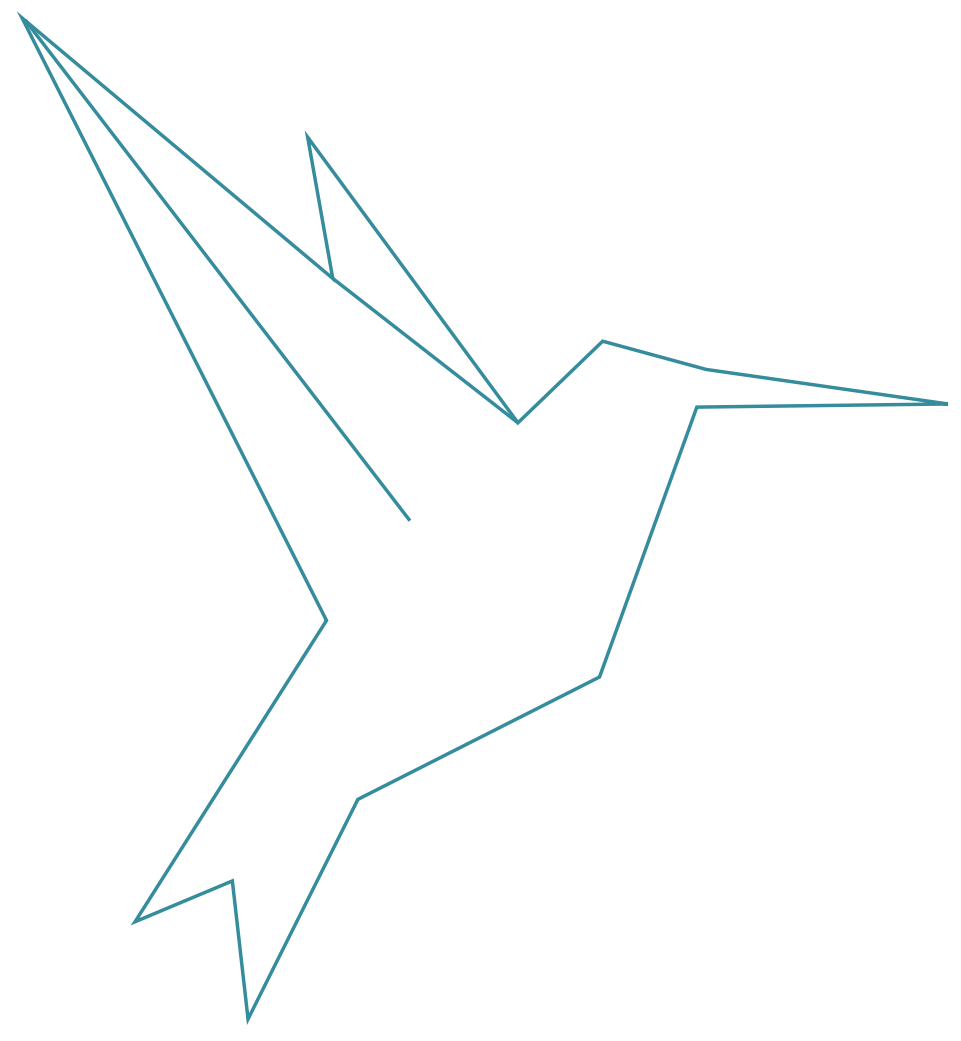




\section{VALORISATION}

This thesis aimed at getting a better understanding of working with Individual Support Plans (ISP) for people with intellectual disabilities (ID) in The Netherlands. The studies that were conducted add to the understanding of ISP in our country and more specifically they offer information for the enhancement of ISP policy and practice. The study outcomes may help improve the effectiveness of working with ISP in support services and agencies. This chapter focuses on opportunities for valorisation and describes actions that already have been taken to disseminate the knowledge gained in the present research project.

\section{RELEVANCE}

If a person persons needs to use professional support in his or her life, it is necessary to determine the type and intensity of support that is required and to make agreements on how and by whom the support is being provided. As such, ISP is a core element of everyday service provision to people who need long-term care. Moreover, ISP is a legal requirement and as such relevant for many thousands of people in the Netherlands. The legal requirement reaches a wide population, and ISP is not only relevant in supporting people with ID, but also in the care and support of elderly and people with psychiatric problems.

However, even though it is such a wide-spread and widely used instrument, little is known about how ISP works. Its usage is based on assumptions and beliefs rather than on empirical evidence. The present studies probe into critical and empirical analysis of ISP practices and formulate conditions that are favourable or unfavourable for their effectiveness.

Finally, service provider organizations spend a lot of money on the development and implementation of ISP documents and to integrate ISP documents in digital systems. Therefore, they should carefully consider what would be beneficial to the use of ISP and what can be done to make ISP of more value for clients, staff and the organisation.

\section{TARGET GROUPS}

\section{People with ID}

This thesis has shown that active and meaningful involvement of service users is not selfevident, and requires thoughtful and personal approaches. As we found out in our study described in chapter 3, people with ID are not fully aware of the function, roles and responsibilities regarding ISP and of how ISP may help them in their life. The results of this thesis serve 
as an entrance for providing better information to people with ID. The recommendations that were made may help people with ID to take advantage of their ISP as an opportunity to increase participation in their support process and to empower them to being partners in the process.

\section{Professionals working with people with ID and their management}

Service providers develop their own ISP forms and procedures and support staff usually is responsible for having ISP meetings with people with ID and their relatives, to develop the ISP document and to follow up on the agreements that are made. They have to find a way to manage the difficulties that are described in this thesis, e.g. balancing the different expectations that exist regarding ISP, such as it being a tool for enhancing person-centered support whilst also being used in the context of quality and accountability. However, improvement is possible in downsizing the ISP document and involving the person with ID, and chapter seven describes different practical implications and recommendations.

\section{Policy makers on both regional and national level}

The studies addressed in this thesis showed that policy makers influence ISP procedures and content in such a strong manner, that it is questionable how reliable ISP document are in assessing the quality of care. For example, our study on sexuality in ISP document showed that even though reference regarding sexuality was found in almost all ISP documents because ISP templates include the subject - the actual ISP was hardly providing information about the current support needs of that person nor about related support agreements. Having boxes ticked does not equal good quality care.

\section{PRODUCTS AND ACTIVITIES}

Different products and activities have been envisaged to disseminate the gained knowledge. This paragraph describes these products and activities.

\section{Products}

The results of the study in chapter 2 were described in the document "Handreiking Ondersteuningsplannen 2013 ", summarising the state of art on ISP in The Netherlands. This document was sent to all member organizations of the Dutch Association on Disability (VGN). Based on this document, we also published a "kennisbundel", for teachers to be used in educating people who will be going to work in the field of ID (Herps, 2014').

I Herps, M. (20|4). Kennisbundel voor docenten Zorg \& Welzijn. Ondersteuningsplannen.

Utrecht:Vilans, Trimbos instituut, V\&VN, Calibris. 
We developed an easy-to-read brochure and made a short video about the research project described in chapter 3. The brochure and video were sent to all participants of the study.

These products are freely accessible from the website www.kennispleingehandicaptensector. $\mathrm{nl}$. This website is targeted at direct support staff working with people with disabilities in the Netherlands. Individual support planning is one of the themes and the author of this thesis is responsible for the content on this page. It contains both insights from our research as well as good practices, examples of ISP in different organizations, tools that staff can use freely and other relevant information on ISP.

\section{Activities}

The study in chapter 2 was conducted during a nation-wide ISP improvement project in which service provider organizations participated. A total of 28 organizations all over the Netherlands participated in this project. During this project, project teams of these organizations met during three one-day meetings. Between these meetings, we contacted the project leaders by email and telephone to check on their progress. This project gave us a better understanding about the difficulties organizations face in ISP and we were able to disseminate the knowledge from our research in this group.

Furthermore, knowledge that was developed during this thesis is implemented in service provider organizations that ask for support and advise in developing and implementing or improving and implementing their ISP procedures and content. In this role, we usually work together with direct support staff and people with ID to develop an ISP that fits their needs, advise on the electronic client record and help implementing the new ideas.

\section{INNOVATION}

The problems addressed in this thesis and the research approach that was applied have been strongly practice-based. Incorporating the perspectives of people with ID, of staff, service providers and policy was needed to address the complexity of ISP. It has shown that problems with ISP manifest themselves on the work floor, but are also found in organizational and policy levels. This means that improving on these issues requires involvement on all of these levels. The main focus of this thesis has always been the person with ID, and how ISP can help him or her in their life. 


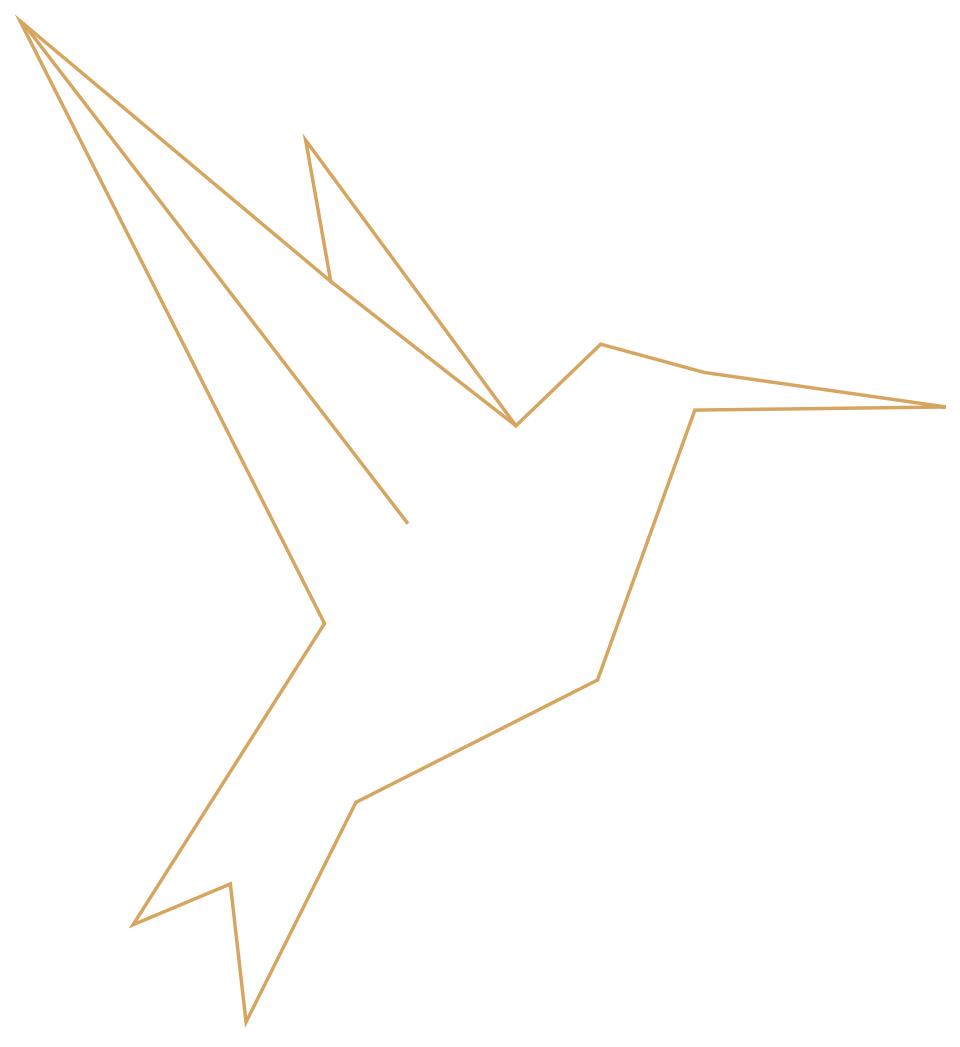




\section{DANKWOORD}

Het doen van de onderzoeken en het schrijven van dit proefschrift was me niet gelukt zonder de steun, hulp en medewerking van een groot aantal mensen en organisaties. In de afgelopen jaren zijn dat er heel wat geweest en via deze weg dank ik iedereen met wie ik de afgelopen jaren over ondersteuningsplannen heb gesproken. Het heeft me altijd geïnspireerd. Een aantal personen en organisaties wil ik in het bijzonder bedanken.

Beste professor Curfs en dr.Wil Buntinx, promotor en co-promotor.Jullie durfden dit traject met $\mathrm{mij}$ in te gaan. Elk van de vele gesprekken in Maastricht -en de ontmoetingen elders in de wereld- zijn waardevol en inspirerend voor mij geweest. lk heb veel van jullie geleerd, zowel academisch als inhoudelijk.

Geachte leden van de beoordelingscommissie, professor dr.Van Merode, prof. dr. Embregts, prof. dr. Ruiter, prof. dr. Townend en prof. dr. Professor Nies: bedankt voor het beoordelen van dit proefschrift. Ook prof. dr. Minkman en prof. dr. Kok wil ik hier bedanken voor het opponeren tijdens de officiële verdediging.

Het maken van een proefschrift kost tijd en vraagt vertrouwen in een goede afloop.Vilans heeft mij van begin tot eind in de gelegenheid gesteld om dit te kunnen doen. Zowel in praktische zin in het voorzien van tijd, als in het geven van vrijheid en vertrouwen om het onderzoek te kunnen doen zoals ik wilde. Ook biedt Vilans volop mogelijkheden om de opgedane kennis uit dit onderzoek direct toepasbaar te maken in de praktijk. En kunnen bijdragen aan verbetering van de zorg, dat is waarvoor ik dit doe.

Zeer dankbaar ben ik voor de medewerking van alle mensen met een verstandelijke beperking, begeleiders en andere medewerkers van verschillende zorgorganisaties in heel Nederland. Wat een voorrecht dat jullie me een kijkje lieten nemen in de -papieren en echte- levens, en bedankt dat jullie de uitdagingen en mooie dingen met mijn collega's en mij wilden delen.

Annemarie en Janneke: wat fijn dat jullie mijn paranimfen zijn! Met jullie achter me komt ook de verdediging goed.

LFB: Ineke, Hetty en uiteraard de andere collega's die mee hebben gedacht in een van de studies. Jan en Vincent: wat een leuk onderzoek was het he? Bedankt dat jullie mee wilden doen en mij zoveel hebben geleerd. 
Marion, Jeanet, Corry, Judith, Hilair,Wil, Marloes en Monica: het leernetwerk ondersteuningsplannen en het maken van de Handreiking was een leerzaam en succesvol traject, dank voor de samenwerking hierin.

Vilans collega's -die niet allemaal meer bij Vilans werken: Jeroen, jij die mij als eerst de kans gaf om dit proefschrift te gaan maken. Michiel, Tamara, Zafanja: wat een plezier hadden we in het interviewen (en iets minder met het uitschrijven) van al die interviews. Judith, Willy en Mireille, altijd een luisterend oor, helpende hand en flinke dosis humor: geweldig! En uiteraard alle andere mensen van het oude team KIG, het huidige team PGZ en team I\&O.

Janneke, Sabine en Marieke (en stiekem ook steeds meer anderen): de afgelopen jaren zijn jullie de vaste maatjes op het thema 'ondersteuningsplannen' geworden. Als team OSP trekken we heel Nederland door en ik dank jullie voor het enthousiasme, de nieuwe kennis en manieren van werken die jullie mij hebben geleerd.

Mijn Maastricht/GKC-collega's (of diner-maatjes) Joke, Dilana, Marian, Annemieke, Ireen.

Tessa, promotie- en reismaatje. Naast reizen en uiteraard kei hard werken, waar ook ter wereld, is het ook heel gezellig. En dan onze reis naar Artisa in Griekenland! In de warme zon, aan zee, in alle rust en omgeven door celebrities kunnen focussen op onze proefschriften. Hard werken, maar ook veel gezelligheid (en heerlijk eten). Mochten we nog eens iets als een proefschrift gaan schrijven dan gaan we weer.

Het schrijven van dit proefschrift heeft me veel (vrije) tijd gekost, en mijn fijne vrienden en (schoon)familie hebben daar altijd begrip voor gehad, waren geïnteresseerd in de voortgang en leefden mee met alles wat er gebeurde. Ook zorgden jullie voor de nodige ontspanning, bedankt Annemarie, Mauro, Eefje, Pieter, Ellen, Ivo, Tijs, Maud, Rosalie, Mark, Sanja, Brord, Jacqueline, Rinio, Corianne, Marjan, Wim, Lia, Marieke en Youri.

Lieve pap en mam. Hier is het dan, mijn proefschrift! Bedankt voor jullie onvoorwaardelijke steun en liefde.

Last, but definitely not least, Bram. Je hebt altijd begrip voor de tijd die ik hierin stak, omdat je als geen ander begrijpt dat je soms wat moet opofferen om je doelen te behalen. Je bent mijn beste voorbeeld in hoe je jezelf kan blijven ontwikkelen en uitdagen. Nu ben jij weer aan de beurt en ik hoop dat ik net zo'n steun voor jou kan zijn. Je haalt het beste in mij naar boven en daar ben ik je dankbaar voor. 



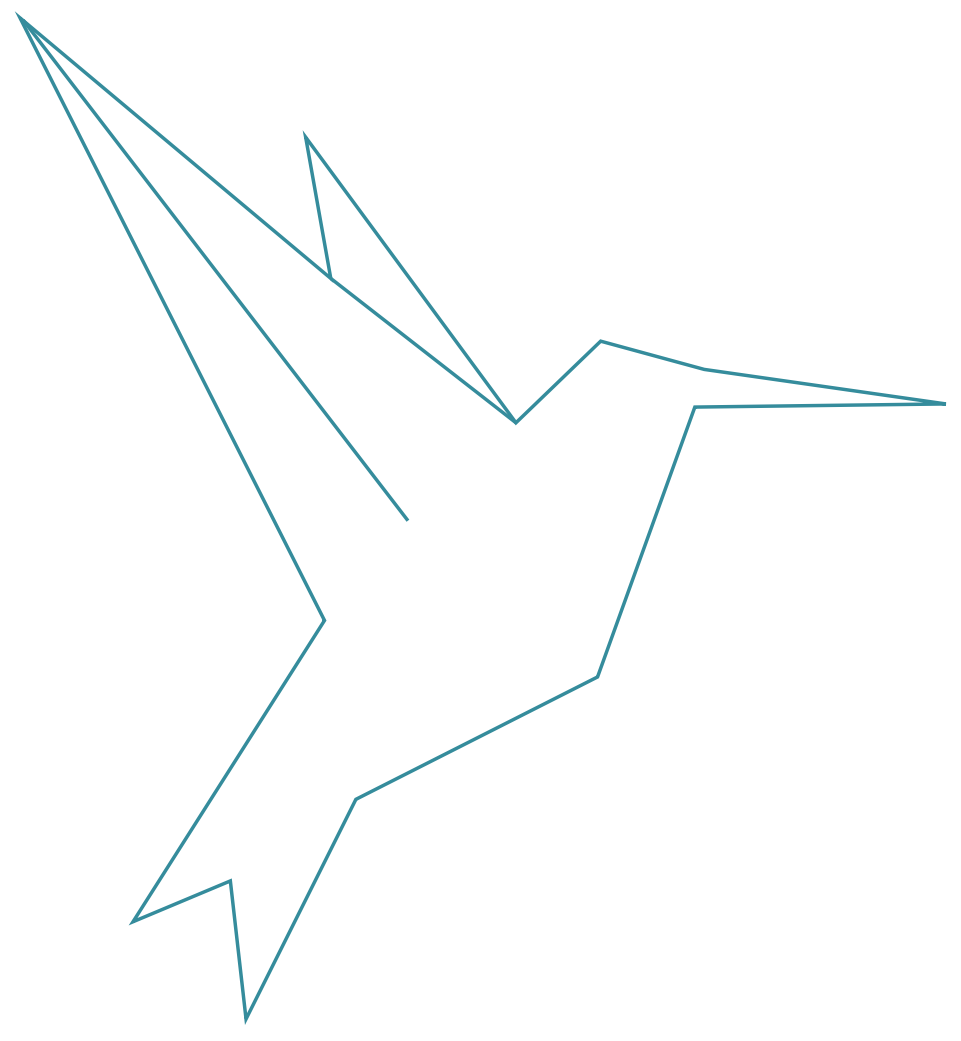




\section{LIST OF PUBLICATIONS}

\section{Peer-reviewed journals}

Herps, M.A., Buntinx, W. H. E., Schalock, R. L., Breukelen, G. J. P.Van, \& Curfs, L. M. G. (20 I 6). Individual support plans of people with intellectual disabilities in residential services: content analysis of goals and resources in relation to client characteristics. Journal of Intellectual Disability Research, 60(3), 254-262.

Herps, M.A., Buntinx, W.H.E. \& Curfs, L.M.G. (20 I 6). Individual support planning with people with ID in The Netherlands: Official requirements and stakeholders' expectation. Alter, European Journal of Disability Research, 10, 281-288.

Herps, M.A., Buntinx,W. H. E., \& Curfs, L. M. G. (20।3). Individual support planning: perceptions and expectations of people with intellectual disabilities in The Netherlands. Journal of Intellectual Disability Research, 57( I I), I027-1036.

Buntinx, W. H. E., \& Herps, M.A. (20/3). Ondersteuningsplannen in de zorg voor mensen met verstandelijke beperkingen. Kenmerken van good practice. Nederlands Tijdschrift voor de Zorg aan mensen met een verstandelijke beperking, 39(I), 63-76.

Herps, M. A., Buntinx, W. H. E., \& Curfs, L. M. G. (20I2). In dialoog over het ondersteuningsplan. Een exploratief onderzoek naar de betrokkenheid van mensen met verstandelijke beperkingen bij het opstellen, uitvoeren en evalueren van hun ondersteuningsplan. Nederlands Tijdschrift in de Zorg Voor Mensen Met Een Verstandelijke Beperking, 38( I), 2-15.

Herps, M.A., Buntinx, W. H. E., \& Curfs, L. M. G. (20 I0). Ontwikkelingen in het ondersteuningsplan in Nederland. Nederlands Tijdschrift voor de Zorg aan mensen met een verstandelijke beperking, 36(2), I I I-136.

Herps, M.A., Buntinx,W. H. E., \& Curfs, L. M. G. (20I I). Ondersteuningsplannen in de gehandicapten- zorg: beschouwingen en perspectief. Nederlands Tijdschrift voor de Zorg aan mensen met een verstandelijke beperking, 37(2), I I0-1 17.

Herps, M.A., Buntinx,W. H. E., \& Curfs, L. M. G. (2010). Ontwikkelingen in het ondersteuningsplan in Nederland. Nederlands Tijdschrift voor de Zorg aan mensen met een verstandelijke beperking, 36(2), I I I-136. 


\section{Other publications}

Gijzel, H., Nap, H. Herps, M., Mulder, S., Van Klink, M., Schrijer-Snoeijs, S., Kuperus, K. \& Minkman, M. (2017). De Wet langdurige zorg in de verzorging, verpleging en gehandicaptenzorg. Ervaringen uit de praktijk. Amstelveen: KPMG \&Vilans, in opdracht van het Sociaal en Cultureel Planbureau.

KPMG \&Vilans (20 I 6). Evaluatie WIz uitvoeringspraktijk. Definitief verslag fase I: literatuuronderzoek. Retreived from:

http://www.vilans.nl/docs/vilans/publicaties/eindverslag-literatuuronderzoek-evaluatie-wlz.pdf

Herps, M.,Vlek, H., Haan, J., Timmer, S., \& de Jong, F. (20 I 4). Onderzoek naar de mogelijkheden voor een integraal zorgplan. Eindrapportage. Utrecht:Vilans.

Buntinx, W. H. E., Herps, M.A., \& De Ruiter, M. (20 I3). Handreiking Ondersteuningsplannen 2013. Utrecht.

Herps, M. (20|4). Kennisbundel voor docenten Zorg \& Welzijn. Ondersteuningsplannen. Utrecht: Vilans, Trimbos instituut, $\vee \& V N$, Calibris. 



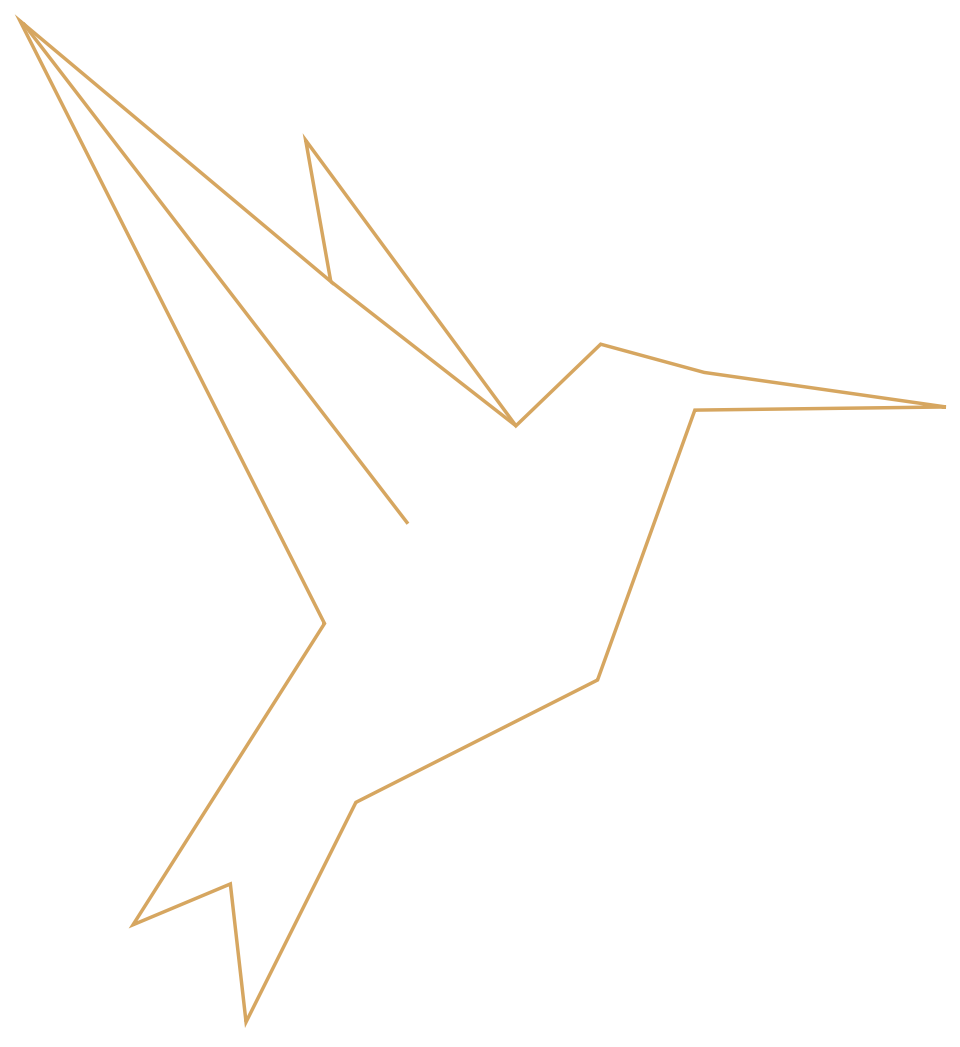




\section{CURRICULUM VITAE}

Marjolein Herps was born in Best, the Netherlands, on September 5, 1983. She graduated in 200 I from secondary school (VWO) at the Bisschop Bekkers College in Eindhoven. From 200 I to 2006 she studied Clinical Child, Family and Education Studies at Utrecht university and specialized in disabilities. During her study, she was active as a research assistant with different research projects, a board member of the study association and as a member in the study programme committee. She also worked in children's day care facilities.

In 2002, she started working at Reinaerde, a service provider in The Netherlands, and provided support in a family with children with disabilities. During summers and during graduating, she also worked at Viataal (now Kentalis), where she supported a family with a deaf blind child and worked at a group home for children with communication problems stemming from deafness or autism, combined with an intellectual disability. She graduated in 2006 on a thesis on the working memory of children with intellectual disabilities.

After graduating, she started working at the Nederlands Instituut voor Zorg en Welzinn (NIZW), which later became Vilans, and where she currently still works. During her time at Vilans, Marjolein has been involved in a wide variety of projects related to improvement of the quality of care and support for people with intellectual disabilities. She was involved in several nation-wide improvement programs and became interested in the topic of individual support planning in one of these projects. She has extensive experience as project leader in different research-, development-, and consultancy projects on both national and regional level. She accomplished her PhD at the governor Kremers Centre - Maastricht University.

Besides her work for Vilans, Marjolein is also a teacher in the post-academic education for psychologists and a columnist for Markant, the journal for service provider organizations in the Netherlands. 